\title{
Preferences, institutions, and economic outcomes : an empirical investigation
}

Citation for published version (APA):

Skriabikova, O. (2014). Preferences, institutions, and economic outcomes : an empirical investigation. [Doctoral Thesis, Maastricht University]. ROA. https://doi.org/10.26481/dis.20141031os

Document status and date:

Published: 01/01/2014

DOI:

10.26481/dis.20141031os

Document Version:

Publisher's PDF, also known as Version of record

\section{Please check the document version of this publication:}

- A submitted manuscript is the version of the article upon submission and before peer-review. There can be important differences between the submitted version and the official published version of record.

People interested in the research are advised to contact the author for the final version of the publication, or visit the DOI to the publisher's website.

- The final author version and the galley proof are versions of the publication after peer review.

- The final published version features the final layout of the paper including the volume, issue and page numbers.

Link to publication

\footnotetext{
General rights rights.

- You may freely distribute the URL identifying the publication in the public portal. please follow below link for the End User Agreement:

www.umlib.nl/taverne-license

Take down policy

If you believe that this document breaches copyright please contact us at:

repository@maastrichtuniversity.nl

providing details and we will investigate your claim.
}

Copyright and moral rights for the publications made accessible in the public portal are retained by the authors and/or other copyright owners and it is a condition of accessing publications that users recognise and abide by the legal requirements associated with these

- Users may download and print one copy of any publication from the public portal for the purpose of private study or research.

- You may not further distribute the material or use it for any profit-making activity or commercial gain

If the publication is distributed under the terms of Article $25 \mathrm{fa}$ of the Dutch Copyright Act, indicated by the "Taverne" license above, 
PREFERENCES, INSTITUTIONS, AND ECONOMIC OUTCOMES: AN EMPIRICAL INVESTIGATION 
(C) Olga J. Skriabikova, Maastricht 2014

All rights reserved. No part of this publication may be reproduced, stored in a retrieval system, or transmitted in any form, or by any means, electronic, mechanical, photocopying, recording, or otherwise, without the prior permission in writing, from the author.

Published by ROA

Postbus 616

6200 MD Maastricht

ISBN: 978-90-5321-531-9

Printed in the Netherlands by Océ Business Services 


\title{
Preferences, Institutions, And ECONOMIC OUTCOMES: An EMPIRICAL Investigation
}

\author{
Proefschrift
}

ter verkrijging van de graad van doctor aan

de Universiteit Maastricht, op gezag van de Rector Magnificus,

Prof. dr. L.L.G. Soete

volgens het besluit van het College van Decanen, in het openbaar te verdedigen op vrijdag 31 oktober 2014 om 16.00 uur door

Olga J. Skriabikova 


\section{Promotor}

Prof. dr. T. Dohmen

\section{Copromotor}

Dr. B. Kriechel

Beoordelingscommissie

Prof. dr. G.A. Pfann (voorzitter)

Dr. B.H.H. Golsteyn

Prof. dr. J. Hartog (University of Amsterdam)

Prof. dr. H.F. Lehmann (University of Bologna) 


\section{ACKNOWLEDGEMENTS}

Five long years I was looking forward to the moment of sharing this dissertation with the world. You, my friends, my colleagues, my judges, my family, and yet unknown to me people, who might have become excited about the findings I am going to present, are in my audience to make me qualify for a scientific degree. There are not enough words in my vocabulary of English to express the gratitude I feel for this opportunity. I try to make the best out of it and to name all significant people on this thorny path, but mistakes are made by people being just fundamentally people. I hope you believe in my good intentions to bring to the light all of those without whom the work you are holding in your hands would never have been possible.

First of all, I thank my first promotor, Thomas Dohmen, for trusting me and believing in my impetus for scientific research, for continuously inspiring me and challenging me to further open up my horizons as a researcher and as a person. Thomas, your directions, your invaluable advice, the whole power of your personality made me always seek for better answers and clearer evidence. With the fire that burns in your heart born out of passion for research, with encyclopedic knowledge of your subject together with large surrounding fields of knowledge, with the everlasting urge to keep things as simple, clear and precise as possible, with constant attention to tiniest nuances, with the sense of humor and artistism of your presentations that instantly turn on and keep on inspiring your audience, you are an amazing person and the greatest supervisor I could ever have desired for.

I thank Ben Kriechel, my second supervisor, my advisor and the best helping hand in the mysterious woods of empirical research. Ben, your openness, understanding and easy approach to all kinds of seemingly unsolvable problems that I came to you with, if not cleared all the darkness away, but made it at least possible to use simple navigation devices to set up some walkable routes. Your smile and a chat with you gave me the feeling that I could really do it, and I did. I thank you for your advice during my PhD project, the papers that came and will come out of it and for your readiness to help me any moment I needed it. I am happy that you helped me with the first steps in the contract research and trusted in my abilities. 
You are a great person to work with, Ben, and I value every single moment of our discussions.

I gratefully acknowledge working together with two fantastic co-authors whom I was happy to meet during my stay at ZEW (Centre for European Economic Research) in Mannheim. Two outstanding PhD-candidates, Beth Argaw and Michael Maier, contributed much of their time and effort to our common project. Beth, your preciseness, thoroughness and systematic approach in statistical estimations exceeds mine in multiples! Michael, your critical questions helped us to stay on the chosen path and formulate our arguments as careful and exact as possible. I thank Bodo Aretz and Jan Fries for making my life at ZEW sociable and entertaining. I am also happy to thank people outside of ZEW whom I met during my stay, who were with me, who helped me to persevere in spite of all troubles, who laughed and cried with me and who have become my very good friends: Inga Ackermann and Anna Budrevich. Girls, you know you mean so much to me. I thank Katrin Hussinger, who is a fantastic person, a passionate researcher and my great friend. Katrin, your help with getting around in Mannheim, your research advice and your jokes are invaluable. I also thank Davide Furceri for waking up my ambitions during a very inspiring talk during the SEEK Conference "Engines for More and Better Jobs in Europe" at ZEW. I certainly would like to acknowledge the help of Esther Kockelkoren, Birgit Piesch and all other people who assisted me to organise this research stay.

I would like to thank my colleagues at ROA, for great inspirational talks, interesting comments, fantastic atmosphere at work and the unforgettable moments at terraces and bars that we spent together. I thank Jan Sauermann for his readiness to help on technical issues and for his great comments on my papers. I am greatly indebted to Eric Bonsang abd Arnaud Dupuy for their helpful comments and to Olivier Marie for his healthy dose of criticism and an objective point of view. I thank Maria Zumbühl for being a fantastic friend and an outstanding sparring partner in scientific discussions. I thank Nicolas Salamanca for his invaluable advice on technical matters as well as for helping me to bring order into logical arrangement of the arguments. You guys were a permanent source of inspiration in my research.

I gratefully acknowledge Raymond Montizaan, apart from being a good researcher, as a marvellous social talker, entertainer, and someone who really knows what one should eat or drink to enjoy their life responsibly though with pleasure. Raymond helped greatly with English formulations and I am really thankful for that. I thank Charlotte Büchner and Martin Humburg for helping me to sort out things with teaching the Macrosociology block and just for being really nice people. 
I enjoyed working and having fun with you. I thank Ruud Gerards for trusting me in my Stata-programming expertise and a productive working together on Metalectro project. I also thank Christoph Meng, Sander Dijksman and Timo Huijgen for helping me out with data issues. I will always be indebted to Frank Cörvers for inviting me to work on a research proposal together with Bernard Casey. I thank Didier Fouarge, Jim Allen and Arjan Non for being great colleagues. I am always happy to see your friendly faces.

Five years I shared my office with two wonderful colleagues, whom I would like to thank separately. I thank Annemarie Künn-Nelen, my first roommate, for readiness to help me with my frustrations and for incredibly helpful suggestions, on dealing with statistical estimators as well as on dealing with personal issues. Thank you, Annemarie, for your patience and for your ears, as you not only offered them to listen to my dilemma's with research questions, estimations and personal struggles, but also contented with my musical choice. I thank my second roommate, Annelore Verhagen, for her sense of humor that really lightened up the room.

I cannot forget the assistance of Joyce Gruijthuijsen in all kinds of financial and administrative matters. Joyce, you arranged so many conferences, visits and whatever other things for me, fast, efficient and always friendly. I wholeheartedly join the committee that gave you the Service award! I also thank the ROA secretary in persons of: Esther Soudant, Willeke Hendrikx, Willeke Klein, Mariëlle Retz, and Miranda Boere for helping with documents, books, publishing matters and for a friendly chat. I always appreciate the assistance of Melissa Llanes in organisational matters and of Margo Romans with respect to EALE conference.

On the way to my $\mathrm{PhD}$, there were many people whose influence on my choices I gratefully acknowledge. Bart Golsteyn has always been a source of inspiration, an advisor in econometric issues and a good friend. Lex Borghans' explanation of economic models opened up the whole world to me. Trudi Schils, Eric de Regt, Denis de Crombrugghe, your inspiring lectures and thorough explanations made my way to understand the economic way of thinking and to learn econometrics. Milena Pavlova, your guidance and advice on my Master thesis and beyond of it are invaluable. I thank Wim Groot for his suggestions and for helping with the publication of our article. I am grateful to Arkadi Predtetchinski, Michael Young, Helga Habis and Natalya Usotskaya for guiding my first steps and being an amazing company. I also thank Jeroen Geerts for indirectly convincing me to become a researcher.

I am absolutely grateful to ROA and to all the people named above for the opportunity to attend the world's top economic conferences to present my papers, to discuss new ideas and to share experiences with so many great economists. I 
thank the participants of the Society of Labour Economists meeting (SOLE, 2012) in Chicago; the European Society of Population Economics meeting (ESPE, 2012) in Bern; the European Society of Labour Economists conference (EALE, 2012) in Bonn and EALE (2013) in Turin; the International Workshop on Applied Economics of Education (IWAEE, 2012) in Vibo Valentia, and the Scottish Economic Society meeting (SES, 2014) in Perth. In particular, my gratitude for their valuable comments goes to Jürg Schweri, Anders Stenberg, Stefanie Schurer, Joop Hartog, Hartmut Lehmann, Silke Anger, Holger Bonin, and many other researchers in the field. The papers collected in this dissertation benefited a lot from our discussions.

I gladly thank the frequent participants of the "AiO seminar" at AE2 and the $\mathrm{PhD}$ organised drinking events. I also name some people who made the life as a PhD-candidate particularly cool and exciting: Ayse Yüksel, Isabella Grabner, Jessie Lemmens, Seher Fazlioglu, Marion Collewet, Roxanne Korthals, Frauke Mayer, Benedikt Vogt, Ulf Zoelits, Gabriele Markoni, Nevena Zhelyazkova, Eva Feron, Aline Meysonnat, Elena Cettolin, Nadine Funcke, Jasper Aalbers, Ina Dackweiler, Julie Dela Cruz, Joost Mulders, Anna Wisniewska, Vera Bossel, Christine Gutekunst. I also thank people outside of (my field of) academia, such as Dorina Baltag and Alex Bivol, Dmitry Bykov and Anastasia Biskup-Bykova with your lovely Stefania, Maico Hoksbergen, Lyzel Elias-Sonnenschein, Lena Demydonok and Lena Zaglada. I am grateful to Ingrid Eyssen and Paul 't Lam for their kind support.

I am really happy to acknowledge the contribution to this dissertation of my new colleagues from the Province of Limburg. Paul Baeten, your support in helping me to find my way in the Province and your willingness to help me with organising the defence are of a great value to me. Hendrik Jan van Elmpt, I am very grateful for your help with the formulations in my Dutch summary. Gé Waeijen, Sevda Caris, Robert Engelen, Charles Claessen, Renè Bijlmakers, Sarah Klein Hanenveld, and other people of our Strategy team, it is a great pleasure to work with you.

In these concluding paragraphs, I thank the most important people in my life, the people without whom the challenging adventure of starting and completing the $\mathrm{PhD}$ would have never been possible. I thank my mum and dad, Svitlana Skriabikova and Ievgen Skriabikov for bringing me to this exciting world, for trusting in the power of my mind and character, for always supporting my choices and for sharing so many difficult moments with me. You helped me to become what I am and this dissertation is my gift to you. I hope you are proud of my achievement. I thank my sister, Tatiana Skriabikova, and my nephews, Iiuri Levotuiev and Yaroslav Levontuiev, because you are great people who helped me endless times and I am so happy that you are my family. I am also very grateful to appreciate the 
support of my grandparents, Zinaida and Alexey Skriabikov, and my grandmother, Zinaida Ignatieva, as well as of my beloved aunt and uncle, Svitlana and Sergey Levontuiev. I am thankful to Bastian, simply because he is the creature with the most impressive personality I have ever known.

I am also very grateful to my Dutch family: Henk Coenen and Marie-José Coenen are the best parents in law I could ever hoped to have. You are so incredibly cheerful, caring, involved and hospitable people. I am so glad to be the part of your family. Erik Coenen and Petra Janssen, you are great people and your caring attention always gives me inspiration to do more and better. Countless close and intimate moments that we had together with the Coenen family provided me with the inspiration and excitement I really needed to work on the difficult parts of dissertation.

I will never forget to thank my closest friends, who are there for me, to share the joys and disappointments of life, during the process of starting, developing and finishing my dissertation and certainly beyond of it. Tatiana Slobodian and Vanechka, thinking about you lightens up my darkest days. I am so happy to be able to help you when I can, and to be a part of your life. Tanechka, the strength of your character, your focus and your good human nature inspired me endlessly since the firt moment I know you. Kateryna Fux, the combination of sweet and smart in your person amazes me continuously. Katya, with your kind advices and attention to me you helped so much to achieve this result. Iryna Rud is a great mate who was for me through the difficult steps of thinking and writing the papers for my dissertation. Irchik, your willingness to listen to my complaints and your suggestions are absolutely invaluable. I also wish to thank my dear friends in Ukraine and beyond, the people who supported me and helped me to get this far: Inna Shepelska, Olga Yeremeeva, Natasha Lisovets and Anna Belinskaya. I miss you, girls, real much, you know it!

My husband, Johan Coenen, is an enormous support to me at whatever I do. My dear Johan, your encouragement during the process of developing and finalising my dissertation was incredibly helpful. Your love and care for me, your unconditional acceptance of whatever I am up to, you appreciation of my personality and my desires, the joy and calmness you give me, the travel and adventures and passion for music we share together, always make me wonder what did I do to deserve you. You are my best mate, my love and my hope for the future. By being on my side, you make all the horizons open and make me believe that almost everything is possible. I thank you for who you are, my man, and know that I will always love you. 
To be sure, there are many more people whom I would like to thank, and there is also much more that I would like to say to those for whom I expressed my gratitude. My sincere apologies for necessary incompleteness. I hope there will be more opportunities in life to express my appreciation. 


\section{Contents}

1 INTRODUCTION 1

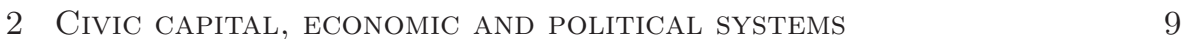

2.1 Introduction . . . . . . . . . . . . . . . . . . . . . 10

2.2 Conceptual framework . . . . . . . . . . . . . . . . . . . . . 14

2.3 Empirical strategy . . . . . . . . . . . . . . . . . . . . . . . . 15

2.4 Data and variables . . . . . . . . . . . . . . . . . . 17

2.5 Results . . . . . . . . . . . . . . . . . . . 22

2.6 Conclusion . . . . . . . . . . . . . . . . . . . . . . . . . . . 28

Appendix . . . . . . . . . . . . . . . . . . . . 30

2.A Descriptive statistics . . . . . . . . . . . . . . . . . 30

2.B Short history of Ukraine . . . . . . . . . . . . . . . . . . 31

3 Risk ATtitudes AND OCCUPATIONAL CHOICE 35

3.1 Introduction . . . . . . . . . . . . . . . . . . 36

3.2 Conceptual framework . . . . . . . . . . . . . . . . . . . . . 38

3.3 Data . . . . . . . . . . . . . . . . . . . . 39

3.4 Empirical strategy . . . . . . . . . . . . . . . . . . . . 40

3.5 Results . . . . . . . . . . . . . . . . . . . . . . . . 44

3.6 Robustness . . . . . . . . . . . . . . . . . . 52

3.7 Conclusion . . . . . . . . . . . . . . . . . . . . . . 55

Appendix . . . . . . . . . . . . . . . . . . 57

4 Risk attitudes AND SELF-EMPloyment 59

4.1 Introduction . . . . . . . . . . . . . . . . . . . . 60

4.2 Data and variables . . . . . . . . . . . . . . . . 63

4.3 Results............................ 65

4.3.1 Evidence from Ukraine . . . . . . . . . . . . . . . . . 65

4.3.2 Evidence from the former East Germany . . . . . . . . . . 67

4.3.3 Evidence from the Netherlands . . . . . . . . . . . . . . . 70

4.4 Concluding remarks . . . . . . . . . . . . . . . . . . . 72

5 Job MOBILITY DURING THE EARLY CAREER $\quad 75$

5.1 Introduction . . . . . . . . . . . . . . . . . 76

5.2 Previous literature . . . . . . . . . . . . . . . . . . . . 77

5.3 Conceptual framework . . . . . . . . . . . . . . . . . . . . . . 79 
Contents

5.4 Empirical approach . . . . . . . . . . . . . . . . . . . . . . . . 81

$5.4 .1 \quad$ Empirical strategy . . . . . . . . . . . . . . . . . 81

5.4 .2 Data . . . . . . . . . . . . . . . . 84

5.5 Results . . . . . . . . . . . . . . . . . 85

5.5.1 Risk attitudes and job changes . . . . . . . . . . . 85

5.5.2 Risk attitude, job mobility and wage growth . . . . . . . . 88

5.6 Robustness checks . . . . . . . . . . . . . . . . . . . . . . . . . . . . . . . . . . . 91

5.7 Conclusion . . . . . . . . . . . . . . . . . . . . . 93

Appendix . . . . . . . . . . . . . . . . . . . . 96

$\begin{array}{lll}6 & \text { Conclusions } & 99\end{array}$

$\begin{array}{ll}\text { BIBLIOGRAPHY } & 105\end{array}$

$\begin{array}{lr}\text { Summary In Dutch } & 119\end{array}$

$\begin{array}{ll}\text { NON-TECHNICAL SUMMARY } & 127\end{array}$

$\begin{array}{ll}\text { BIOGRAPHY } & 135\end{array}$

$\begin{array}{ll}\text { VALORISATION ADDENDUM } & 137\end{array}$

$\begin{array}{ll}\text { ROA Dissertation Series } & 145\end{array}$ 


\section{List OF FigURES}

1.1 Ukraine before and after transition . . . . . . . . . . . . 4

2.1 Map of Ukraine . . . . . . . . . . . . . . . . . . . . . . . . . . 18

2.2 Distribution of political preferences . . . . . . . . . . . . . 19

2.4 Correlation of trust in strangers and trust in family . . . . . . . . 20

2.5 Correlation of preferences for economic and political systems . . . . 22

2.6 Share of citizens supporting the development of a market-based economic system . . . . . . . . . . . . . . . . . . 26

2.7 Share of citizens supporting the development of a democratic political system . . . . . . . . . . . . . . . . . . . 27

3.1 Earnings risk before and after transition . . . . . . . . . . . . . . 43

3.3 Earnings risk and risk attitude: Balanced panel . . . . . . . . . . . 45

4.1 Intrafamily transmission of risk attitudes, information, self-employment 61

5.1 Expected relationship between risk attitude and wage growth depending on job changing behaviour . . . . . . . . . . . . . 81

5.2 Wage growth and job mobility profiles by risk attitude: out of sample prediction . . . . . . . . . . . . . . . . 9 90 



\section{LIST OF TABLES}

2.1 Difference in civic capital across West and East of Ukraine . . . . . 21

2.2 Civic capital and political preferences . . . . . . . . . . . . . . 23

2.3 Preferences for a market-based economic system . . . . . . . . . . . 24

2.4 Preferences for a democratic political system . . . . . . . . . . . . 25

2.A Summary statistics . . . . . . . . . . . . . . . . 30

3.1 Earnings per industry sector, data from the Ukrainian Statistics cf. the ULMS . . . . . . . . . . . . . . . . . 40

3.2 Earnings risk and risk attitudes before and after transition . . . . . 44

3.3 Relationship between earnings risk and individual risk attitudes . . 47

3.4 Earnings risk and individual risk attitudes in the balanced panel sub-sample . . . . . . . . . . . . . . . . . . 48

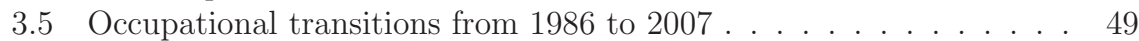

3.6 Switching to an occupation with high or low earnings risk . . . . . . 51

3.7 Earnings risk and individual risk attitudes: External data set . . . . 53

3.A Descriptive statistics per occupation in 1986 and in $2007 \ldots 58$

4.1 Descriptive statistics . . . . . . . . . . . . . . . . . . . 64

4.2 Self-employment in Ukraine . . . . . . . . . . . . . . . . . . . . 66

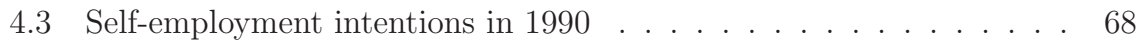

4.4 Self-employment in East Germany . . . . . . . . . . . . . . . . . . . 69

4.5 Self-employment in the Netherlands . . . . . . . . . . . . . . . 71

5.1 Descriptive statistics . . . . . . . . . . . . . . . 85

5.2 Risk attitudes and the total number of job changes . . . . . . . . 87

5.3 Risk attitudes, total number of job changes and total wage growth . 89

5.4 Robustness check accounting for initial sorting factors . . . . . . . . . 92

5.5 Robustness check using different years of experience . . . . . . . . . 93

5.6 Robustness check using a categorical job change variable . . . . . . 94

5.A Sample selection procedure . . . . . . . . . . . . . . 96

5.B Distribution of job changes during the early career . . . . . . . . . 97 

1 InTRODUCTION 


\section{Introduction}

This dissertation focuses on fundamental economic problems of occupational choice and mobility. Theoretical and empirical research using the rational choice framework has identified a wide variety of macro- and micro-level factors that affect economic behaviour. ${ }^{1}$ More recently, the challenges of explaining different choices of individuals confronted with observationally identical choice situations called for an extension of the standard theory by including parameters reflecting heterogeneity in unobserved characteristics, such as preferences. ${ }^{2}$ The relevance of (risk) preferences for economic decision-making has been recognised already in the classical economic literature (Schumpeter, 1934; Arrow, 1972; Kanbur, 1979). During the last decennia, wider availability of micro-data facilitated the accumulation of empirical evidence investigating the role of preferences for economic decision-making in different domains (for example, Heckman and Rubinstein, 2001; Viscusi and Hersch, 2001; Zak and Knack, 2001; Borghans, Ter Weel, and Weinberg, 2008; Doepke and Zilibotti, 2008; Krueger and Schade, 2008; Dohmen and Falk, 2011). Nevertheless, many issues including the origin of preferences and causality of the documented relationships are still contested.

In this dissertation, I exploit structural changes in political and economic institutions to provide field evidence on the effects of directly measured preferences, such as risk aversion and trust, on economic choices. In particular, I argue that the economic and political transition of Ukraine from a Soviet Union republic with a planned economy and an authoritative political system to a sovereign state with a market economy and a democracy-oriented political system provides a unique setup that allows to shed some light on the causal impact of economic preferences. The purpose of this dissertation is thus to identify the effects of preferences on economic choices using transition as a source of exogenous variation in labour market organisation and not to describe specific issues related to adaptation to new economic and political conditions resulting from transition.

\footnotetext{
${ }^{1}$ To name a few contributions, occupational choice and mobility are influenced by occupational wage structures (Killingsworth, 1984; Banerjee and Newman, 1993); tax and interest rates (Blau, 1987; Parker, 2004; Cullen and Gordon, 2007); compensating wage differentials (Roy, 1951; Heckman and Honore, 1990); liquidity constraints (Stiglitz and Weiss, 1981; Blanchflower and Oswald, 1998); job match productivity (Burdett, 1978; Johnson, 1978); human capital in terms of ability, training, experience and tenure (Benewitz and Zucker, 1968; Boskin, 1974; Miller, 1984; Shaw, 1987; Iyigun and Owen, 1998).

${ }^{2}$ Throughout this dissertation, preferences are treated as 'economic preference parameters', i.e. stable, measurable, quantifiable features of character or personality that affect individual behaviour. This definition can encompass personality traits as in McCrae et al. (2000) and non-cognitive skills as in Heckman, Stixrud, and Urzua (2006).
} 
Figure 1.1 displays the time-line from 1986 to 2012 to provide a general background of Ukraine in recent years. ${ }^{3}$ A Soviet republic before 1991, Ukraine became independent and set off on the transition path in the early 1990's. The transition period was characterised by major economic restructuring, large-scale privatisation, development of private entrepreneurship, opening up of the borders and reorganisation of the political system into a more open representative democratic state. In contrast to other Eastern European countries, the process of adjustment in Ukraine was accompanied by a substantial drop in real GDP and real wages. Even though Ukraine is still lagging behind other countries in Eastern Europe, the average purchasing power of Ukrainian citizens measured in current PPP US dollars has returned to its pre-transition level during the period of 2005-2012, as Figure 1.2a shows. Self-employment, barely non-existent in the 1980's, increased significantly since the beginning of the 1990's (Figure 1.2b) but the share of selfemployed among the employed individuals is still substantially lower than in the OECD countries (OECD, 2008).

The transition phenomenon and the transition adjustment processes have been addressed elsewhere (Svejnar, 1999; Boeri and Terrell, 2002; Åslund, 2007; Kupets, Leshchenko, Osinkina, Taran, and Komarov, 2009; Lehmann and Muravyev, 2012). However, I focus on three particular features of the political and economic systems that changed during the transition caused by the break-up of the Soviet Union. First, citizens of the Soviet Union republic of Ukraine were restricted in the choice of political or economic systems during the period between $1945^{4}$ and 1991. A strong suppression of ideas contradicting the communist ideology made it more difficult to transmit information or preferences about different political and economic systems that existed before Ukraine had become Soviet. This feature is exploited in Chapter 2. Second, because wages were set centrally through a wage grid system for all occupations in the Soviet Union, the earnings risk was low and it was very similar across all occupations. The earnings risk increased dramatically after transition. This feature is further discussed in Chapter 3. Third, the command economy of the Soviet Union relied on the centrally-controlled large enterprises. It banned private entrepreneurship, which led to the situation that there were no self-employed individuals in the beginning of the 1990's. This aspect of transition is addressed in Chapter 4. The following paragraphs further elaborate on the content and methods used in the chapters of this dissertation.

\footnotetext{
${ }^{3}$ A more detailed account of Ukrainian history is in Appendix 2.B.

${ }^{4}$ Different parts of Ukrainian territory had not become Soviet Union simultaneously. The East of Ukraine had became a part of the Soviet Union during the early 1920's, however the occupation of Western districts was finalised only in the course of World War II.
} 


\section{Introduction}

Figure 1.1: Ukraine before and after transition

(a) Dynamics of the GDP and purchasing power

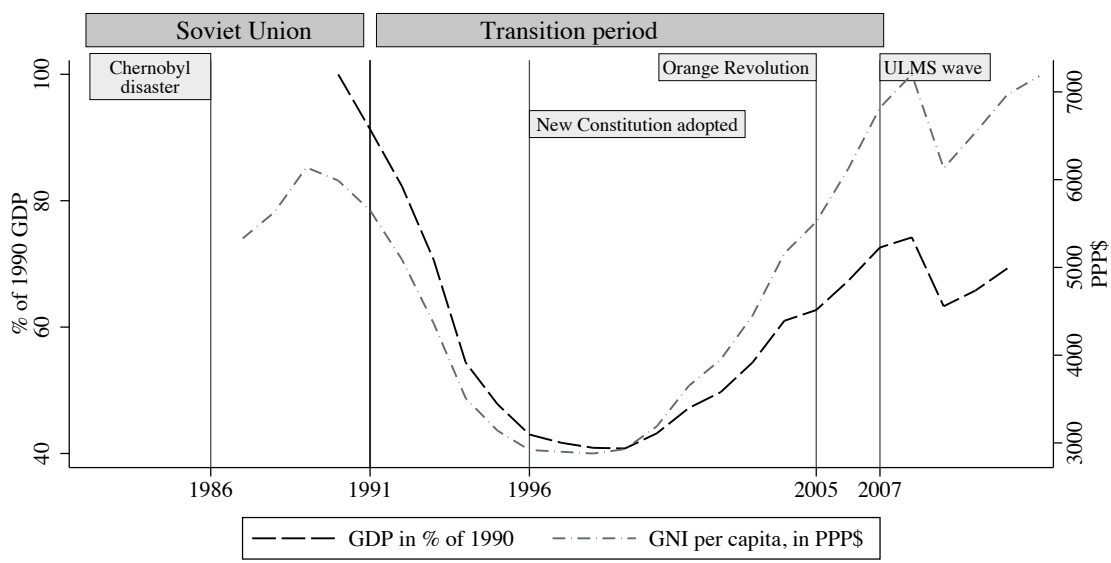

Note: Data for the GDP percent of 1990 are from the Ukrianian State Statistics Service. Data for the GNI in PPP\$ are from the World Bank.

(b) Size of enterprises and self-employment

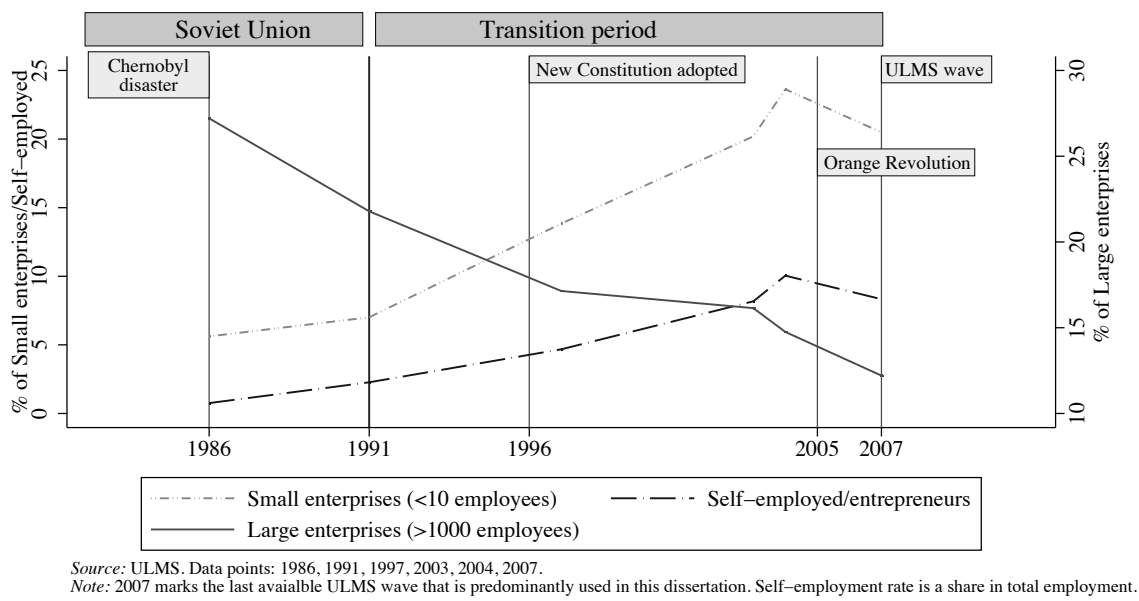

Chapter 2 sets up the background and introduces the history of Ukraine. Historical events are used to shed light on the origins of such an important economic preference as social trust. The research question of Chapter 2 is motivated by the 
unresolved puzzle of the direction of causality between the development of economic and political structures, which has been discussed extensively in the recent literature (Przeworski and Limongi, 1993; Helliwell, 1994; Giavazzi and Tabellini, 2005; Acemoglu, Johnson, Robinson, and Yared, 2008). Given inconclusive evidence on whether democratic development stimulates growth or whether market liberalisation is beneficial for democracy, I argue that a 'third factor' is likely to affect the co-evolvement of political and economic structures. Relying on the turbulent history of Ukraine with heterogeneous experiences of being occupied by different political entities before the country had become a part of the Soviet Union, I show that historical institutions affect the development of preferences for certain types of economic and political systems through their influence on the accumulation of civic capital (a set of shared cooperative norms of behaviour facilitated by social trust). The eastern part of the Ukrainian territory was subjected to the harsh rule of the Russian Empire since 17th century (until World War I), which adversely affected civic capital of its population. A more lenient rule of the Polish-Lithuanian Commonwealth (1569-1772) and the Habsburg Empire in the West (1772-1918) were more conductive to the development of civic capital. Since the Soviet occupation limited the transmission of political preferences, it is likely that the post-transition differences in the level of support for democratic political structures and marketbased economic systems are brought about by inherited differences in civic capital.

Chapter 3 considers more modern economic and political developments in Ukraine to investigate the role of economic preferences in occupational sorting. The problem of occupational choice between different professions, as well as in terms of choosing employment status, has received close attention in the literature. Roy (1951) developed a model explaining occupational choice based on comparative advantage of individual skills. ${ }^{5}$ Blau, Gustad, Jessor, Parnes, and Wilcock (1955) proposed a comprehensive theoretical framework discussing inputs from three disciplines: economics, psychology, and sociology. Empirical evidence by King (1974) suggests that the earnings risk is a relevant aspect of occupational choice for entrants in occupations with higher earnings risk are compensated by higher earnings. ${ }^{6}$ In Chapter 3, I study empirically whether individuals with different risk attitudes choose occupations varying in earnings risk. The economic transition exogenously affected wage structure in Ukraine, such that the earnings distribution across occupations, which was narrow before transition, increased dra-

\footnotetext{
${ }^{5}$ Heckman and Honore (1990) analysed the implications when the normality assumptions of the original model (Roy, 1951) are relaxed.

${ }^{6}$ The relationship between earnings risk and wage compensation has recently been studied, for example, by Hartog and Vijverberg (2007a) and by Schweri, Hartog, and Wolter (2011).
} 


\section{Introduction}

matically after transition (Figure 3.1 in Chapter 3 illustrates this phenomenon). The finding that risk averse individuals are more likely to switch to occupations with low earnings variance after transition and that more risk tolerant individuals, in contrast, are more likely to switch to occupations with high earnings risk after transition suggests that risk attitudes have a causal impact on the choice of occupation.

In Chapter 4, the recent histories of two countries affected by the transition from the command to the market economy, Ukraine and East Germany, ${ }^{7}$ are used to identify the effect of risk attitudes on self-employment. Self-employed individuals have a larger variance of earnings than individuals in regular employment (Parker, 1999; Rosen and Willen, 2002; Falter, 2007b); however, earnings risk is only one of the components of uncertainty the self-employed face. The importance of willingness to take risks for entrepreneurship has been already discussed in early literature (Cantillon, 1755; Knight, 1921; Schumpeter, 1934, 1939). Recent empirical studies suggest a causal effect of risk attitude on the probability of becoming self-employed (Caliendo, Fossen, and Kritikos, 2009; Brown, Dietrich, Ortiz-Nuñez, and Taylor, 2011). In Chapter 4, I extend the understanding of the role of risk attitudes for self-employment in conditions when no previous information on self-employment is available. The fact that many existing businesses are transmitted through family channels (Hout and Rosen, 2000; Fairlie and Robb, 2007; Andersson and Hammarstedt, 2010) suggests that some specific knowledge about what it is like to be self-employed can decrease risk of self-employment. Since risk attitudes are correlated across generations (Dohmen, Falk, Huffman, and Sunde, 2012; Zumbuehl, Dohmen, and Pfann, 2013), it might be possible that there is no causal relationship between risk attitudes of the children of self-employed parents and their decisions to become self-employed. Lack of self-employment between 1945 and 1990's in the Soviet Ukraine and in the German Democratic Republic provides an original setup to study whether risk attitudes matter for self-employment when parents were very limited in how much knowledge about self-employment they could transmit to their children.

Chapter 5 continues the investigation of the role of risk attitudes for occupational mobility. In this chapter, I explain why risk attitudes contribute to different wage growth patterns resulting from job mobility of individuals who are heterogenous in their risk attitudes and provide field evidence that is consistent with the explanation. The relationship between job mobility and wages spurred an extensive

\footnotetext{
${ }^{7}$ I use East Germany because of the similar restrictions on self-employment that were in force during the Soviet Union time. The data from East Germany contain a unique measure of intentions to become self-employed elicited right before the reunification of Germany.
} 
debate in the literature, resulting into several theoretical models with contradictory predictions regarding a positive effect of job changes on wage growth (Burdett, 1978; Johnson, 1978; Jovanovic, 1979a,b). The empirical findings were also mixed (Topel and Ward, 1992; Light and McGarry, 1998; Munasinghe and Sigman, 2004; Dustmann and Pereira, 2008). In Chapter 5, I argue that since changing job is a risky decision, risk averse individuals require higher compensation to make a job change. This implies that, ceteris paribus, risk averse individuals will make less job changes than more risk-tolerant individuals. However, job changes of risk averse workers will be associated with larger wage increases from each job change compared to more risk-tolerant workers. In this way, heterogeneity in risk attitudes affects job changing behaviour, which in turn generates a different pattern of wage increases associated with job changes of risk averse and of more risk-tolerant workers. My findings using the data on German workers during their early career support these two predictions. 

2 Civic CApital and PREFEREnCES FOR ECONOMIC AND POLITICAL SYSTEMS 


\subsection{INTRODUCTION}

Whether economic growth is responsible for democratisation or whether democratic institutions provide fertile ground for economic development remains a heated debate in the literature (Przeworski and Limongi, 1993; Barro, 1999; Tavares and Wacziarg, 2001; Glaeser, La Porta, Lopez-de Silanes, and Shleifer, 2004; Sunde, 2006; Acemoglu, Johnson, Robinson, and Yared, 2008). ${ }^{1}$ In this chapter, we test whether a third factor affects both preferences for a market economy and preferences for a democratic political system, thereby generating a spurious correlation between preferences for systems with little government regulation as opposed to systems with strong government regulation. In particular, we investigate the role of civic capital, as a set of shared cooperative beliefs, norms and values facilitated by social trust, for the formation of political preferences. While civic capital is an inherited trait, a stable economic preference parameter, which is only malleable to a certain extent during the individual life course, 'political preferences' are choices. ${ }^{2}$

The arguments for the role of economic growth in facilitating the development of democratic structures are commonly referred to as 'modernisation' theory that was first proposed by Lipset (1959). It is argued in this literature that economic growth can facilitate democracy through mechanisms such as human capital development, expansion of the middle class, affluence, urbanization, improved living standards, reduction of income inequality, better protection of property rights, and emancipation of women (Barro, 1999; Boix and Stokes, 2003; Giavazzi and Tabellini, 2005; Papaioannou and Siourounis, 2008b). A different literature, on the other hand, maintains that economic development is promoted by democratic institutions, such as autonomy of the state, checks and balances on executives' authority, reduction of uncertainty, reduction of income inequality, protection of property rights, and promotion of human capital development (Przeworski and Limongi, 1993; Knack and Keefer, 1995; Acemoglu and Johnson, 2005; Tavares and Wacziarg, 2001; Rodrik and Wacziarg, 2005). While some factors that are thought to affect the relationship between democracy and economic development, e.g. human capital accumulation, protection of property rights, and reduction of income inequality are the same in both classes of models, the way that causality runs is juxtaposed.

Empirical evidence on the direction of causality is also controversial: support

\footnotetext{
${ }^{1}$ This chapter is joint work with Thomas Dohmen and Ben Kriechel. This chapter was presented at Maastricht University (2011) and at the Scottish Economic Society conference (SES, 2013). ${ }^{2}$ Our definition of civic capital follows from Guiso, Sapienza, and Zingales (2011) and differs from 'social capital', which is sometimes treated as an outcome that can be altered by individual investment (i.e. in Glaeser, Laibson, and Sacerdote, 2002).
} 


\subsection{Introduction}

for both arguments has been found. The outcomes range from supporting the role of economic development for democratisation (for example, Giavazzi and Tabellini, 2005) to no effect at all after including the relevant controls or fixed effects (Boix and Stokes, 2003; Acemoglu, Johnson, Robinson, and Yared, 2008). Estimates of the effect of democracy on growth were sometimes found to be positive (Pettersson, 2004; Rodrik and Wacziarg, 2005; Papaioannou and Siourounis, 2008a), zero or even negative (Tavares and Wacziarg, 2001; Glaeser, La Porta, Lopez-de Silanes, and Shleifer, 2004), depending on the estimation technique or the sample used. In a recent study, Grosjean and Senik (2011) find that market liberalisation has no causal effect on preferences for democracy but that democratisation affects support for market economy. In summary, the empirical literature indicates that although there is a strong correlation between economic and democratic developments, no clear-cut picture emerges on the direction of causality. Possibly, this relationship is not causal, but driven by another factor which has an impact on the development of both political and economic structures.

In this study, we argue that a factor which can affect the relationship between economic growth and democracy is civic capital. There are theoretical models supported by empirical evidence indicating that civic capital plays an important role in promoting economic development by reducing transaction costs and enhancing efficiency (Arrow, 1972; Fukuyama, 1995; Knack and Keefer, 1997; Zak and Knack, 2001; Guiso, Sapienza, and Zingales, 2004; Algan and Cahuc, 2010; Tabellini, 2010). Another strand of literature shows that civic capital is a determinant of political institutions' viability and of the stability of a democracy because it is conductive to democratic beliefs and principles (Almond and Verba, 1963; Inglehart, 1988; Putnam, 1993; Badescu and Uslaner, 2003; Tabellini, 2008a). Trusting individuals are less likely to demand excessive regulation from the state (Glaeser and Shleifer, 2003; Djankov, Glaeser, La Porta, Lopez-de Silanes, and Shleifer, 2003; Pinotti, 2008; Aghion, Algan, and Shleifer, 2010). It is plausible that societies with much civic capital will be more likely to prefer a market economy and a more democratic political structure. On the other hand, societies with little civic capital might be more likely to prefer systems with more governmental control over economic and political affairs.

We hypothesize that civic capital is a decisive factor that puts a society on a path towards either a 'good' or a 'bad' state. A 'good' state is characterised by freedom of speech, protection of human rights and property rights, and economic prosperity. In a 'bad' state, citizens are exploited by their government, state regulation prevails, and economic development is limited. In the 'good' state, individuals possess a set of cooperative norms, beliefs, and values towards a wide range 
of (unknown) people making them less likely to demand governmental regulation in political and economic life. As a result, well-balanced institutions are established and conditions for free trade emerge, setting off for economic prosperity. In the 'bad' state, citizens lack trust in strangers. They behave cooperatively only towards a circle of close family members and friends. In contrast, civic norms of behaviour do not apply to unknown people, because strangers are perceived as untrustworthy. Negative externalities expected from unregulated market entry of uncivic entrepreneurs raise the demand for more government regulation (Pinotti, 2008). In turn, more regulation triggers increase in distrust (Aghion, Algan, and Shleifer, 2010). We posit that individuals choose to establish systems and institutions that are well-aligned with their preferences. Civic capital and individual preferences for institutions will be highly correlated if trusting citizens favour systems with little government intervention, whereas uncivic citizens demand more state regulation because they lack trust.

In this study, we propose a method to relate historically determined variation in civic capital to current political and economic systems, and establish that civic capital has an impact on both. We build on the argument that civic capital formation is affected by historical events (Paldam and Swedsen, 2001; Guiso, Sapienza, and Zingales, 2008b; Nunn and Wantchekon, 2011; Grosfeld, Rodnyansky, and Zhuravskaya, 2010; Heineck and Süssmuth, 2013; Jacob and Tyrell, 2010), and that it is transmitted through the generations (Bisin and Verdier, 2001; Guiso, Sapienza, and Zingales, 2008a; Tabellini, 2008b; Cesarini, Dawes, Johannesson, Lichtenstein, and Wallace, 2009; Algan and Cahuc, 2010; Dohmen, Falk, Huffman, and Sunde, 2012). Based on these two propositions, we contend that civic capital is relatively stable (at least, within a time horizon that is relevant for the study), and that the effect of historical institutions can be used as an exogenous source of information about the level of its accumulation.

More specifically, our identification strategy is based on the arguably exogenous variation across regions in contemporary Ukraine that are rooted in history. The first element is the fact that the territory of the country has been split up for centuries under different political regimes which heterogeneously affected the level of civic capital accumulation. In particular, during the 18th - 19th centuries, the East of Ukraine was ruled by the Russian Empire, which was characterised by an oppressive style of governance, with strict orthodox religion, harsh rules, and even serfdom. On the contrary, the West of Ukraine experienced a more predictable, stable, and lenient rule of the Habsburg Empire (Becker, Boeckh, Hainz, and Woessmann, 2011). The second element of the identification based on the 


\subsection{Introduction}

historical events is the uniform rule of the Soviet Union, which enforced the same economic and political system on the whole territory since 1945. Ukraine has been a unitary republic since then. Its political and, to a large extent, economic situation has been alike across the regions. Until the collapse of the Soviet Union in 1991, citizens residing in any part of Ukraine had virtually no influence on the economic and political system in the country. We argue that contemporaneous differences in political preferences across the regions can partly be attributed to these two historical experiences that operated as quasi-natural experiments, as civic capital which was affected by the historical events has been transmitted to today's generations.

Our analysis mainly uses data from the Ukrainian Longitudinal Monitoring Survey (ULMS), a nationally and regionally representative household survey, which aside from a rich set of social and demographic characteristics of respondents, also contains data on political preferences and trust. Additionally, we rely on supplementary data sets such as: the World Values Survey (WVS), the Central and Eastern Eurobarometer (1990-1997), and the Consolidation of Democracy in Central and Eastern Europe (1990-2001) to trace the development of political preferences since the early transition period.

We develop a conceptual framework building upon recent theoretical advancements and empirical findings that links theories explaining the formation and transmission of civic capital to empirical analyses of the relationship between trust and economic and political outcomes. In the empirical part, we present heterogeneity in civic capital across Ukrainian regions resulting from different historical experiences and analyse effect of civic capital on political preferences of Ukrainian citizens. Our results indicate that it is plausible to interpret the effect on preferences for economic systems as causal and support the conjunction that civic capital has an impact on preferences for political systems. We find that high level of shared civic capital is a significant predictor of preferences favouring economic and political systems with little control from the government, such as a market economy and a democratic state. On the contrary, in the regions with little shared civic capital, economic and political systems with more government control are preferred. Civic capital is likely to stimulate co-development of political and economic systems that is generally observed around the globe.

The chapter proceeds as follows: the next section sketches our conceptual framework, section 2.3 presents our empirical approach. Section 2.4 describes the data and main variables. Section 2.5 presents and discusses the results. The last section concludes. 
2 Civic capital, economic and political systems

\subsection{Conceptual FRAmework}

If people's preferences ultimately determine what kind of political and economic system will prevail in a state, it is important to ask how these preferences are formed. We argue that preferences for a particular kind of economic or political system are affected by shared norms of cooperation, values and beliefs, facilitated by social trust, to which we refer as civic capital. The current level of civic capital depends on the experience of previous generations because of intergenerational transmission of preferences and beliefs. Parents educate their children based on their own perceptions of the social environment. Prominent models of cultural transmission (for example, Bisin and Verdier, 2001; Tabellini, 2008b) show that preferences, norms and beliefs are transmitted from one generation to the next. Empirical evidence (Uslaner, 2008; Cesarini, Dawes, Johannesson, Lichtenstein, and Wallace, 2009; Aghion, Algan, and Shleifer, 2010; Dohmen, Falk, Huffman, and Sunde, 2012) supports these models.

It has been shown empirically that norms of cooperative behaviour, which determine how well citizens can solve a public good problem, vary dramatically across societies around the globe. Evidence suggests that these norms are historically determined since it has been shown experimentally in various contexts that pro-cooperative behaviour is hardly related to any demographic characteristics of group members (Henrich, Boyd, Bowles, Camerer, Fehr, Gintis, and McElreath, 2001; Herrmann, Thöni, and Gächter, 2008; Gächter and Herrmann, 2009).

Numerous empirical investigations show that historical events affect population's civic capital (Guiso, Sapienza, and Zingales, 2006, 2008b; Nunn and Wantchekon, 2011; Rainer and Siedler, 2009; Heineck and Süssmuth, 2013; Jacob and Tyrell, 2010; Tabellini, 2010; Becker, Boeckh, Hainz, and Woessmann, 2011). Favourable historical events and favourable experience with institutions help to build up civic capital. Individuals who grow up in a trusting environment are more likely to expect other individuals to be trustworthy. Civic norms of behaviour foster cooperation, which brings clear benefits to a community and facilitates its development.

On the contrary, harmful historical events, such as wars and experience with totalitarian political institutions, reduce civic capital by destroying social trust, i.e. trust in strangers (Nunn and Wantchekon, 2011; Becker, Boeckh, Hainz, and Woessmann, 2011). It is costly to trust in an environment in which a random individual is likely to be an uncivic one. When social trust is lacking, people choose to only trust people who are close to them in terms of social distance (Tabellini, 2008b), such as family members and friends. Closing up social networks eventually 
leads to acceptance and even encouragement of unfair behaviour towards strangers. These uncivic norms of behaviour will be persistent, because parents transmit conservative priors to their children (Guiso, Sapienza, and Zingales, 2008a).

Although conservative priors might be individually rational, in general, uncivicness leads to an inefficient increase in demand for state control over political and economic affairs (Djankov, Glaeser, La Porta, Lopez-de Silanes, and Shleifer, 2003). However, because public officials are also recruited from the same pool of uncivic citizens, it is likely that public officials are also uncivic and corrupt (Aghion, Algan, and Shleifer, 2010). Uncivic officials reinforce the belief that no one can be trusted. When this path is launched, a following generation would only demand more regulation, leading to even more distrust.

On the other hand, when no negative historical events hinder accumulation of civic capital, an efficient cooperative outcome can be reached. ${ }^{3}$ Civic norms of behaviour, i.e. norms of cooperation not limited to the inner circle of family and close friends, are transmitted and reinforced, thereby reducing demand for regulation (Pinotti, 2008). Social trust and widespread norms of pro-cooperative behaviour decrease demand for state regulation and promote development of trade and market structures by reducing transaction costs (Knack and Keefer, 1997; LaPorta, Lopez-de Silanes, Shleifer, and Vishny, 1997; Guiso, Sapienza, and Zingales, 2004; Algan and Cahuc, 2010; Tabellini, 2010). Such a society will also tend to avoid autocratic political regimes by establishing systems of power checks and bureaucratic regulations, setting up basis for a properly functioning democratic state (Almond and Verba, 1963; Inglehart, 1988; Putnam, 1993; Uslaner, 1999; Badescu and Uslaner, 2003; Tabellini, 2008a).

\subsection{EMPIRICAL STRATEGY}

To empirically analyse the effect of civic capital on preferences for economic and political systems, two main assumptions need to be satisfied. First, civic capital has to be exogenously determined. Second, we need to make sure that no third factor, such as current institutions, can potentially confound the relationship between civic capital and political preferences. In this study, we propose and empirically test the link between civic capital and preferences for economic and political systems, under the conditions that plausibly satisfy the above mentioned assumptions. We analyse

\footnotetext{
${ }^{3}$ Because of institutional inertia, conservatively transmitted priors and interaction between beliefs and institutions, positive shocks to civic capital do not have such long lasting consequences as negative shocks do. Therefore, longer periods of adjustment are needed before a path towards another, more cooperative outcome, can be launched (Jacob and Tyrell, 2010).
} 
the relationship between civic capital and preferences for economic and political systems in a transition country with a rich historical background, Ukraine, because of two sources of exogenous variation that its history provides.

The first element is the fact that Ukraine has been split under and ruled by various political regimes for centuries. Its population was affected by different institutions and events depending on the region. We argue that the current level of civic capital reflects different historical circumstances which Ukrainian citizens experienced before the Soviet Union occupation, because of a conservative nature and intergenerational transmission of civic capital.

The eastern part of current Ukrainian territory was under the influence of Russian tsardom that later became the Russian Empire in the 17th century (a more detailed account of the history of Ukraine is in Appendix 2.B.). The regime of the Russian Empire was highly oppressive and unpredictable, characterised by harsh rules, pervasive orthodox religion and serfdom (Åberg, 2000; Subtelny, 2005; Riabchuk, 2008). Ukrainians in the East were subject to constant persecutions (Subtelny, 2005), which is likely to have had an adverse effect on their civic capital.

The western part, on the contrary, was integrated into a Polish-Lithuanian Commonwealth during the 17th century. Later it became a part of the Habsburg Empire. While these circumstances were not necessarily favourable for the accumulation of civic capital, when compared to the conditions of the Russian Empire, the Polish-Lithuanian Commonwealth and the Habsburg Empire were more tolerant towards the local population. The rule of the Habsburgs was described as an honest and reliable bureaucracy which respected the identity and local differences of various parts of the empire (Magocsi, 2010; Becker, Boeckh, Hainz, and Woessmann, 2011). It is likely that these differences in historical treatment affected civic capital accumulation differently in the two parts, such that more civic capital was preserved in the West compared to the East.

The second element of the experiment in the Ukrainian history is the existence of the totalitarian regime of the Soviet Union in Ukraine since the early 1920's in the East and since the World War II in the West. Citizens could not choose their own political and economic structures until the collapse of the Soviet Union in 1991. Moreover, obsessive control by the totalitarian structures of the Soviet authorities did not allow citizens to freely express and discuss their opinions about the desirability of other political and economic systems. It is unlikely that preferences for economic and political systems, which could have been inherited from before the Soviet Union period, were transmitted to the following generations. In contrast, civic norms of behaviour and beliefs about strangers are more persistent because they are formed through intra-family interactions (Tabellini, 2008b). Civic capital 
would require at least several generations to re-accumulate following a favourable exogenous change in the environment (Guiso, Sapienza, and Zingales, 2008a). In other words, the period of Ukrainian history between 1946 and 1991 represents a 'frozen' state, in which inherited differences in civic capital were transmitted from one generation to another, while preferences for economic and political systems were not.

The sudden end of the Soviet Union in the 1991 was an exogenous shock that removed totalitarian governmental control. Ukrainian population started to develop preferences for economic and political systems which would be in line with their civic norms. In the West, where civic capital was less damaged by oppressive regimes, pro-social norms of behaviour are likely to stimulate demand for systems with little regulations, such as a market-based economy and a democratic state. In contrast, lack of social trust and uncivic norms of behaviour in the East is likely to generate demand for strong government regulation, i.e. for a centrally planned (command) economy and an autocratic Soviet style political system. ${ }^{4}$

\subsection{DATA AND VARIABLES}

The main data source that we use for testing our predictions is the 2007 wave of the Ukrainian Longitudinal Monitoring Survey (ULMS). ${ }^{5}$ We restrict the sample to the regions to which we refer as West and East based on the historical background. The territory of Ukraine consists of 24 'oblasts' (territorial and administrative units), of which seven western oblasts are defined as 'West' and five eastern oblasts are defined as 'East'. Shaded areas on the map on Figure 2.1 picture the location of these regions. We use outermost regions for the empirical analysis, since these are territories for which clear predictions can be made with respect to civic capital. ${ }^{6}$ The summary statistics of the variables for the sample used in the estimation are presented in Table 2.A in Appendix 2.A.

Our two dependent variables reflecting demand for a more or less regulated economic and political systems are defined using answers to the following questions: "What kind of economic system, in your opinion, is most suitable for Ukraine?" and "What kind of political system, in your opinion, is most suit-

\footnotetext{
${ }^{4}$ Analysis of the relationship between preferences for political and economic systems and the development of such systems is beyond the scope of this study. We assume that citizens' preferences reflect their beliefs about desirability of a certain system.

${ }^{5}$ More details on the ULMS can be found in Lehmann, Muravyev, and Zimmermann (2012).

${ }^{6}$ Because of the turbulent history of Ukraine, the center, North and South territories were changing hands frequently, thereby creating an overly complex mix of influences.
} 
Figure 2.1: Map of Ukraine

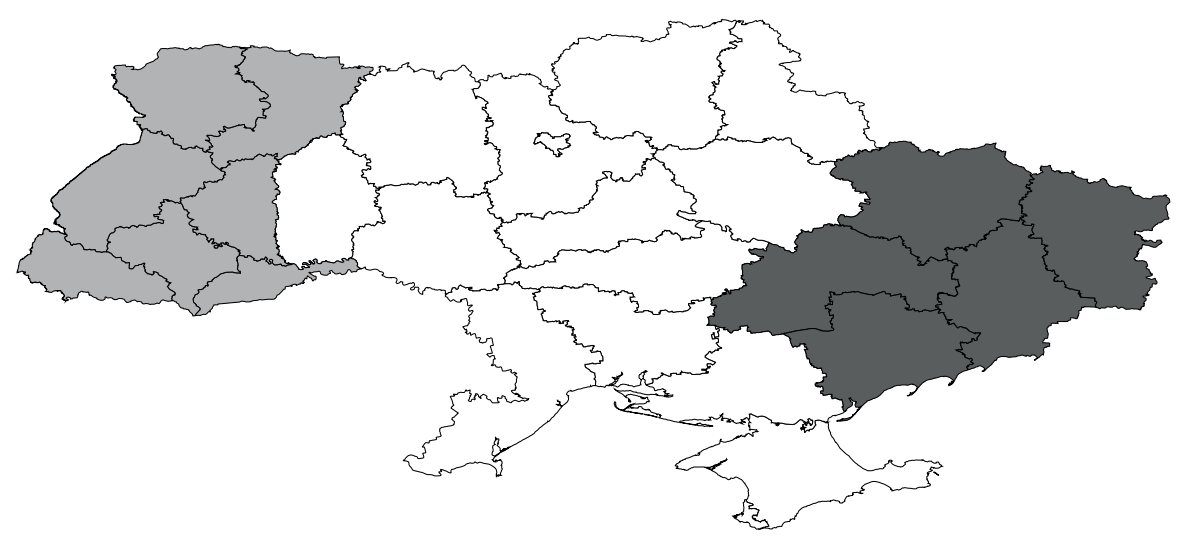

Note: West and East regions are shaded on the map.

able for Ukraine?". ${ }^{7}$ The categories for the variable 'economic system preference' are: (1) The centrally-planned economy which was in our country until perestroika; (2) A centrally-planned economy with elements of a market economy; (3) The economic system which exists today; (4) A market economy with strong government regulation; (5) A market economy with little government regulation; (6) A free market economy without government regulation. The 'political system preference' categories are as follows: (1) The Soviet system which was in our country until perestroika; (2) The Soviet system, but in a different, more democratic form; (3) The political system which exists today; (4) A western-type democracy. Figure 2.2 plots the distribution of preferences for economic and political systems in the population. Remarkably, the current economic system and the current political system has the lowest share of supporters.

For the first part of our empirical analysis, we construct two binary variables reflecting a preference towards the system with more or less state control. The dummy 'preference for a market-based' economic system is equal to one if categories (4), (5), or (6) of the economic preference are chosen, and to zero otherwise. The dummy 'preference for a democratic political system' is equal to one if the preferred political system is a western-type democracy (category (4)), and it is equal to zero otherwise. In the second part of the analysis, a multinomial logit model

\footnotetext{
${ }^{7}$ All the questions are translated from Ukrainian or from Russian, which are two main languages spoken in Ukraine.
} 
Figure 2.2: Distribution of political preferences

(a) Preferences for economic systems

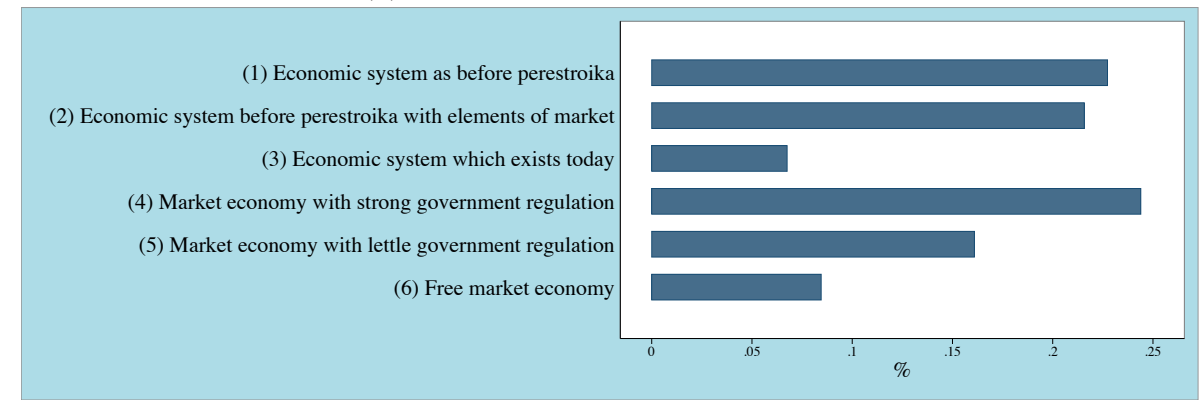

(b) Preferences for political systems

(1) Soviet system before perestroika

(2) Soviet system with elements of democracy

(3) Political system which exists today

(4) Western-type democracy

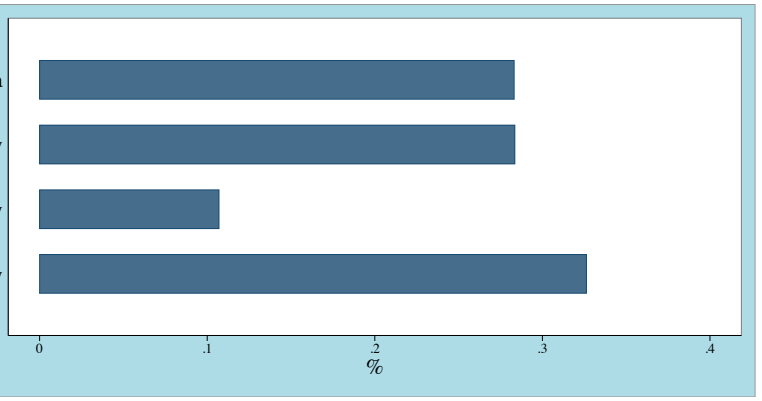

is estimated, which better accounts for the categorical nature of the dependent variables.

Our explanatory variable, 'shared civic capital', reflects the level of 'civicness' or readiness to act pro-socially towards (unknown) individuals relative to inner circle of family because destroyed social trust is likely to be compensated by excessive reliance on close social networks (LaPorta, Lopez-de Silanes, Shleifer, and Vishny, 1997; Guiso, Sapienza, and Zingales, 2008b). To illustrate the negative relationship between trust in strangers and trust in family, Figure 2.4 plots the oblast mean levels of the two dimensions of trust against each other. To construct the 'shared civic capital' measure, we first define civic capital as the ratio of trust in strangers 
Figure 2.4: Correlation of trust in strangers and trust in family

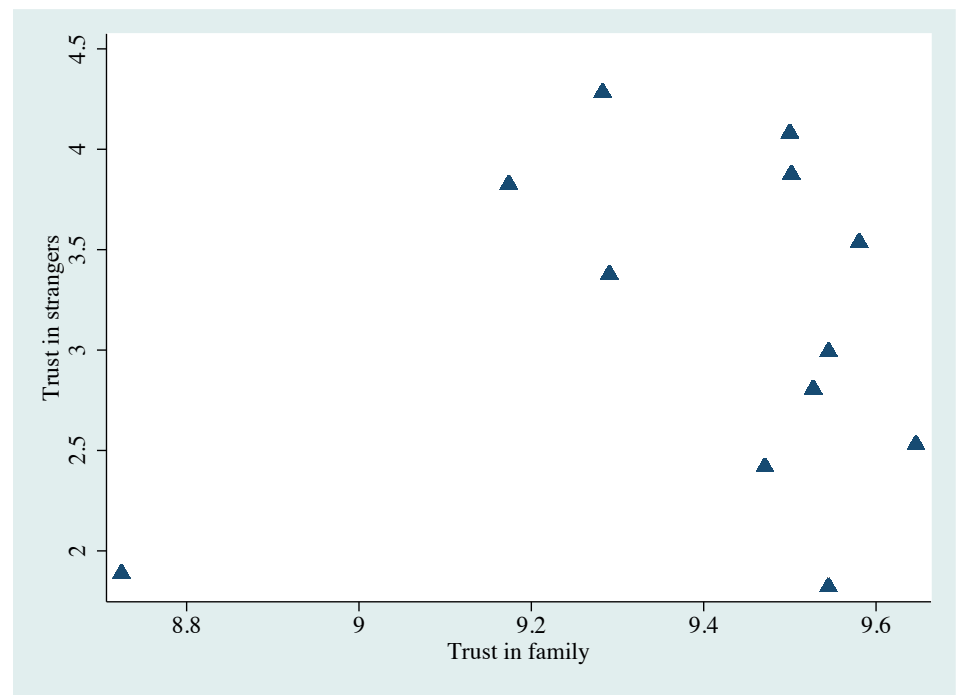

Source: ULMS, 2007.

Note: The data points represent averages of trust in strangers and trust in family per oblast. Higher values reflect more trust.

to trust in family on individual level. ${ }^{8}$ We take the mean of civic capital per oblast as the measure of shared civic capital. ${ }^{9}$

Table 2.1 shows the mean values of various indicators of inherited civic norms and values per West and East. According to our civic capital measure, there is significantly more civic capital in the West than in the East $(p$-value $<.01)$. Civic capital should also be reflected in other norms facilitating collective action, such as pro-social orientation, willingness to contribute to a public good, and disapproval of anti-social behaviour. Table 2.1 shows that most of the differences across West and East along various facets of civic capital are significant.

\footnotetext{
${ }^{8}$ Trust in strangers is measured by a survey question reading as "How would you assess your attitude towards other persons: Are you a person who in general trusts other persons, or are you a person who rather does not trust other persons? Please mark a number on the following scale, where the value 0 means: 'I do not trust other persons at all' and the value 10: 'I trust other persons completely". Trust in family is measured by an answer to an identical questions referring to trust in 'family members' instead of 'other persons'.

${ }^{9}$ For each individual, his or her own value of civic capital is excluded from calculation of the shared civic capital measure.
} 
Table 2.1: Difference in civic capital across West and East of Ukraine

\begin{tabular}{|c|c|c|c|c|}
\hline & West & East & $t$-value ${ }^{1}$ & Observations \\
\hline Civic capital (individual level) & 0.43 & 0.39 & -3.10 & 2467 \\
\hline \multicolumn{5}{|l|}{ How justifiable is... } \\
\hline Claiming government benefits ${ }^{2}$ & 2.92 & 2.94 & 0.23 & 2259 \\
\hline Avoiding a fare on public transport & 3.62 & 4.34 & 6.07 & 2406 \\
\hline Cheating on taxes & 2.99 & 3.50 & 4.49 & 2357 \\
\hline Someone accepting a bribe & 1.82 & 2.16 & 4.13 & 2478 \\
\hline Lying & 2.77 & 3.39 & 2.90 & 615 \\
\hline Political assassination & 1.26 & 1.57 & 2.65 & 610 \\
\hline \multicolumn{5}{|l|}{ Orientation towards society } \\
\hline It is better to stick to own affairs ${ }^{3}$ & 2.15 & 2.62 & 5.11 & 578 \\
\hline Concerned with immediate family ${ }^{4}$ & 1.22 & 1.39 & 3.40 & 630 \\
\hline $\begin{array}{l}\text { Concerned with people in the neigh- } \\
\text { bourhood }\end{array}$ & 3.14 & 3.21 & 0.81 & 624 \\
\hline Concerned with people in the region & 2.95 & 3.16 & 2.60 & 613 \\
\hline Concerned with fellow countrymen & 2.81 & 3.04 & 2.83 & 610 \\
\hline Concerned with Europeans & 3.57 & 3.90 & 4.08 & 587 \\
\hline Concerned with human kind & 3.19 & 3.38 & 2.02 & 584 \\
\hline Willing to fight for the country ${ }^{5}$ & 0.87 & 0.72 & -7.92 & 1871 \\
\hline \multicolumn{5}{|l|}{ Control and responsibility over one's life } \\
\hline $\begin{array}{l}\text { Freedom of choice and control over } \\
\text { your life }\end{array}$ & 5.98 & 5.12 & -7.97 & 2345 \\
\hline $\begin{array}{l}\text { Living day to day because of uncer- } \\
\text { tain future }\end{array}$ & 0.48 & 0.62 & 3.45 & 584 \\
\hline $\begin{array}{l}\text { Perceived extent of political } \\
\text { corruption }^{8}\end{array}$ & 3.20 & 3.41 & 5.37 & 1290 \\
\hline
\end{tabular}

Source: World Values Survey; pooled waves 1996, 1999, 2006.

Note: Columns 'West' and 'East' report means of the variables named in the first column.

${ }^{1} t$-value refers to the $t$-test statistic on the significance of the difference between West and East.

2 The variables in this set "How justifiable is..." are measured on a scale from 1 to 10 , where 1 means 'never justifiable' and 10 means 'always justifiable'. The full wording of the item is 'Claiming government benefits one is not entitled to'.

3 'It is better to stick to own affairs' is measured on a scale from 1 to 5 , where 1 means 'strongly agree' and 5 means 'strongly disagree'.

${ }^{4}$ The following variables ("Concerned with...") are measured on a scale from 1 to 5 , where 1 means 'very much' and 5 means 'not at all'.

5 'Willing to fight for the country' is a dummy variable, 1 meaning 'yes'.

6 'How much freedom of choice and control you have over your life' is measured on a scale from 1 to 10,1 meaning 'none at all' and 10 meaning 'a great deal'.

7 'Living day to day because of uncertain future' is a dummy variable, where 1 means 'tends to agree'.

8 Perceived extent of political corruption is measured on a scale from 1 to 4 , in which 1 means 'almost no public officials are corrupt' and 4 means 'almost all public officials are corrupt'. 
2 Civic capital, economic and political systems

\subsection{Results}

In Ukraine, the demand for regulation of economic and political affairs is highly correlated. Figure 2.5 plots preferences for a market-based economy and a democratic state against each other. The Spearman's correlation coefficient of .87 ( $p$ value $<.01)$ is line with widely documented tendency of economic and political systems to co-evolve along the dimension of regulation (Barro, 1999; Rodrik and Wacziarg, 2005; Papaioannou and Siourounis, 2008b; Acemoglu, Johnson, Robinson, and Yared, 2008).

Figure 2.5: Correlation of preferences for economic and political systems

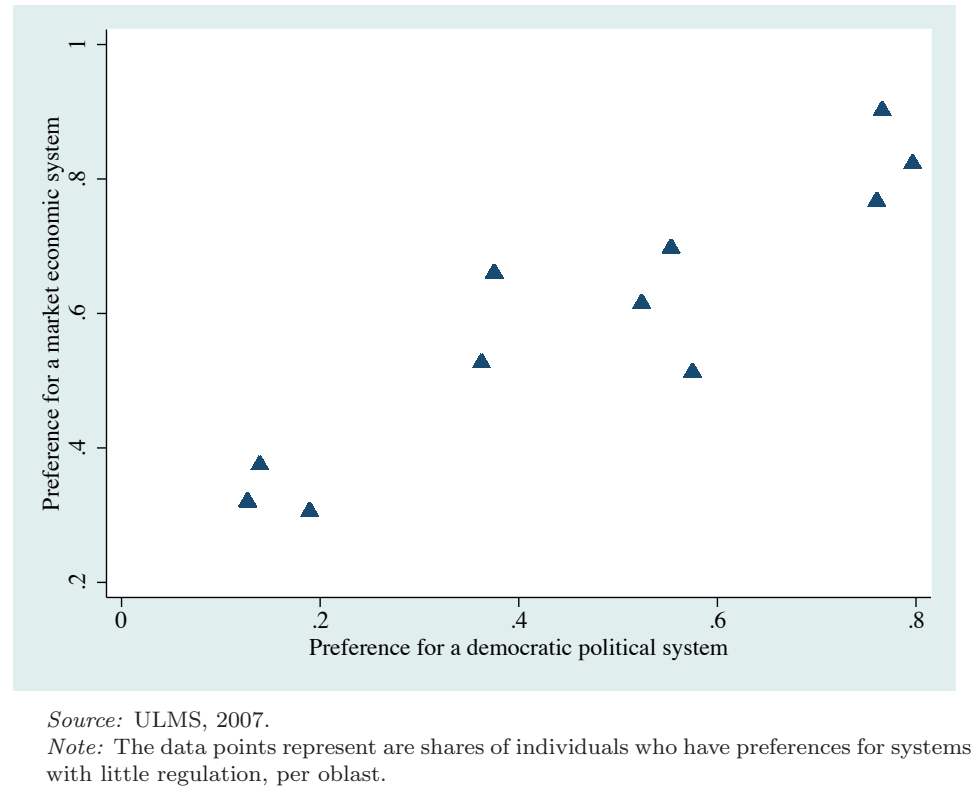

Table 2.2 presents the estimates of the effect of shared civic capital on the preferences for economic and political systems. To simplify the exposition, we first present the results of the logit model estimation. The dependent variable is the (binary) preference for a market economy-based system in columns (1) and (2), and preference for a democratic political system in columns (3) and (4). The variables are as defined in section 2.4. Each model includes an interaction term between residence in the West and shared civic capital in the oblast of residence. Table 2.2 
Table 2.2: Civic capital and political preferences

\begin{tabular}{l} 
Market-based economy \\
\cline { 2 - 4 } \\
\cline { 2 - 4 }
\end{tabular}

reports the marginal effects evaluated at sample means and reported in the form of elasticities of civic capital on preferences for systems with low government control for the West and for the East.

In columns (1) and (3) no control variables are included. The difference between the effect of civic capital in the East and in the West is statistically significant, as indicated by Chi-square test reported in the bottom of Table 2.2, supporting the findings on the aggregate level. When including of a large set of control variables in columns (2) and (4), the findings remain qualitatively intact, although the difference in the effect of civic capital in column (4) is no longer significant. The set of control variables includes individual characteristics (demographics, education, employment and marital status, number of children, nationality, size of place of residence, log of household income per household member), parental education background, and regional characteristics (regional unemployment rate and 
log of regional GDP), own civic capital and the opinion about the developments in Ukraine during the last two years following the Orange revolution. ${ }^{10}$

Table 2.3: Preferences for a market-based economic system

\begin{tabular}{lcccc}
\hline & $(2)^{1}$ & $(3)$ & $(4)$ & $(5)$ \\
\cline { 2 - 4 } Civic capital in the East & $1.639^{* *}$ & -2.744 & $1.699^{* *}$ & $2.290^{* * *}$ \\
& $(0.640)$ & $(1.789)$ & $(0.676)$ & $(0.784)$ \\
& -0.379 & -0.653 & $0.395^{*}$ & 0.122 \\
Civic capital in the West & $(0.424)$ & $(0.693)$ & $(0.219)$ & $(0.203)$ \\
& & & Yes \\
Control variables: & & & Yes \\
Individual demographic and socio-economic characteristics & Yes \\
Opinion about the Orange Revolution events in Ukraine & & Yes \\
Parental background & & & \\
Characteristics of region and place of residence & & 3.28 & 7.01 \\
\hline Difference between the effects in the East and in the West: ${ }^{2}$ & & 0.01 \\
Chi-squared & 6.22 & 1.12 & 0.29 & 0.07 \\
$p$-value & & & \\
\hline
\end{tabular}

Source: ULMS.

Note: Estimation: Multinomial logit. This table presents results of a single model estimation. Observations: 2414. Table entries are elasticities. The coefficients represent the change in probability of choosing an economic system resulting from an increase in civic capital of $1 \%$ relative to the base category.

Dependent variable is the preference for economic systems in the following categories:

(1) Centrally-planned economy that was in Ukraine before perestroika (base category);

(2) Centrally planned economy but with elements of market economy;

(3) The economic system that exists today in Ukraine;

(4) Market economy with strong government regulation;

(5) Market economy with little government regulation and a free market economy without government regulation.

1 The column numbering corresponds to the categories of the dependent variable. 1 is omitted because it is the reference category.

2 These results are based on Wald tests of the equality of the predicted marginal effects.

Although the logit model results are easier to interpret, to properly account for a categorical nature of our dependent variables, we proceed to the multinomial logit results presented in Tables 2.3 and 2.4. The models include an interaction term between shared civic capital and residence in the West, which allows to interpret the effect of civic capital separately for the West and for the East. The models also include a full set of control variables, as specified above. Column numbers represent the categories of the political preferences variables as described in section $2.4,{ }^{11}$

${ }^{10}$ Although this opinion variable is important to control for, since the West of Ukraine was much more supportive of European integration and pro-democratic development than the East, the findings are not affected by the inclusion.

${ }^{11}$ We merge categories (5) and (6) in economic system preference, i.e. preference for an economic system with little government regulation and a free market economic system. 
Table 2.4: Preferences for a democratic political system

\begin{tabular}{|c|c|c|c|}
\hline & $(2)^{1}$ & $(3)$ & $(4)$ \\
\hline \multirow[t]{2}{*}{ Civic capital in the East } & $2.350^{* * *}$ & -1.253 & $1.993^{* *}$ \\
\hline & $(0.515)$ & $(1.294)$ & $(0.781)$ \\
\hline \multirow[t]{2}{*}{ Civic capital in the West } & -0.608 & $-1.354^{* *}$ & $0.499^{* * *}$ \\
\hline & $(0.389)$ & $(0.672)$ & $(0.137)$ \\
\hline \multicolumn{4}{|l|}{ Control variables: } \\
\hline \multicolumn{2}{|c|}{ Individual demographic and socio-economic characteristics } & & Yes \\
\hline \multicolumn{2}{|c|}{ Opinion about the Orange Revolution events in Ukraine } & & Yes \\
\hline \multicolumn{2}{|l|}{ Parental background } & & Yes \\
\hline \multicolumn{2}{|l|}{ Characteristics of region and place of residence } & & Yes \\
\hline \multicolumn{4}{|c|}{ Difference between the effects in the East and in the West: ${ }^{2}$} \\
\hline Chi-squared & 19.49 & 0.00 & 3.48 \\
\hline$p$-value & 0.00 & 0.95 & 0.06 \\
\hline \multicolumn{4}{|c|}{$\begin{array}{l}\text { Source: ULMS. } \\
\text { Note: Estimation: Multinomial logit. This table presents results of a single model estimation. Observations: } \\
2340 . \text { Table entries are elasticities. The coefficients represent the change in probability of choosing an economic } \\
\text { system resulting from an increase in civic capital of } 1 \% \text { relative to the base category. } \\
\text { Dependent variable is the preference for political systems in the following categories: } \\
\text { (1) Old style Soviet system (reference category); } \\
\text { (2) Soviet system with elements of democracy; } \\
\text { (3) The political system that exists today in Ukraine; } \\
\text { (4) Western type democracy. } \\
1 \text { The column numbering corresponds to the categories of the dependent variable. } 1 \text { is omitted because it is the } \\
\text { reference category. } \\
2 \text { These results are based on Wald tests of the equality of the predicted marginal effects. }\end{array}$} \\
\hline
\end{tabular}

such that each table entry corresponds to the change in probability to support a particular kind of an economic or a political system relative to the base category (the centrally planned economy before perestroika in Table 2.3 or the old-style Soviet political system in Table 2.4) resulting from a $1 \%$ increase in shared civic capital.

For example, column (4) of Table 2.3 shows that a $1 \%$ increase in shared civic capital is associated with a $1.7 \%$ increase in the probability of supporting a market economy with strong government regulation relative to the base category. The size of the effect in the West is much smaller, only a $0.4 \%$ increase in the probability of supporting a market economy with strong government regulation is predicted, resulting from a $1 \%$ increase in shared civic capital $(p$-value $<0.01)$. Similarly, from Table 2.4, a 1\% increase in shared civic capital in the East increases support for a democratic political system by $2 \%$, whereas in the West by $0.5 \%$.

Differences in political preferences across East and West can be attributed to the inherited differences in civic capital if the conditions under which these political preferences remained stable until 1991. Given lack of data on preferences and 
beliefs during the Soviet time, this is impossible to verify directly. An indirect way of testing this assumption is to reconstruct the evolvement of political preferences since the beginning of the transition period. If there is a causal effect of civic capital on political preferences, we should observe virtually no difference in the beginning of transition, since political preferences were similar (or undefined) under the Soviet regime. With the years, inherited civic capital in the West should affect the formation of political preferences such that an increasing share of population will develop preferences for economic and political systems with little government intervention.

Figure 2.6: Share of citizens supporting the development of a market-based economic system

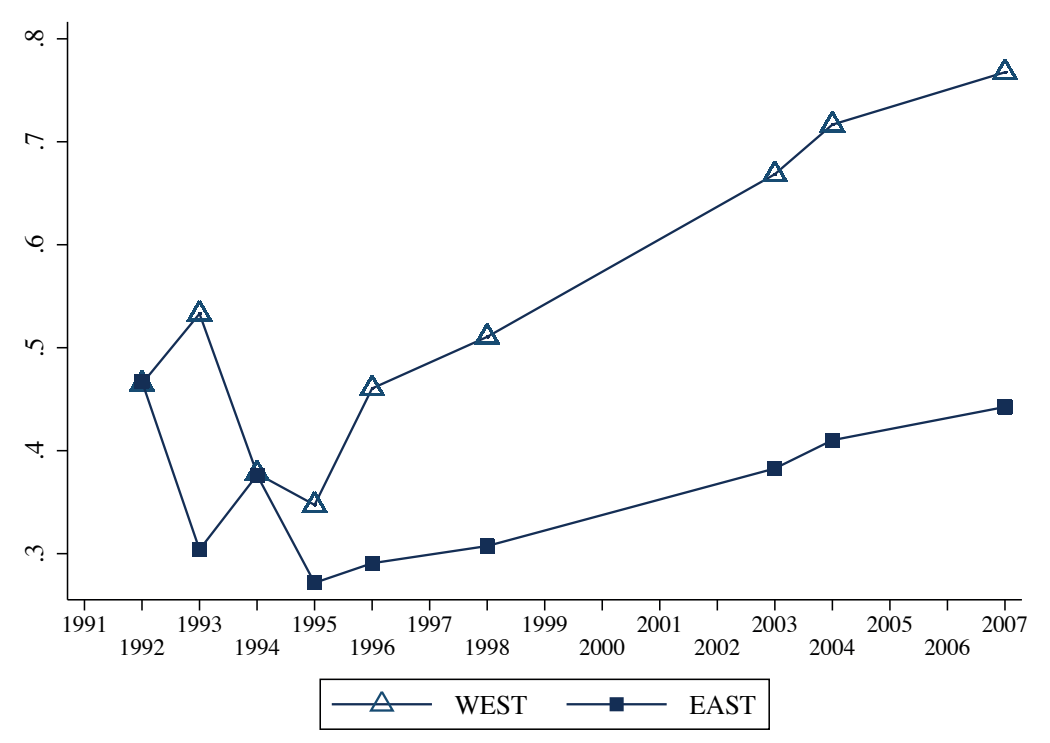

Source: World Values Survey (WVS), Central and Eastern Eurobarometer, Consolidation of Democracy in Central and Eastern Europe, ULMS. Unweighted averages per year, combined where available.

Using a combination of all available (to our knowledge) data sources on political preferences of Ukrainian population, we construct a measure which reflects a share of the population that supports a market-based economy (against a planned economy) or a democratic political state (as opposed to an authoritarian state) in the West and in the East. Figure 2.6 displays the development of preferences for a market-based economy starting from 1992, when the earliest year for which 
we have data on the regional level. The line with hollow triangles indicating data points displays the share of supporters of a market economy in the West, whereas the solid line with squares reflects the share of supporters of a market economy in the East.

Figure 2.7: Share of citizens supporting the development of a democratic political system

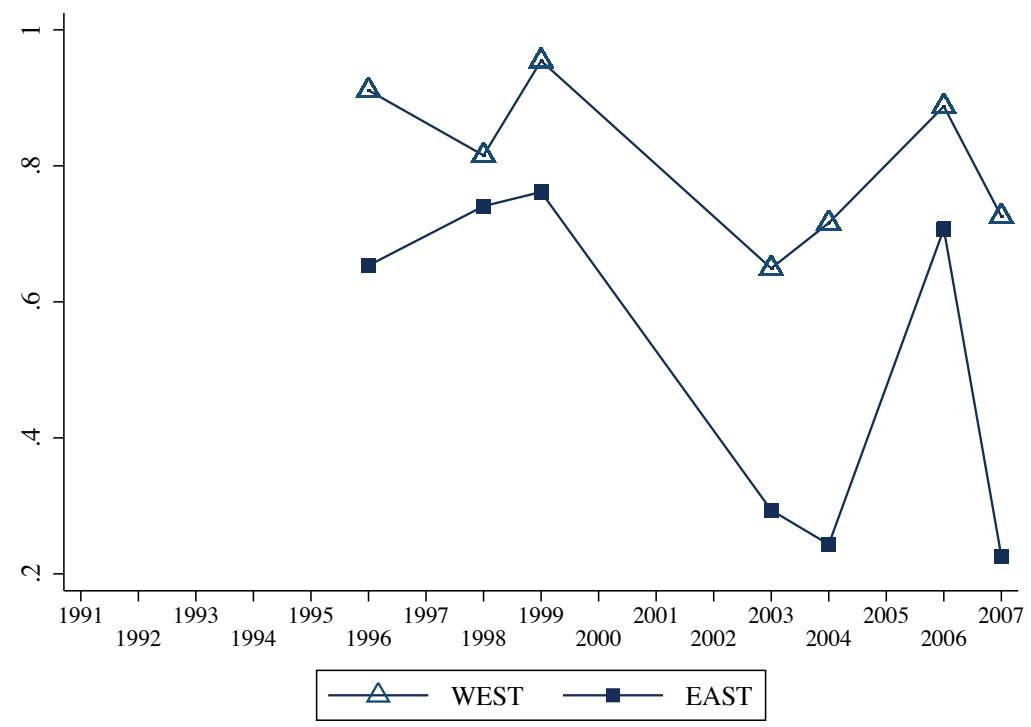

Source: World Values Survey (WVS), Central and Eastern Eurobarometer, Consolidation of Democracy in Central and Eastern Europe, ULMS. Unweighted averages per year, combined where available.

The development path of the market economy preference is diverging dramatically across the regions. The initial share of the population (about 45\%) supporting a market-economy based system was uniform across West and East. However, in the West, after an initial dip during the early 90's, possibly attributable to a poorly performing economy with $60 \%$ reduction in yearly GDP, ${ }^{12}$ the share of the population which prefers a market- economy based system was steadily increasing up to 2007. In contrast, in the East, the share of market economy supporters in 2007 still did not reach the same level as in 1990.

Figure 2.7 plots the development of preferences for a democratic political structure in Ukraine. For this measure, the earliest available regional level data

\footnotetext{
${ }^{12}$ See Figure 1.2a in Chapter 1.
} 
come from 1995, therefore we have no information on the regional fractions of the population that supported democracy at the dawn of the transition period. The development paths look similar to the economic system preference: there is a higher demand for democracy in the West, which is relatively stable during the observation period, whereas in the East, the initially high share of citizens who preferred a democratic political system declines from about .65 to less than .20 from 1995 to $2007 .{ }^{13}$

\subsection{Conclusion}

In this chapter, we offer and test a potential third factor explanation of the possibly spurious relationship between economic growth and democratic development. We investigate the role of civic capital, a set of cooperative norms, values, and beliefs in shaping preferences for economic and political systems. Using a special situation that occurred in Ukraine, the country that experienced different political regimes on its territory before the second half of the 20th century, after which it was a part of the Soviet Union until 1991, we exploit exogenous sources of variation in civic capital across the regions of the country to test our predictions. More specifically, under the assumption that during the Soviet Union period civic capital was transmitted trough the generations while preferences about political and economic systems were not, we examine the relationship between the inherited civic capital and the political preferences.

We use the fact that the accumulation of regional civic capital was affected by the rule of the Polish-Lithuanian Commonwealth and the Habsburg Empire (West) or the Russian Empire (East). We document a significant difference in civic capital between the West and the East, which is attributable to the effect of historical institutions.

We find a positive effect of civic capital on both preferences for a democratic political system and for a market-based economic system. We also document that civic capital has a diminishing marginal effect on demand for systems with little government intervention. In the West, where much civic capital was preserved, the increase in preference for democratic structures and a market-based economy resulting from a small increase in shared civic capital is significantly lower than in the East.

We trace the development of preferences for economic and political systems since the transition to provide empirical evidence that it is unlikely that political

\footnotetext{
${ }^{13}$ In 2006, a different definition of regions was used in the data set (WVS) than the one we use in this study, which might explain an outlier in the East in 2006.
} 
preferences were formed during the Soviet Union period. The same share of population had a preference for a market-based economy in the beginning of transition (1992), regardless whether it was in the West or in the East. After the mid-1990's, the development paths diverge dramatically. A similar picture emerges for the preference for a political system, although we do not have the data for the early 1990's.

The analysis reported in this chapter sheds light on the important interrelationship between economic growth and development of democracy. We argue that a third factor, which has been shown to play a role in facilitating economic development and in promoting democracy, causes the co-evolution of economic and political structures. Following the well-established literature which shows that historical events have long-lasting effects on trust, we argue that civic capital accumulation across the territory of Ukraine was affected differently by various historical institutions. Subsequently, we provide empirical evidence which suggests that civic capital has a causal effect on the development of preferences for a market-economy based system and hints at the causality of the relationship between civic capital and preferences for a democratic political system. 


\section{ApPENDIX}

\section{A Descriptive statistics}

Table 2.A: Summary statistics

\begin{tabular}{lllll}
\hline \multicolumn{1}{c}{ Variable } & Mean & Std. Dev. & Min & Max \\
\hline Preference for a market-based economic system & 0.49 & 0.50 & 0 & 1 \\
Preference for a democratic political system & 0.33 & 0.47 & 0 & 1 \\
Civic capital & 0.41 & 0.29 & 0.1 & 6 \\
Age & 45.3 & 16.1 & 18 & 73 \\
1 if Male & 0.43 & 0.49 & 0 & 1 \\
1 if Medium education & 0.65 & 0.48 & 0 & 1 \\
1 if Higher education & 0.23 & 0.42 & 0 & 1 \\
1 if Unemployed & 0.05 & 0.21 & 0 & 1 \\
1 if Out of labour force & 0.39 & 0.49 & 0 & 1 \\
Log per head household income & 3.53 & 1.57 & 1.2 & 9.7 \\
1 if Not married & 0.21 & 0.40 & 0 & 1 \\
1 if Separated or missing & 0.17 & 0.38 & 0 & 1 \\
Number of children & 1.44 & 1.01 & 0 & 6 \\
1 if Lives in an urban settlement & 0.13 & 0.33 & 0 & 1 \\
1 if Lives in a town & 0.34 & 0.48 & 0 & 1 \\
1 if Lives in a city & 0.26 & 0.44 & 0 & 1 \\
1 if Ukrainian & 0.77 & 0.42 & 0 & 1 \\
Opinion on the past two years since Orange Revolution & 2.12 & 0.95 & 1 & 5 \\
1 if Medium education mother & 0.28 & 0.45 & 0 & 1 \\
1 if Higher education mother & 0.08 & 0.28 & 0 & 1 \\
1 if Unknown education mother & 0.03 & 0.17 & 0 & 1 \\
1 if Medium education father & 0.23 & 0.42 & 0 & 1 \\
1 if Higher education father & 0.09 & 0.28 & 0 & 1 \\
1 if Unknown education father & 0.11 & 0.32 & 0 & 1 \\
Log regional GDP & 8.73 & 0.13 & 7.9 & 8.9 \\
Regional unemployment rate & 6.67 & 1.25 & 5.4 & 13 \\
\hline
\end{tabular}

Source: ULMS, State Statistics Committee of Ukraine.

Note: For details on variables definition refer to section 2.4. Omitted categories are: Female, Lower education, Employed, Married, Lives in a village, Lower education mother, Lower education father. 'Opinion on the past two years since Orange Revolution' is a categorical variable, which is equal to 1 if 'the situation got much worse' and it is equal to 5 if 'the situation got much better'. 


\section{B ShORT HISTORY OF UKRAINE}

The political entity of Kyiv Rus $\left(10^{t h}-11^{\text {th }}\right.$ centuries) is the earliest state formation on the territory of current Ukraine. After it was devastated in 1240 by the Mongols, the successor became a Western Kingdom of Galicia and Volhynia (Magocsi, 2010). The Kingdom played an important role in the region for the next 100 years, when it was dismayed and the territory came under control of Poland and Lithuania (Subtelny, 2005). The Eastern part was constantly under attack by the Golden Orde, the Mongolian and Tatar nomads, when the Grand Duchy of Muscovy started uniting Russian lands (Magocsi, 2010).

In the meantime, an autonomous and well-regulated Cossack military state was created on the Dnieper banks (Subtelny, 2005). The state had an independent government, adopted a democratic election procedure for designation of commanding officers and hetman (chief commander), organized a general assembly as a supreme authority elected and provided other liberties for its citizens. According to some sources (Riabchuk, 2008), high moral values, like honour, honesty and patriotism were important in socializing the population of the Cossack state. In 1649, Russian tsardom fully sanctioned serfdom, attaching peasants to the lands and the landlord (Magocsi, 2010). Serfs were seeking refuge in the Cossack state, to escape the punishment for leaving their land.

In 1654, the Cossacks made an agreement with Muscovy, seeking protection against the Polish, but this eventually lead to the integration of Eastern Ukraine into Russian tsardom (Åslund, 2007). Cossack lands came under complete control of Russia from 1686 (Subtelny, 2005). On the other hand, a treaty singed in 1658 created the powerful Polish-Lithuanian Commonwealth, which included the Western part of Ukraine. Since mid-17 century, Ukraine lived under two different political systems: the rule of the elected Polish king was limited by the nobility, who were almost autonomous in how they ran their properties, whereas in territories under the Russian control, the nobility lost their privileges and power, and the administration was becoming more and more centralised (Magocsi, 2010).

During the 18th-19th centuries the East (and South) of Ukraine constituted a part of the Russian Empire, called 'Little Russia'. Ukraine was considered belonging to the Russian Empire by right (Subtelny, 2005). The Orthodox church, an essential part of life, was ruled by the Russian patriarch. The centralisation of local administration ran from Saint-Petersburg was becoming stronger than ever, local nationalities were suppressed and local governance was not tolerated. The administration was organised along military lines such that superiors bullied their subordinates and corruption became a wide-spread, though for Ukrainians a 
new phenomenon (Subtelny, 2005). Additionally, the army of the Russian Empire needed recruits. Those were drafted and taken away from home against their will to serve for the Tsar for 25 years.

At the end of the 18th century, the Polish-Lithuanian Commonwealth weakened and came under the Habsburg Empire. The outmost Western regions of Ukraine became a part of the Austrian-Hungarian Empire in 1772. Several important differences existed in the organisation of the two Empires that separated Ukrainian territory and its people. In contrast to the Russian Empire, the Habsburg Empire was characterised by well-run, predominantly local administration. Reforms, starting from 1740, were meant to transform the Empire into a modern bureaucratic state (Magocsi, 2010). Moreover, the German language never gained so much dominance as the Russian language and culture in the neighbouring empire. In contrast to the Russian empire, where the majority of the population was Russian, in the Habsburg Empire 11 major ethnic groups were presented, not counting the smaller ones (Subtelny, 2005). The Habsburgs respected local customs and traditions and allowed teaching children in peoples' own language at the elementary school. In Russia, Ukrainian language and nationality were forbidden and prosecuted, which is officially declared in the so-called 'Ems order' of 1876. Teaching at schools was only allowed in Russian. The 'Little Russian dialect' was prohibited for use (Magocsi, 2010).

In 1781, serfdom was severely restricted in the Austrian Empire. At the same time, compulsory elementary schooling was introduced, increasing the education level, especially among the poorest strata of society: the peasants (Magocsi, 2010). In the Russian Empire, the number of schools actually declined from the 18th to the 19th century. There was no compulsory education and the investments in education, for that period of time, were among the lowest in the world (Magocsi, 2010). The Tsar organised a secret police and informers in 1826, following a series of revolts. Serfs could be bought and sold in the Russian Empire, they had no rights until 1861, when serfdom was finally abolished.

In the beginning of the $20^{\text {th }}$ century, between the years 1917 and 1922, Ukraine had several attempts of establishing an independent nation state. However, soon the major part of the territory was occupied by Bolsheviki, and Soviet authority was established over the whole country that became the Ukrainian Soviet Socialistic Republic, with the exception of Western oblasts (shaded region in the West, see map on Figure 2.1). The Western oblasts were divided between Poland, Romania, Hungary, and Czechoslovakia between 1919 and 1939 (Grytsak, 2000).

The Soviet troops invaded Poland in 1939 and appropriated Eastern Galicia and Volhynia (Western regions of Ukraine and North-Eastern parts of contempo- 
rary Romania and Poland) to the Ukrainian SSR. The last Western oblast (Zakarpatska, or Transcarpathia) was added after the war, in 1945. Since that time Ukraine exists as a unitary republic with similar political and economic conditions across the whole territory, initially as a part of the Soviet Union, and as an independent state since 1991. 

3 Risk ATtitudes AND OCCUPATIONAL CHOICE:

EVIDENCE FROM AN ERA OF EVOLVING HETEROGENEITY IN OCCUPATION-SPECIFIC EARNINGS RISK 


\subsection{INTRODUCTION}

Occupational choice is an important decision that individuals have to make at the beginning of their career, and that has a profound impact on their future labour market outcomes. ${ }^{1}$ Not surprisingly, there is a long tradition of research in the social sciences on the determinants and consequences of occupational choice (Blau, Gustad, Jessor, Parnes, and Wilcock, 1955; Miller, 1984; Ham, Junankar, and Wells, 2009; Bentolila, Michelacci, and Suarez, 2010). Economists have documented a relationship between risky characteristics of occupations and risk attitudes of workers in these occupations. For example, DeLeire and Levy (2004) show that single parents with dependent children are less likely to work in occupations with high fatality risk. ${ }^{2}$ More direct measures of risk attitudes have also been used in the literature to document a correlation between workers' willingness to take risks and the earnings risk of their chosen occupation (e.g. Bonin, Dohmen, Falk, Huffman, and Sunde, 2007; Fouarge, Kriechel, and Dohmen, 2012). ${ }^{3}$ Since average earnings tend to be higher in occupations with a higher earnings variance (King, 1974; Leigh, 1981; Hartog and Vijverberg, 2007b), it is plausible that a causal sorting pattern exists. ${ }^{4}$ Workers who are more willing to take risks profit from working in more risky occupations that pay a risk premium. However, with field data from Western labour markets it is typically difficult to identify a causal impact of workers' willingness to take risks on occupational sorting due to endogenous evolution of wage structure and worker composition. ${ }^{5}$

In this chapter, we investigate whether a change in relative earnings risk of occupations that was not anticipated when labour market participants chose their occupation triggers occupational (re-)sorting of workers based on their risk attitudes. Such a sorting pattern leads to a better alignment of workers' risk preferences to the earnings risk of their occupation. In particular, we study occupational

\footnotetext{
${ }^{1}$ This chapter is joint work with Thomas Dohmen and Ben Kriechel. We would like to thank Juerg Schweri, Olivier Marie, Arnaud Dupuy, Didier Fouarge for their helpful comments. The chapter was presented at the DUHR seminar at Maastricht University (2011), SOLE (2012), ESPE (2012), IWAEE (2012), EALE (2012) and the ZEW (2012).

${ }^{2}$ Grazier and Sloane (2008) replicate the findings of DeLeire and Levy (2004) in the USA for the UK.

${ }^{3}$ Other studies investigated the relationship between risk preferences and employment contract type (Guiso, Jappelli, and Pistaferri, 2002; Brown, Farrell, Harris, and Sessions, 2006), or a choice for self-employment (Van Praag and Cramer, 2001; Cramer, Hartog, Jonker, and Van Praag, 2002; Ekelund, Johansson, Järvelin, and Lichtermann, 2005).

${ }^{4}$ Fuchs-Schündeln and Schündeln (2005) build on the idea that risk preferences are related to the choice of sector in their study of the importance of precautionary savings motive.

${ }^{5}$ A laboratory experiment by Dohmen and Falk (2011) shows that risk attitudes affect the decision to select into variable payment schemes. Fouarge, Kriechel, and Dohmen (2012) suggest causality of the relationship between risk attitudes and unexplained earnings variance as they study a population of recent labour market entrants.
} 


\subsection{Introduction}

sorting in the Ukrainian labour market, which experienced profound changes in its occupational wage structure that were initiated by the economic transition from a Soviet type planned economy to a market economy. This setting provides a unique opportunity to investigate how risk attitudes affect the decision to sort into occupations that differ with respect to earnings risk. More specifically, we exploit the fact that the (unexplained) earnings variance was very low and similar across occupations in Soviet times, as wages were centrally set by the government and highly regulated. When Ukraine became independent in 1991, the transition from a centrally planned economy to a market economy set in. During this transition, the wage structure of the Ukrainian labour market changed markedly. The variance of earnings increased in almost all occupations. But what is more important for our analysis, differences in earnings risk between occupations became also much larger. The differential evolvement of earnings risk across occupations is expected to affect occupational choice and occupational mobility.

When occupations do not differ with respect to earnings risk, there is no reason to take it into account when choosing an occupation. Since earnings risk was very similar across occupations in Soviet times, it was probably not an important criterion in occupational choice, so that the correlation between earnings risk and risk preferences is expected to be low before transition. ${ }^{6}$ Market liberalisation during the transition from a centrally planned to a market economy brought about an increase in earnings risk and, importantly, increased heterogeneity of earnings across occupations. If workers sort into occupations based on their risk preferences, we should expect the correlation between risk preferences and earnings risk to become positive during the transition.

We relate risk attitudes to the occupation-specific earnings variance before and after transition, to check whether the occupational earnings variance was indeed irrelevant for occupational choice before the collapse of the Soviet Union, and whether it has evolved to become a significant determinant of occupational choice during the transition period. We then investigate whether individuals switch occupations such that their risk attitudes are better aligned to the occupational earnings risk. We use the Ukrainian Longitudinal Monitoring Survey (ULMS) as our main data source. The ULMS is a household panel survey that contains the current wage and employment information for all three waves (2003, 2004, and 2007), as well as retrospective information on labour market status, occupations and wage income going back to 1986, thus covering the period prior to the collapse of the command economy.

\footnotetext{
${ }^{6}$ We also expect this correlation to be close to zero for purely mechanical reasons, simply because there was virtually no variation in occupational earnings risk.
} 


\section{Risk attitudes and occupational choice}

The structure of the chapter is as follows. We sketch a conceptual framework in section 3.2. The data and main variables are described in section 3.3. We proceed by presenting our empirical approach and important features of the changes in the occupational wage structure during transition that are relevant for our study in section 3.4. The findings are presented and discussed in section 3.5. Section 3.6 addresses sensitivity of the findings by checking the relationships by varying the estimation sample, using an external data set to derive an alternative earnings risk measure, and discussing possible bias sources, such as heterogeneity and abilitybased selection. The last section concludes.

\subsection{COnCEPtual FRAMEWORK}

Our conceptual framework builds on the following observations and ideas: Occupations differ with respect to their riskiness. Sources of occupational risk include occupational health hazard, fatality risk, unemployment risk and earnings risk, i.e. the variability of wages that is not explained by differences in human capital. ${ }^{7}$ In this study we focus on the earnings risk dimension, which arises from two sources (cf. King, 1974). First, earnings cannot be perfectly predicted based on personal characteristics (e.g. talents, skill, knowledge and any other type of human capital) even if ability was known (Weiss, 1970; Arcidiacono, 2004), and hence we assume that individuals do not know where they will end up in the earnings distribution at the time when they sort into an occupation. Second, variability in earnings can result from cyclical and structural shocks.

In an expected utility framework, risk averse agents demand a compensation to accept earnings uncertainty (Hartog, 2011). In the most simple model, in which the number of slots in occupations is fixed and workers can be ranked in terms of their risk aversion, the least risk averse $n$ workers fill the available $n$ slots in the most risky occupation. The risk premium is determined by the marginal worker, i.e. the $n^{\text {th }}$ most risk averse worker. The $n-1$ least risk averse workers have an incentive to sort into the most risky occupation as the offered risk premium more than compensates them for the risk they have to incur in that occupation. King (1974) was probably the first to provide empirical evidence by showing that occupations that entail higher earnings risks offer entrants higher expected earnings, and that individuals from wealthier families work in occupations which are more risky.

We adopt the approach taken by McGoldrick (1995) and Bonin et al. (2007) and measure the earnings risk in different occupations by the residual distribution

\footnotetext{
${ }^{7}$ See, for example, Hamermesh (1999); Guiso, Jappelli, and Pistaferri (2002); DeLeire and Levy (2004); Grazier and Sloane (2008).
} 
of wages, i.e. the random component of wages after conditioning on measures of human capital. We interpret the cross-sectional unexplained wage variation as representing wage uncertainty that labour market participants are confronted with when they choose an occupation. If labour market participants, who differ in willingness to take risk, take the earnings risk of an occupation into account when they make their occupational choice, a positive correlation between earnings risk and risk attitudes results.

In this chapter, we shed light on the causal nature of this relationship by analysing how the correlation between earnings risk and risk attitudes develops in the aftermath of a historical shock that affected earnings risk in occupations differently.

\subsection{DATA}

The data in this study come from a nationally representative household panel data set, the Ukrainian Longitudinal Monitoring Survey (ULMS), which covered about 6700 adults in the 2007 wave. The data set is structured similarly to the German Socio-Economic Panel Study (SOEP). The first ULMS wave (2003) contained a retrospective appraisal of respondents' labour market status, such as occupation and earnings, in 1986, the year of the Chernobyl nuclear disaster which is certainly recalled by respondents. ${ }^{8}$ Recall bias regarding wages is likely to be low for another reason: wages were public information and did not change much for decades during the era of the centralised economy of the Soviet Union. In order to verify our claim that respondents' retrospective information is accurate, we collected data provided by the Central Statistics Bureau of the Ukrainian SSR on wages per industry for the late 1980's. Since these official wage statistics are not available for occupations but for industries, we compare retrospective wage information of respondents from the ULMS on the industry level with official statistics on industry-specific wages in Table 3.1. Averages constructed from the ULMS are remarkably similar to the ones reported by the official sources, which confirms the reliability of the retrospective information in our data-source.

Availability of directly measured risk attitudes is another feature of the ULMS. Risk attitudes are measured from the answer to the survey question: "How do you see yourself: Are you generally a person who is fully willing to take risks or do you

\footnotetext{
${ }^{8}$ Such major events serve as reference points that make it easier to remember one's own living conditions that prevailed at that time, thereby diminishing recall bias (Eisenhower, Mathiowetz, and Morganstein, 2004).
} 
Table 3.1: Earnings per industry sector, data from the Ukrainian Statistics cf. the ULMS

\begin{tabular}{ll|ll}
\hline Statistics Office Ukrainian SSR $^{1}$ & 1985 & ULMS data $^{2}$ & 1986 \\
\hline Building and construction & 207.1 & Construction & 221.6 \\
Heavy industry & 201.5 & Industry & 206.4 \\
Transport and Communication & 165.0 & Transport, telecommunications & 177.5 \\
Credit and insurance & 168.9 & Financial intermediation, real estate & 162.2 \\
Agriculture & 162.8 & Agriculture, forestry & 144.6 \\
Public administration & 152.8 & Public administration and defense & 210.1 \\
Trade and purchasing & 133.8 & Sale, maintenance, repair of vehicles & 137.1 \\
Service & 134.2 & Other service, municipal services & 143.7 \\
Health and social care, Education & 131.5 & Education, health, and social care & 126.2 \\
ICT & 131.5 & & - \\
Science & 183.0 & & - \\
Art & 140.7 & & - \\
Culture & 107.9 & & - \\
& - & Electricity, gas, and water supply & 180.6 \\
& - & Other & 189.0 \\
\hline Total & 173.9 & Total & 172.8 \\
\hline
\end{tabular}

Source: ${ }^{1}$ Central Statistics Bureau of the Ukrainian Soviet Socialist Republic, ${ }^{2}$ Ukrainian Longitudinal Monitoring Survey.

Note: All wages are reported in roubles. Central Statistics Bureau data are available for 1985. Data from the ULMS is based on the mean per industry as reported by the ULMS respondents. The classification of industries differs across the data-sources. For comparison purposes, the official statistics wages per industry were averaged in: "Transport and communication" (original value for 'Transport' is 186.1, for 'Communication' it is 143.9); and in "Health and social care, Education" (original value for 'Health and social care' is 121.4, for 'Education' it is 141.6).

try to avoid taking risks? Please give me a number from 0 to 10 , where the value 0 means: 'Completely unwilling to take risks' and the value 10 means: 'Completely willing to take risks'. You can use the values in between to make your estimate." 9 Table 3.A in the Appendix shows the distribution of the dependent and independent variables, demographic control variables per occupation per year, as well as the relative size of occupations (in this sample).

\subsection{EMPIRICAL STRATEGY}

To build ideas, imagine that the earnings risk is the same in all occupations. In that case, it is not a distinguishing characteristic of occupations, and therefore it

\footnotetext{
${ }^{9}$ The wording is translated from Ukrainian. Dohmen, Falk, Huffman, Sunde, Schupp, and Wagner (2011) show that this question is significantly correlated with lottery choices and explains behaviour in a range of important real life decision domains.
} 
should not be a relevant choice criterion. Then, individuals' risk attitudes should be unrelated to occupational earnings risk. ${ }^{10}$ If, on the other hand, occupations differ in the degree of earnings risk, we should expect that individuals who are more willing to take risks are more likely to work in risky occupations, especially if risk is compensated for. Our empirical strategy builds on the fact that the Ukrainian labour market developed from the first described situation to the latter.

The labour market in the Ukrainian Soviet Socialist Republic was characterized by a virtual absence of earnings risk and by high rigidity. In the centrally planned economy, wage setting took place centrally, at the governmental level, and wages were defined in strict wage grids. In addition, the wage distribution within an occupation was narrow. Thus, there was little uncertainty about an occupation's wages. Our estimates reveal that the unexplained variability in earnings as measured by the standard deviation of residuals from a Mincer type wage equation per occupation, was narrow and very similar across occupations.

With the collapse of the Soviet Union and the independence of Ukraine in 1991, drastic changes were initiated. As the centrally planned economy ceased to exist, market structures started to evolve. In particular, with the beginning of privatisation and evolution of private business, the wage grid system was abolished, at least in the private sector, and it became possible to differentiate wages. The wage risk has increased to different degrees across occupations, creating heterogeneity in the wage risk distribution. If labour market participants care about the wage risk in their occupation, individuals who are not willing to take risks are expected to switch to occupations with low earnings risk after transition, and individuals who are more willing to take risks should be expected to change to occupations with larger earnings risk.

Figure 3.1 depicts the change in earnings risk across occupations during the transition period. We measure occupation-specific earnings risk following the earlier literature (Bonin, Dohmen, Falk, Huffman, and Sunde, 2007; Hartog and Vijverberg, 2007b). To construct this measure, we estimate the following augmented Mincer wage regression:

$$
\log (\text { wage })_{i j}=\mathbf{X}_{i} \beta+\mathbf{Z}_{i} \gamma+\varepsilon_{i}
$$

in which the dependent variable is monthly log wages ${ }^{11}$ of individual $i$ that is employed in an occupation $j,{ }^{12} \mathbf{X}_{i}$ is a matrix of standard human capital con-

\footnotetext{
${ }^{10}$ Risk aversion might affect the decision to participate in labour market when the earnings risk is high, but there will be no heterogeneity with respect to occupational choice (in terms of heterogeneity of the earnings risk).

${ }^{11}$ We use nominal wage data, because we never pool observations from across years.

${ }^{12}$ Occupations in the ULMS are classified according to the International Standard Classification of Occupations (ISCO-88) on the two-digit level.
} 


\section{Risk attitudes and occupational choice}

trol variables (gender, age, age squared and cubed, tenure and tenure squared, years of education, capital residence and public sector employment) and $\mathbf{Z}_{i}$ is a set of occupation dummies. Standard errors are clustered on the level of occupations. Years of education are calculated based on the highest completed level of education. We define the standard deviation of the estimated residual from this regression $\left(\hat{\varepsilon}_{i}\right)$, as the measure of the earnings risk (unexplained earnings variance) per occupation $\left(\hat{\sigma}_{j}\right)$.

Figure 3.1 displays the range of occupation-specific earnings risk (horizontal axis) and the fraction of workers exposed to that risk, i.e. working in a particular occupation (vertical axis) prior to transition in 1986 (panel A), and in 2007, to which we refer as the post-transition period (panel B). The range of the earnings risks measure has increased from .28 - .61 in 1986 to $.32-1.35$ in 2007.

The evolution of earnings risk is expected to affect the decision of a risk averse individual to work in a particular occupation. In fact, Ukraine offers a particularly interesting setting to study the relationship between earnings risk and occupational sorting, because the transition to the market-based economy in Ukraine, that brought about substantial heterogeneity in earnings risks across occupations, was not expected when workers who participated in the labour market in 1986 made their occupational choice. If the hypothesis that workers sort into occupations based on their risk preferences is correct, we should expect a stronger positive correlation between earnings risk and risk attitudes of workers to evolve during transition. Moreover, this effect should partly result from workers switching to occupations in which their risk attitudes are better aligned to the occupational earnings risk.

To investigate whether this latter pattern exists in our data, we restrict the analysis to the balanced panel of respondents who were employed in 1986 and in 2007, and investigate the correlation between earnings risk and risk attitudes for individuals who switch their occupation and individuals who stay in the same occupation from 1986 to 2007. Sorting on preferences implies that individuals, initially randomly distributed across occupations with respect to a characteristic that was not important at the time of the distribution (in this case, the occupations-specific earnings risk), would leave occupations in which their preferences are badly aligned with the earnings risk when this occupational characteristic would suddenly gain importance, and switch to occupations in which their preferences are better aligned. Likewise, we should expect those whose risk preferences are by chance aligned to the occupational earnings risk that evolved during transition to stay in their initially chosen occupation. In that case, we should also observe a positive correlation between risk preferences and earnings risk among stayers. However, if there are 
Figure 3.1: Earnings risk before and after transition

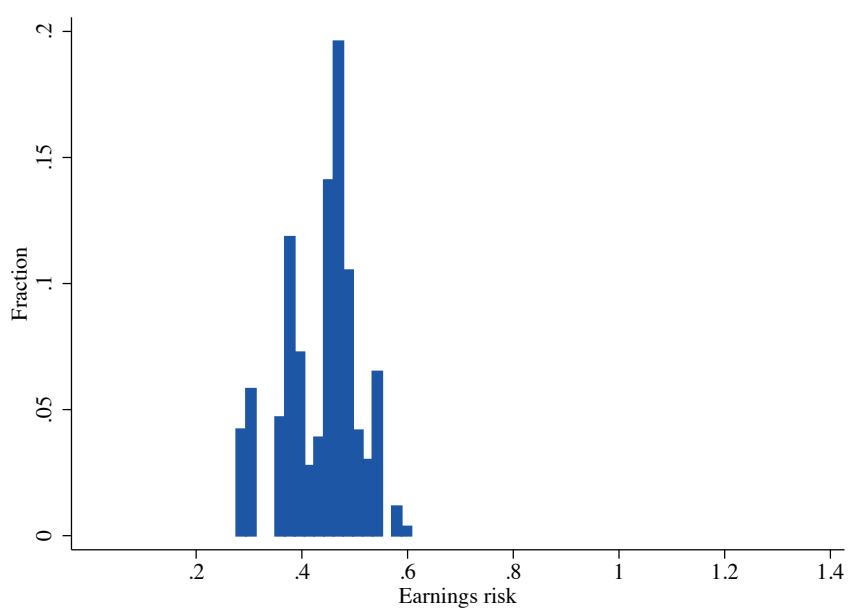

(a) Before transition: 1986

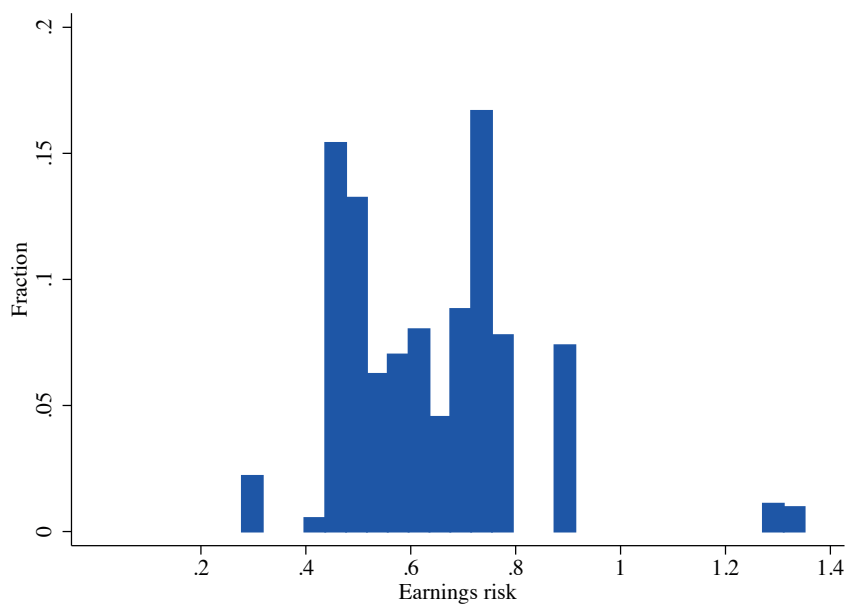

(b) After transition: 2007

constraints to mobility or if occupational mobility is costly, this relationship is expected to be weaker. 


\subsection{Results}

We start by documenting Spearman rank correlations between individual risk attitudes and occupation-specific earnings risk $\left(\hat{\sigma}_{j}\right)$ as defined in section 3.3 before and after transition. In 1986, the correlation coefficient not significantly different from zero (see column (1) of Table 3.2, Panel A). To confirm that this result was not merely brought about by a lack of variation in earnings before the transition, we correlated the risk attitudes of individuals working in a particular occupation in 1986 with the earnings risk as measured in 2007, when there is substantial variability in earnings risk across occupations. This correlation was 0.03 and it was also not statistically significant ( $p$-value $>0.9$, not reported).

Table 3.2: Earnings risk and risk attitudes before and after transition

\begin{tabular}{lrr}
\hline & Panel A: Before the transition (1986) \\
\hline & $(1)$ & $(2)$ \\
\hline Spearman's $\rho$ & 0.154 & -0.061 \\
$p$-value & 0.452 & 0.766 \\
\hline Occupations & 26 & 26 \\
\hline
\end{tabular}

Panel B: After the transition (2007)

\begin{tabular}{|c|c|c|}
\hline & (1) & $(2)$ \\
\hline Spearman's $\rho$ & 0.454 & 0.332 \\
\hline$p$-value & 0.017 & 0.091 \\
\hline Occupations & 27 & 27 \\
\hline \multicolumn{3}{|c|}{$\begin{array}{l}\text { Source: ULMS. } \\
\text { Note: Table reports Spearman rank correlation coefficients }(\rho) \text { between the earnings risk (the standard } \\
\text { deviation of residuals from a Mincer type wage regression, see section } 3.4 \text { for details) and the mean } \\
\text { of individual risk attitudes per occupation. Panel A refers to the pre-transition period (1986), panel } \\
\text { B refers to the post-transition period (2007). All available observations on employed individuals are } \\
\text { used for the estimation reported in column (1). In column }(2) \text {, the sample is restricted to include panel } \\
\text { observations: individuals who were employed in } 1986 \text { and in } 2007 \text {. The estimation in column }(1) \text { is based } \\
\text { on the sample of } 2991 \text { workers in } 2007 \text { (2489 in 1986) and in column }(2) \text { on } 964 \text { panel observations. }\end{array}$} \\
\hline
\end{tabular}

In 2007, however, the correlation coefficient is positive and statistically significant ( $\rho=0.454$ with a $p$-value $<0.02$, see column (1) in Panel B of Table 3.2). The correlation in 2007 is also significantly different from the correlation in 1986. This finding confirms our hypothesis that the unexplained component of earnings variance was not a relevant parameter for occupational choice in the centrally planned economy, but that a positive and statistically significant relationship between risk attitudes and occupational earnings risk emerged during transition when earnings risk became a distinguishing characteristic of occupations. 
In column (2), the sample is restricted to include a balanced panel of individuals who were employed in 1986 and in 2007. We find essentially the same result which shows that our findings are not affected by sample composition. ${ }^{13}$ Figure 3.3 summarises the results graphically for the balanced sub-sample of individuals who were employed in 1986 and in 2007. We relate the occupation-specific earnings risk to the mean of individual risk attitudes per occupation before and after the transition period has started. The left panel shows the correlation in the pre-transition period (1986) and the right panel shows the correlation in the after-transition period (2007). The mean of individuals' risk attitudes working in a particular occupation can be read off the horizontal axis. The vertical axis depicts the occupation-specific earnings risk $\left(\sigma_{j}\right)$. The size of the squares corresponds to the size of the occupation in that year.

Figure 3.3: Earnings risk and risk attitude: Balanced panel

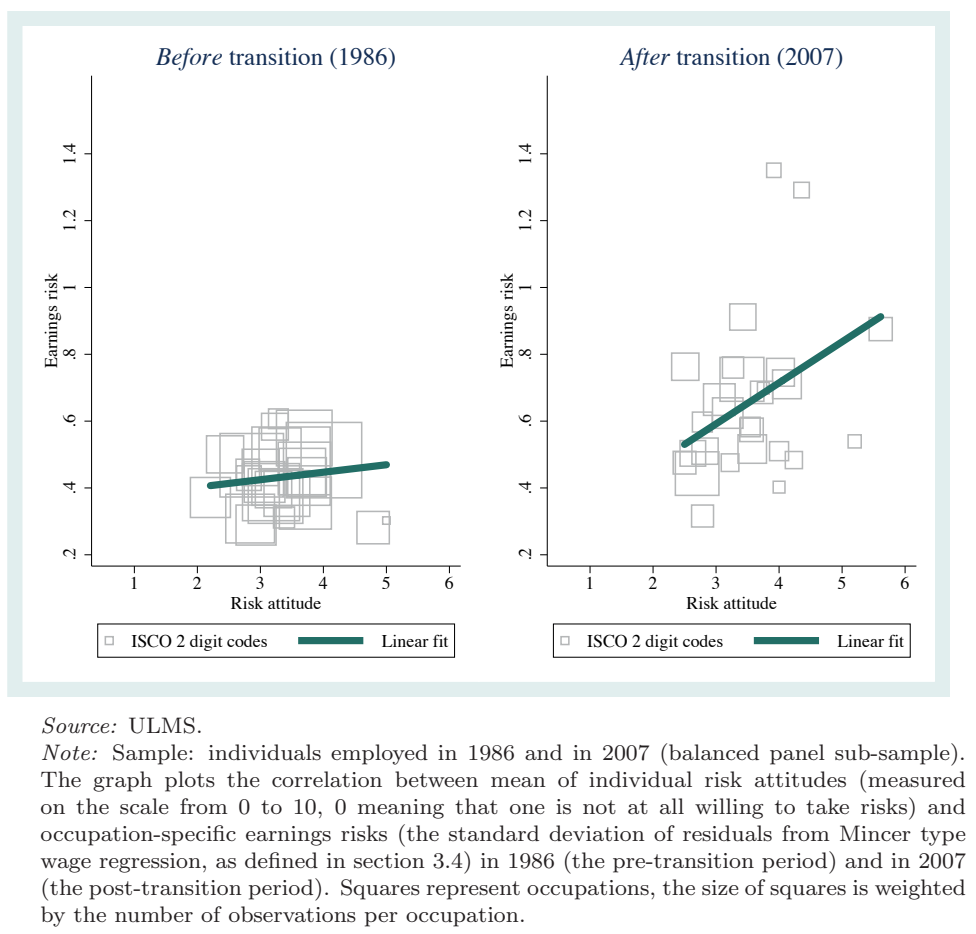

\footnotetext{
${ }^{13}$ As an additional check, we estimated a specification using the data from two age cohorts, i.e. two samples between 36 and 52 years of age in 1986 and in 2007. The results remain qualitatively unchanged.
} 


\section{Risk attitudes and occupational choice}

Next, we focus on the 2007 sub-sample in order to analyse whether the correlation between the occupation-specific earnings risk and individual risk attitudes found on the aggregate level, also holds on individual level in a regression set-up. Table 3.3 presents the results of OLS regressions of occupation-specific earnings risk, $\sigma_{j}$, on risk attitudes (with standard errors clustered at the level of occupations). No controls are included in the specification reported in column (1). In column (2), a set of controls (gender, age, tenure, capital residence, public sector employment, height, and the natural logarithm of individual wage) is added. The specification in column (3) additionally controls for self-employment status.

The estimates in column (1) reveal a positive and significant correlation between risk attitudes and earnings risk, thus corroborating the descriptive results of the previous section. Columns (2) and (3) show that adding control variables does not affect the coefficient on risk attitudes: it is positive and significant, regardless of the specification. ${ }^{14}$

An intriguing question to ask is whether the positive relationship between willingness to take risks and the occupational earnings variance observed after transition is a consequence of individuals switching to jobs that better match their preferences. If no one would change occupations during the transition period that we observe, the positive correlation in the post-transition period might be a result of endogenous formation of preferences. ${ }^{15}$

To answer this question, we restrict the analysis to the balanced panel of 964 individuals who were employed in 1986 and in 2007. Of this sample, $74 \%$ has changed their occupation between 1986 and 2007. We relate risk attitudes of these job-switchers to the unexplained earnings variance in their current job in order to find out whether their preferences are better aligned with the earnings risk in their occupation than the preferences of individuals who did not change their occupation during this time period. ${ }^{16}$ To check whether individuals move out of occupations

\footnotetext{
${ }^{14}$ These findings are similar to the results reported by Brown, Farrell, Harris, and Sessions (2006), Bonin, Dohmen, Falk, Huffman, and Sunde (2007) and Fouarge, Kriechel, and Dohmen (2012) for the UK, Germany, and the Netherlands respectively.

${ }^{15}$ Another way of testing whether individuals sort into jobs based on the available information and their preferences would be to examine the sub-sample of new entrants to the labour market (see Fouarge et al. 2012). However, we do not find a significant difference between the correlation coefficients (between risk attitudes and occupation-specific earnings risks) for workers who entered the labour market prior to transition or after transition. This might be a result of rigidity and high youth unemployment, which is likely to restrict the choice set of labour market entrants.

${ }^{16}$ In our sample, risk attitude is not related to the probability of switching occupations per se: the correlation coefficient between the probability of changing occupation between 1986 and 2007 and risk attitude is insignificant, as well as the regression coefficient on risk attitude controlling for gender and age.
} 
Table 3.3: Relationship between earnings risk and individual risk attitudes

\begin{tabular}{|c|c|c|c|}
\hline & (1) & (2) & (3) \\
\hline Risk attitude & $\begin{array}{c}0.036^{* *} \\
(0.016)\end{array}$ & $\begin{array}{c}0.027^{* *} \\
(0.012)\end{array}$ & $\begin{array}{c}0.023^{* *} \\
(0.010)\end{array}$ \\
\hline 1 if Male & & $\begin{array}{c}0.164 \\
(0.152)\end{array}$ & $\begin{array}{c}0.166 \\
(0.151)\end{array}$ \\
\hline Tenure & & $\begin{array}{c}0.010 \\
(0.007)\end{array}$ & $\begin{array}{c}0.011 \\
(0.007)\end{array}$ \\
\hline Age & & $\begin{array}{c}0.001 \\
(0.004)\end{array}$ & $\begin{array}{c}-0.000 \\
(0.004)\end{array}$ \\
\hline Years of schooling & & $\begin{array}{c}0.062^{*} \\
(0.035)\end{array}$ & $\begin{array}{c}0.061^{*} \\
(0.035)\end{array}$ \\
\hline 1 if Public sector & & $\begin{array}{r}-0.095 \\
(0.144)\end{array}$ & $\begin{array}{c}-0.039 \\
(0.129)\end{array}$ \\
\hline 1 if Capital residence & & $\begin{array}{c}-0.093 \\
(0.113)\end{array}$ & $\begin{array}{c}-0.076 \\
(0.115)\end{array}$ \\
\hline Log wage & & $\begin{array}{c}0.090 \\
(0.086)\end{array}$ & $\begin{array}{c}0.071 \\
(0.075)\end{array}$ \\
\hline Height & & $\begin{array}{c}0.006^{*} \\
(0.003)\end{array}$ & $\begin{array}{c}0.006^{*} \\
(0.003)\end{array}$ \\
\hline 1 if Self-employed & & & $\begin{array}{c}0.466 \\
(0.384)\end{array}$ \\
\hline Constant & $\begin{array}{c}-0.139 \\
(0.210)\end{array}$ & $\begin{array}{c}-2.645^{* *} \\
(1.163)\end{array}$ & $\begin{array}{c}-2.542^{* *} \\
(1.135)\end{array}$ \\
\hline$R^{2}$ & 0.0105 & 0.0601 & 0.0749 \\
\hline Observations & 2991 & 2912 & 2912 \\
\hline
\end{tabular}

Source: ULMS.

Note: OLS regression coefficients are reported. Dependent variable: earnings variance (the standard deviation of residual from Mincer type wage regression, as defined in section 3.4, standardized). Clustered on the level of occupation standard errors in parentheses. Significance stars indicate *** $\mathrm{p}<0.01$, ** $\mathrm{p}<0.05$, * $\mathrm{p}<0.1$. Occupations containing less than 10 observations are dropped. Risk attitude is measured on a scale from 0 to 10,0 meaning that one is not at all willing to take risks.

that did not correspond to their preferences, we also relate risk attitudes of the job-switchers to the earnings variance (measured in 2007) of the occupation in which they were employed in 1986 (would they have stayed in the same job).

Table 3.4 summarises the results. Panel A displays the correlation between risk attitudes of job switchers and the earnings risk in the new (i.e. current) occupation, Panel B reports the correlation between risk attitudes of job switchers and earnings risk (measured in 2007) of their previous occupation. Panel C shows the results for job-stayers. Risk attitudes of those who change occupations are significantly positively related to the measure of earnings risk in the occupation 
Table 3.4: Earnings risk and individual risk attitudes in the balanced panel sub-sample

\begin{tabular}{|c|c|}
\hline \multicolumn{2}{|c|}{ Panel A: Job-switchers: current job } \\
\hline Spearman $\rho$ & 0.142 \\
\hline$p$-value & 0.000 \\
\hline Observations & 712 \\
\hline \multicolumn{2}{|c|}{ Panel B: Job-switchers: would they have stayed in the old job } \\
\hline Spearman $\rho$ & 0.022 \\
\hline$p$-value & 0.558 \\
\hline Observations & 712 \\
\hline \multicolumn{2}{|c|}{ Panel C: Job-stayers } \\
\hline Spearman $\rho$ & 0.014 \\
\hline$p$-value & 0.827 \\
\hline Observations & 252 \\
\hline \multicolumn{2}{|c|}{$\begin{array}{l}\text { Source: ULMS. } \\
\text { Note: Table reports Spearman correlation coefficients }(\rho) \text { between earnings risk (defined as the standard } \\
\text { deviation of occupational wage residuals on ISCO } 88 \text { 2-digit level) and individual risk attitudes (on the } \\
\text { scale from } 0 \text { to } 10 \text { ) for balanced panel sample of individuals employed in } 1986 \text { and } 2007 \text {. In panel A } \\
\text { and panel B job-switchers are analysed. The correlation coefficient in panel A refers to the new job of } \\
\text { job-movers, i.e. their risk attitude is related to the occupation to which they have switched. In panel } \\
\text { B the correlation with the earnings risk in } 2007 \text { of the old occupation of job-switchers is shown (if they } \\
\text { would have stayed in the same job). In panel C risk attitudes of job-stayers are correlated with the } \\
\text { earnings variance in their job, variance is calculated on } 2007 \text { data. }\end{array}$} \\
\hline
\end{tabular}

they switched to. If these individuals had stayed in their previous occupation, we would not have observed a significant correlation (see panel B). These results support the hypothesis that individuals sort into occupations with characteristics that are better aligned with their risk preferences. In panel $\mathrm{C}$, the correlation of the preferences of job-stayers with the earnings risk in their job is insignificant. The absence of a significant relationship between risk attitudes of occupational stayers and the earnings risk in their occupation might be a result of constrained occupational mobility.

Occupations with strict entry requirements are likely to constrain occupational mobility. Few workers would move out of such occupations because it would be difficult for them to switch to another occupation on a comparable level. For example, $74 \%$ of workers employed in occupation life sciences professionals (22) in 1986, remained in this occupation in 2007, as can be read of the shaded cell in the 
diagonal in Table 3.5. Workers who switched their occupation from occupation 22 , moved to only four other occupations in 2007. On the contrary, workers who were employed as personal and protective service workers (occupation 51) in 1986, moved to 15 different occupations, which suggests that it is relatively easy to enter this occupation. Table 3.5 presents an occupational transition matrix, in which occupations in 1986 are listed in rows and occupations in 2007 in columns. Shaded cells on the diagonal show the percentage of occupational stayers.

Table 3.5: Occupational transitions from 1986 to 2007

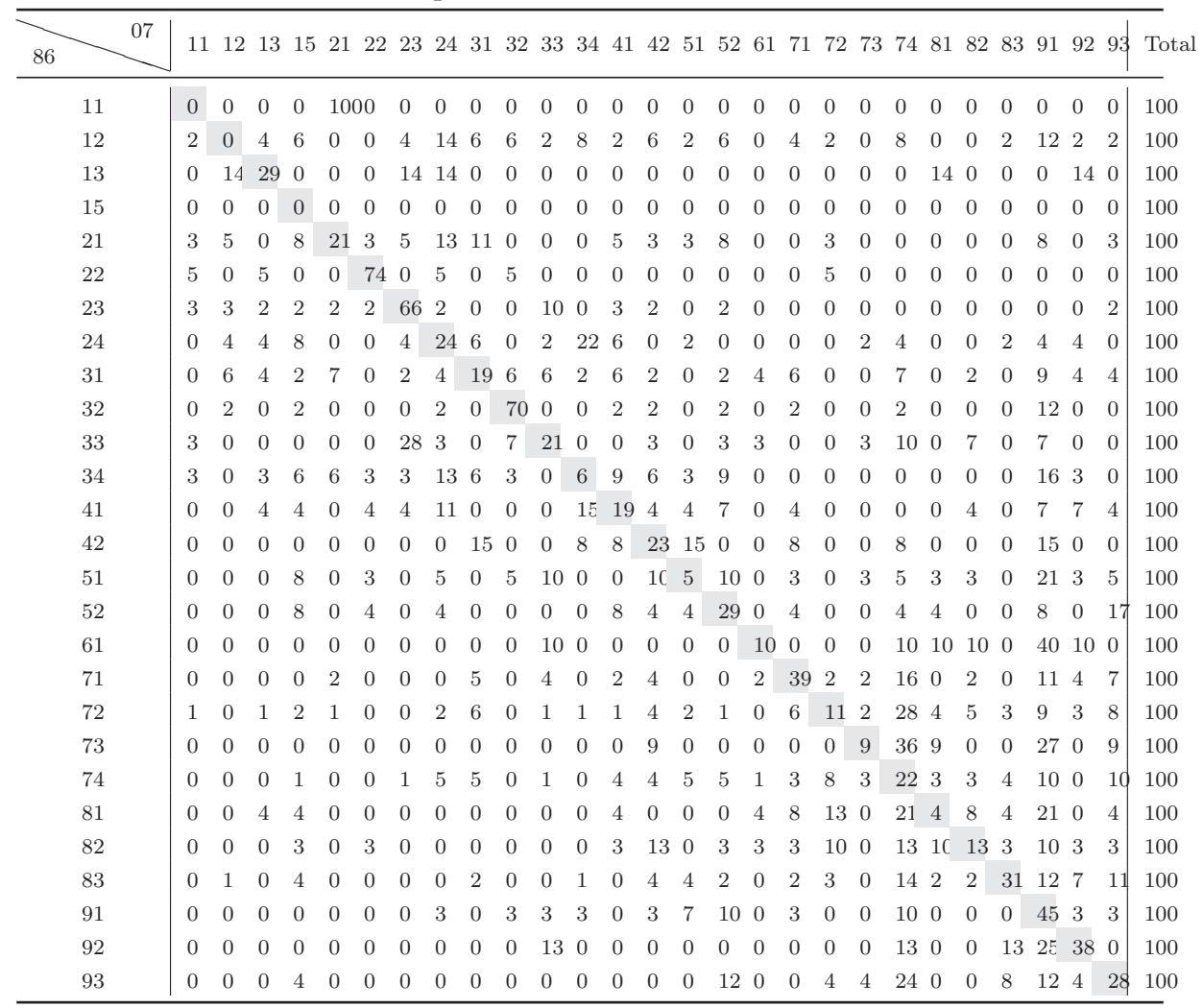

Source: ULMS.

Note: The first column displays 2-digit ISCO occupation codes in 1986, the first row shows occupation codes in 2007. The numbers are percentages switching occupation from 1986 to 2007. Shaded cells in the diagonal show the share of stayers in a given occupation. The overall share of stayers is $26 \%$.

We also analyse the relationship between risk attitudes of individuals and earnings variance in their occupation separately for occupations with relatively many stayers and those with relatively few stayers (split by above or below the sample mean, which is $26 \%$ of job-stayers). For the sub-sample of occupations with many stayers, the correlation coefficient (on occupational level) is insignificant, 


\section{Risk attitudes and occupational choice}

while it is positive and significant $(\rho=.44, p<0.06)$ for the sub-sample with higher mobility.

The lack of correlation between risk attitudes of job-stayers and the earnings risk in their occupation also serves as indirect evidence that a correlation between earnings risk and risk attitudes is not the result of individuals adapting their preferences because of exposure to a risky environment. Evidence that exposure is unlikely to drive the results stems from recent empirical work that indicates that risk attitudes are rather stable over time (Andersen, Harrison, Lau, and Rutström, 2008; Reynaud and Couture, 2012; Dohmen, Falk, Huffman, Sunde, Schupp, and Wagner, 2012). ${ }^{17}$ Taken together, our findings in Table 3.4 and in Table 3.5 thus support the hypothesis that individuals sort into occupations that differ with respect to earnings risk based on their risk attitudes.

In order to investigate whether less risk-averse people indeed switch to occupations with higher earnings risk, while more risk-averse people switch to occupations with lower earnings variance, we next examine the direction of job change in greater detail. More specifically, we define a categorical variable with three categories based on the actual sample distribution of risk attitudes: the variable is labeled "Low risk attitude" for individuals with risk attitudes below the 33rd percentile, "Medium risk attitude" for individuals with risk attitudes between the 66th and the 33rd percentile, and "High risk attitude" for individuals with risk attitudes above the 66th percentile. Likewise, we define a categorical occupationspecific earnings risk variable, with categories "Low earnings risk" if the earnings risk is below the 33rd percentile, "Medium earnings risk" if the earnings risk in this occupation is between the 33rd and the 66th percentile of earnings risk distribution, and "High earnings risk" if the occupation has earnings risk which is above the 66th percentile. The results of ordered probit estimates on the sample of job switchers are presented in Table 5. The dependent variable in columns (1) and (2) is the categorical earnings risk variable on the level of occupations. In columns (3)

\footnotetext{
${ }^{17}$ There is a recent literature that addresses the stability of risk preferences over time, using measures based on subjective assessments and (hypothetical and incentivised) lottery choices (e.g., Harrison, Johnson, McInnes, and Rutström, 2005; Sahm, 2012; Andersen, Harrison, Lau, and Rutström, 2008; Baucells and Villasís, 2009). These studies do not find evidence for systematic changes in risk preferences, with the exception of age. Sahm (2012), for example, reports a general increase in risk aversion with age, but finds that risk preferences are the rank-order stable. Dohmen, Falk, Huffman, Sunde, Schupp, and Wagner (2012) also provide evidence that risk attitudes measured by the survey question that we use in this study, are rather stable, although measured with error. They document that the correlation over a very short period of 4 to 6 weeks, a period over one could assume that preferences are stable, is about 0.6 in different samples. Using data on the risk attitude measures available in the SOEP, they then report correlations of 0.5 between the measures taken with time interval of two years. After five years, the correlation is still 0.47 . These results indicate that risk preferences are persistent, even if somewhat malleable over time.
} 
and (4) the scale of this variable is reversed, such that higher values correspond to lower earnings risk.

Table 3.6: Switching to an occupation with high or low earnings risk

\begin{tabular}{|c|c|c|c|c|}
\hline & \multicolumn{2}{|c|}{ High earnings risk } & \multicolumn{2}{|c|}{ Low earnings risk } \\
\hline & (1) & $(2)$ & $(3)$ & (4) \\
\hline 1 if Medium risk attitude & $\begin{array}{c}-0.060 \\
(0.112)\end{array}$ & $\begin{array}{r}-0.086 \\
(0.089)\end{array}$ & & \\
\hline 1 if High risk attitude & $\begin{array}{l}0.383^{* * *} \\
(0.111)\end{array}$ & $\begin{array}{l}0.300^{* * *} \\
(0.099)\end{array}$ & & \\
\hline 1 if Medium risk attitude & & & $\begin{array}{c}0.442^{\text {*** }} \\
(0.080)\end{array}$ & $\begin{array}{c}0.386^{\text {*** }} \\
(0.097)\end{array}$ \\
\hline 1 if Low risk attitude & & & $\begin{array}{c}0.383^{\text {*** }} \\
(0.111)\end{array}$ & $\begin{array}{c}0.300^{\text {*** }} \\
(0.099)\end{array}$ \\
\hline Constant 1 & $\begin{array}{r}-0.142 \\
(0.350)\end{array}$ & $\begin{array}{c}0.508 \\
(2.224)\end{array}$ & $\begin{array}{c}-0.083 \\
(0.337)\end{array}$ & $\begin{array}{c}-0.831 \\
(2.226)\end{array}$ \\
\hline Constant 2 & $\begin{array}{c}0.466 \\
(0.341)\end{array}$ & $\begin{array}{c}1.131 \\
(2.266)\end{array}$ & $\begin{array}{c}0.525^{*} \\
(0.314)\end{array}$ & $\begin{array}{c}-0.208 \\
(2.181)\end{array}$ \\
\hline Additional controls & No & Yes & No & Yes \\
\hline Observations & 712 & 694 & 712 & 694 \\
\hline
\end{tabular}

Source: ULMS.

Note: Ordered probit estimation coefficients are reported. Dependent variable: a categorical variable with three categories, which equal to 1 if earnings risk in the new occupation (2007) is high, i.e. above the $66^{t h}$ percentile (in columns (1) and (2)) or low, i.e. below the $33^{\text {rd }}$ percentile (in columns (3) and (4)). The dependent variable is equal to 2 if the earnings risk in the new occupation is between the $33^{\text {rd }}$ and the $66^{\text {th }}$ percentile. The dummy variable 'High risk attitude' is equal to 1 if individual's risk attitude is above the $66^{\text {th }}$ percentile of the sample risk attitude distribution, 'Medium risk attitude' is equal to 1 if individual's risk attitude is between the $33^{r d}$ and the $66^{\text {th }}$ percentile, 'Low risk attitude' is equal to 1 if individual's risk attitude is below the $33^{\text {rd }}$ percentile. Clustered standard errors in parentheses. Significance stars indicate ${ }^{* * *} \mathrm{p}<0.01, * * \mathrm{p}<0.05, * \mathrm{p}<0.1$. Sample contains individuals who were employed in 1986 and in 2007, and have changed their occupation in between. Additional controls are: age, gender, tenure, years of schooling, an indicator for public sector employment, an indicator for residence in the capital city, marital status, and height.

The coefficient on "High risk attitude" is positive and significant in columns (1) and (2), which means that individuals who are on average more willing to take risks are more likely to switch to occupations with high earnings variance after transition. Individuals with average or low willingness to take risks, in contrast, are more likely to switch to occupations with low earnings variance, as can be seen from columns (3) and (4). Additional analyses show that the most risk averse individuals are more likely to withdraw from participation in the labour market in 2007, conditional on age and on being employed in 1986, which suggests that for a certain share of workers, the increase in average earnings accompanying the rise 
in occupational earnings risk was insufficient to compensate for utility losses due to higher uncertainty. ${ }^{18}$

\subsection{Robustness}

To check the robustness of our findings, we analyse data from another survey, the European Social Survey (ESS), which contains information on occupation and income to calculate an alternative measure of the earnings risk. We pool observations from three cross-sections (2004, 2006, and 2008), and regress the percentile of household income ${ }^{19}$ on a similar set of covariates as in the analysis in section 3.5. The standard deviation (on the level of occupations) of the residuals from this regression serves as a dependent variable in column (2) of Table 3.7. Column (1) replicates the analysis of column (2) from Table 3.3 presented above. The regressors are the same in both columns. ${ }^{20}$ The documented positive relationship between risk attitudes and the occupation-specific earnings risk is a robust result, independent of the sample definition or the method of earnings variance calculation.

One potential concern might be that our definition of occupations (two-digit ISCO-88 code) is too broad and therefore hides important heterogeneity within occupations. The concern would be that occupations, that potentially require different skills and job tasks and that therefore might have earnings distributions with little common support, are aggregated. In that case the broad occupation would be classified as more risky according to our definition than it is from the individual's perspective. This kind of aggregation would bias our estimated coefficients downwards. Due to problems of small sample size, we cannot check for the correlation between risk attitudes and earnings risk of occupations defined on the three-digit ISCO-88 level. ${ }^{21}$

Another concern might be that our measure of the earnings risk is not the relevant earnings risk measure if individuals possess information about where they would end up in the earnings distribution of a particular occupation. For example, if the earnings variance in an occupation reflects differences in ability and if

${ }^{18}$ The results are available on request.

${ }^{19}$ Instead of wages, the ESS asks about the estimated percentile of household income, which we use as a proxy for labour earnings.

20 The self-employment indicator is excluded from the set of controls because the coding of self-employment differs across the data sets.

${ }^{21}$ Two recent studies using a similar methodology to ours, Fouarge at al. (2012) and Bonin et al. (2007) use samples that are large enough to permit estimation on 2-digit as well as on 3-digit ISCO-88 level. Both studies confirm the positive correlation between risk attitude and occupational earnings risk for more narrowly defined occupations. 
Table 3.7: Earnings risk and individual risk attitudes: External data set

\begin{tabular}{|c|c|c|}
\hline & $\begin{array}{c}\text { ULMS } \\
(1)\end{array}$ & $\begin{array}{c}\text { ESS } \\
(2)\end{array}$ \\
\hline Risk attitude & $\begin{array}{c}0.027^{* *} \\
(0.012)\end{array}$ & $\begin{array}{l}0.015^{* *} \\
(0.007)\end{array}$ \\
\hline 1 if Male & $\begin{array}{c}0.169 \\
(0.152)\end{array}$ & $\begin{array}{c}-0.074 \\
(0.112)\end{array}$ \\
\hline Tenure & $\begin{array}{c}0.010 \\
(0.007)\end{array}$ & $\begin{array}{c}-0.002 \\
(0.006)\end{array}$ \\
\hline Age & $\begin{array}{c}0.001 \\
(0.004)\end{array}$ & $\begin{array}{c}0.000 \\
(0.003)\end{array}$ \\
\hline Years of schooling & $\begin{array}{c}0.062^{*} \\
(0.035)\end{array}$ & $\begin{array}{l}0.116^{* *} \\
(0.046)\end{array}$ \\
\hline 1 if Public sector & $\begin{array}{c}-0.093 \\
(0.144)\end{array}$ & $\begin{array}{c}0.073 \\
(0.101)\end{array}$ \\
\hline 1 if Capital residence & $\begin{array}{c}-0.097 \\
(0.110)\end{array}$ & $\begin{array}{l}0.209^{* *} \\
(0.093)\end{array}$ \\
\hline 1 if Married & $\begin{array}{c}-0.037 \\
(0.047)\end{array}$ & $\begin{array}{c}-0.018 \\
(0.030)\end{array}$ \\
\hline Log wage & $\begin{array}{c}0.091 \\
(0.085)\end{array}$ & $\begin{array}{c}0.152^{*} \\
(0.085)\end{array}$ \\
\hline Height & $\begin{array}{c}0.006^{*} \\
(0.003)\end{array}$ & $\begin{array}{c}0.002 \\
(0.002)\end{array}$ \\
\hline Constant & $\begin{array}{c}-2.640^{* *} \\
(1.165)\end{array}$ & $\begin{array}{c}-2.969^{* * *} \\
(1.026)\end{array}$ \\
\hline $\mathrm{R}^{2}$ & 0.0603 & 0.1064 \\
\hline Observations & 2912 & 2815 \\
\hline
\end{tabular}

Source: ULMS; ESS.

Note: OLS regression coefficients are reported. Dependent variable in column (1): the standard deviation of residuals from Mincer type wage regression, as defined in section 3.4; in column (2): standard deviation (per occupation) of household income percentile (pooled over 2004, 2006, and 2008, ESS data). Dependent variables are standardised. Clustered standard errors in parentheses. Significance stars indicate $^{* * *} \mathrm{p}<0.01,{ }^{* *} \mathrm{p}<0.05,{ }^{*} \mathrm{p}<0.1$. Risk attitude is measured on a scale from 0 to 10,0 meaning that one is not at all willing to take risks.

individuals know their ability, the earnings risk they would face is much smaller than the variance of earnings distribution suggests. It is unlikely, however, that individuals know exactly where they end up in the earnings distribution. As long as the variance of earnings in occupations is a good indicator of the residual earnings risk for a given level of known ability, our results remain qualitatively valid. In addition, recent evidence indicates that information on ability is not driving the results. Berkhout, Hartog, and Webbink (2010) use information on student's secondary and tertiary school grades in the Netherlands as a proxy for ability. Their 


\section{Risk attitudes and occupational choice}

findings remain unchanged after correcting for school grades. Berkhout, Hartog, and Webbink (2010) conclude that unobserved heterogeneity does not seem to be as important as it is often claimed. Similar findings were reported based on ability bias correction by IQ deciles on NLSY data (Hartog, 2011). To eliminate possible unobserved heterogeneity reflected in the already realised wage distributions, Schweri, Hartog, and Wolter (2011) elicited student's subjective expectations regarding the form of their expected earnings risk. They report that it is unlikely that students possess superior private information regarding their career prospects. Schweri, Hartog, and Wolter (2011) also find no effect of math grade on expected median wages, which again suggests that individuals do not have a good idea about where they end up in the earnings distribution.

We argue that heterogeneity in job tasks and conditions is not a threat to our findings. Hartog and Vijverberg (2007b) analysed uncertainties in returns to schooling using a similar measure as is employed in the current analysis. Their estimates were not sensitive to the inclusion of multiple kinds of job disamenities, such as physically challenging or toxic conditions. Additionally, we estimated specifications (on individual level), that control for working hours per week and health state, both in the first stage (Mincer wage regression), and in the second stage (similar to the ones presented in Table 3.3, not reported here). There was no difference in the coefficient of risk attitude. Lastly, we do not find a positive relationship between risk attitudes and the earnings risk before the transition whereas differences in job requirements existed then, too.

Given the absence of occupational sorting based on individual risk attitudes and the earnings risk in 1986, it is informative to study whether there was some preference-based sorting before 1991. An inspection of the average risk attitudes of workers in specific occupations in 1986 reveals that that the most risk-loving individuals were concentrated in military occupations. ${ }^{22}$ The fact that huge Soviet territories required mobility from soldiers and officers, as well as the Afghanistan war in which the Soviet Union was involved during the 1980's, readily explains high riskiness of the occupation and risk-loving people that it attracted.

The relationship between risk attitudes and risky non-monetary characteristics supports the idea that individuals sort into occupations based on their risk preferences. Interestingly, risk attitudes were not related to earnings risk in 1986, when earnings risk was not a relevant sorting dimension, as occupations did not vary with respect to unexplained earnings variance. During the transition to a market economy, differences in earnings risk across occupations grew, making it a

\footnotetext{
${ }^{22}$ Military occupations are excluded from the main analysis. The results hold with the inclusion of military occupations.
} 
relevant dimension of occupational choice, and a relationship between risk preferences and occupational earnings risk evolved.

\subsection{Conclusion}

In this chapter we provide evidence that suggests a causal relationship between individual risk attitudes and occupational sorting. We show that in the circumstances in which earnings variance was an irrelevant characteristic of occupations due to strict command economy regulations, individual attitude towards risk was unrelated to the occupation-specific earnings risk. Using the economic transition as a source of an exogenous shock to the occupational wage structure and a recently available data source with direct risk attitude measures and wage income data from the pre-transition period, as well as from the post-transition period, we document that labour market participants in Ukraine adjusted their occupational choices in a predictable way.

More specifically, as the distribution of earnings risks across occupations expanded and became heterogenous due to exogenous factors related to transition, individuals that are more willing to take risks switched to occupations with large earnings risk, and individuals that are less willing to take risks switched to occupations with low earnings risk. This led to the evolvement of the sorting pattern similar to the one documented in Western labour markets, where labour market participants are more likely to be employed in occupations in which their risk attitudes are well-aligned with the earnings risk in their occupation. ${ }^{23}$

A number of additional robustness checks corroborate the findings and our assumptions. For example, we assure reliability of the retrospective wage information from the ULMS using an official statistics record: we find remarkable similarity between the mean earnings per industry from the official statistics source and based on the responses from the ULMS. By varying the estimation sample, we show that our findings are not sensitive to sample composition, sample ageing or outliers. We also discuss other potential sources of bias, such as aggregation of information and ability based sorting, to conclude that it is unlikely that these factors affect the results.

This study focuses on the cross-sectional unexplained earnings variance risk as a relevant dimension of occupational earnings risk. Other dimensions of earnings risk, such as unemployment risk and intertemporal variation of earnings might still be important for occupational choice. However, it is likely that these characteristics

\footnotetext{
${ }^{23}$ DeLeire and Levy (2004); Bonin, Dohmen, Falk, Huffman, and Sunde (2007); Fouarge, Kriechel, and Dohmen (2012).
} 
of occupational wage risk are to a certain extent reflected in the cross-sectional unexplained earnings variance, therefore, qualitatively we would expect to receive similar results using a different measure of occupational earnings risks. ${ }^{24}$

A potentially interesting question that arises from the finding that risk attitudes play an important role in occupational choice would be studying the consequences of 'wrong' sorting, due to, for example, inflexibility of the labour market or resulting from forced or limited educational and occupational choices. Such consequences may include, but are not limited to, lower life and job satisfaction, health problems such as chronic conditions, abuse of psycho-active substances, and related losses in productivity.

\footnotetext{
${ }^{24}$ Fouarge, Kriechel, and Dohmen (2012) use a range of measures of occupational earnings risk (including the occupational probability of unemployment) and find that the positive correlation between individual willingness to take risks and occupational earnings variance holds irrespectively of the measure used.
} 
Appendix 


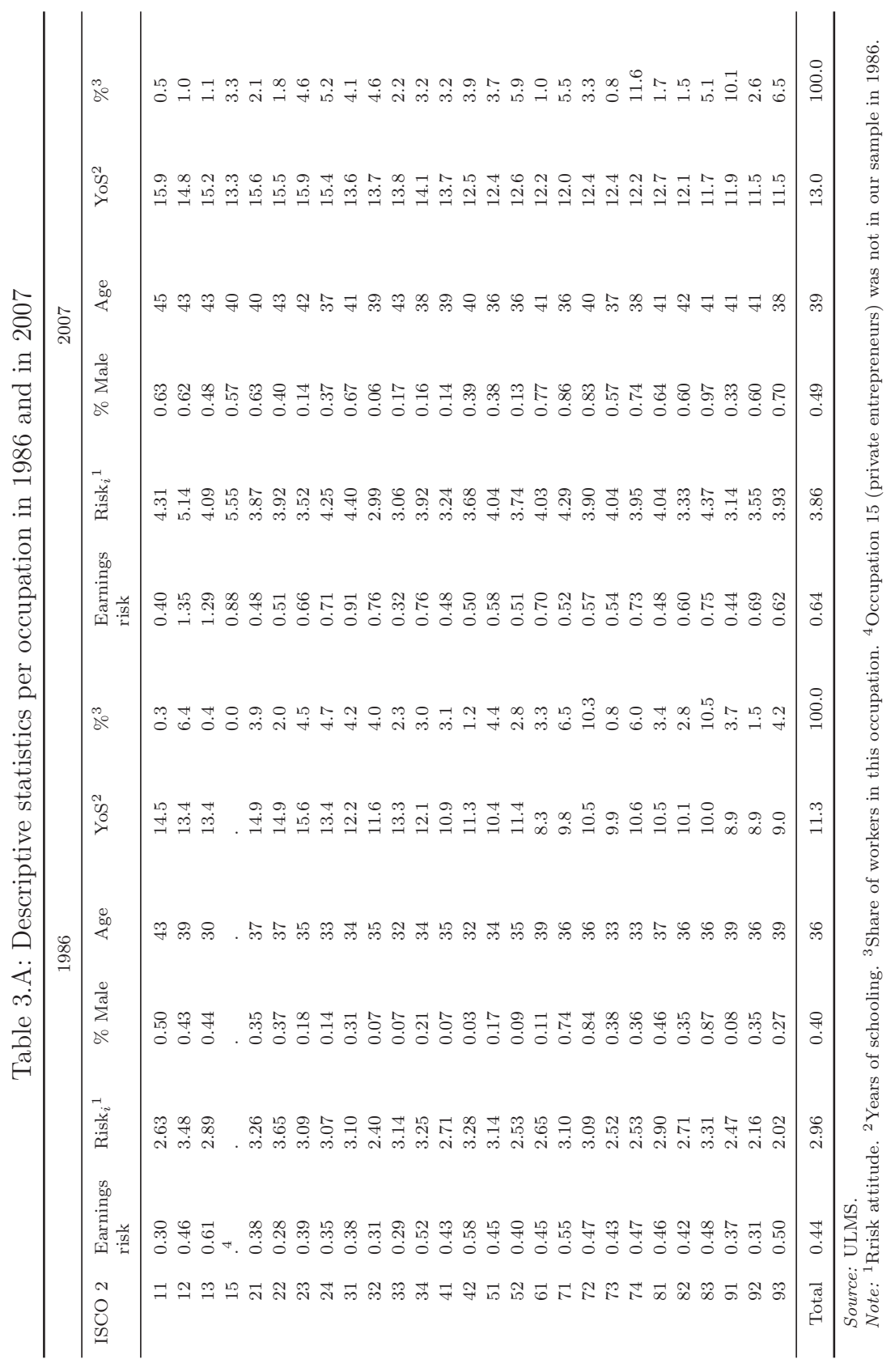


4 NeW EVIDENCE ON THE RELATIONSHIP BETWEEN RISK ATTITUDE AND SELF-EMPLOYMENT 


\subsection{INTRODUCTION}

Self-employment is an important driver of economic activity. ${ }^{1}$ Not surprisingly, what determines self-employment has occupied research agendas of economists for a long time, and several factors have been identified. ${ }^{2}$ Already in 1755, Cantillon recognised that entrepreneurial activities are risky. He argues that self-employed face a more variable stream of earnings because of uncertain product demand, which results in revenue fluctuations and can lead to business failure. ${ }^{3}$

Given the risky nature of self-employment, heterogeneity in risk preferences across individuals should affect the choice of employment status. ${ }^{4}$ A host of empirical studies have established a robust positive correlation between individual willingness to take risks and the probability of being self-employed (e.g. Cramer, Hartog, Jonker, and Van Praag, 2002; Ekelund, Johansson, Järvelin, and Lichtermann, 2005; Fossen, 2011). Recently, Caliendo, Fossen, and Kritikos (2009), using German data, showed that risk attitudes measured in 2004 predict transition into self-employment in 2005, which might suggest a causal effect of risk attitude on the probability of becoming self-employed. Similarly, Brown, Dietrich, Ortiz-Nuñez, and Taylor (2011), based on PSID data, document that risk attitudes measured in 1996 predicted self-employment transition up to nine years later. They also rightly caution the reader that an unobserved fixed effect might influence both the decision to become self-employed and the risk attitude.

A plausible unobserved factor is the effect that parents have on children's decision to become self-employed and the effect that parents have on children's risk attitudes. We illustrate this relationships in Figure 4.1. Two arrows from the family to self-employment point out that families can directly and indirectly affect the probability that their children will become self-employed. The most obvious

\footnotetext{
${ }^{1}$ This chapter is joint work with Thomas Dohmen and Ben Kriechel. The chapter was presented at Maastricht University (2012), the ZEW (2013) and EALE (2013). A revised version of this chapter is published as Skriabikova, Dohmen, and Kriechel (2014).

${ }^{2} \mathrm{~A}$ non-exhaustive list of micro-level self-employment determinants includes financial aspects, e.g. liquidity constraints, access to credit markets, wealth (Evans and Jovanovic, 1989; Lindh and Ohlsson, 1996; Hundley, 2006); human capital, e.g. formal education, skills, labour market experience (Rees and Shah, 1986; Evans and Leighton, 1989; Lazear, 2004, 2005); entrepreneurial ability (Hartog and van Praag, 2010); social capital and networks (Gomez and Santor, 2001); risk attitude (Van Praag and Cramer, 2001; Ekelund, Johansson, Järvelin, and Lichtermann, 2005) and personality traits (Evans and Leighton, 1989; Schiller and Crewson, 1997; Burke, FitzRoy, and Nolan, 2002).

${ }^{3}$ Empirical studies on earnings distributions consistently show that self-employed earnings are more variable than wages. See, for example, Falter (2007b), Rosen and Willen (2002); Parker (1999) and references therein.

${ }^{4}$ The role of the entrepreneur as a risk-bearer has been discussed already in early theoretical work (Knight, 1921; Schumpeter, 1934, 1939).
} 
channel is a direct transfer of business from parents to children. ${ }^{5}$ There might also be indirect channels that increase the likelihood that children of self-employed parents become self-employed themselves (Hout and Rosen, 2000; Falter, 2007a; Andersson and Hammarstedt, 2010). In particular, growing up in a self-employed family can provide children with invaluable information on what it is like to be self-employed. Recently, studies have also argued and provided empirical evidence that (risk) attitudes are transmitted from parents to children (Bisin and Verdier, 2001; Tabellini, 2008b; Dohmen, Falk, Huffman, and Sunde, 2012).

Figure 4.1: Intrafamily transmission of risk attitudes, information, selfemployment

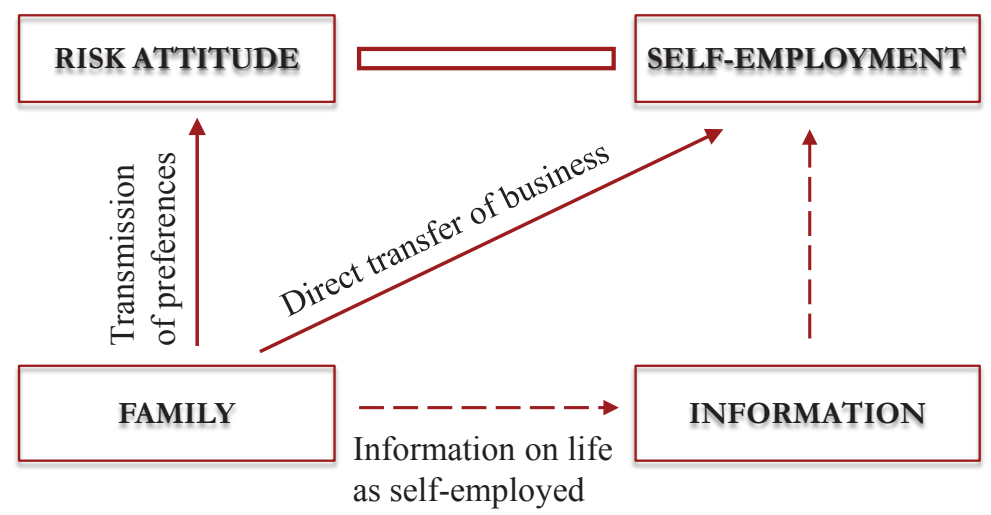

If self-employed become more willing to take risks because of exposure to the risky environment that the self-employed face, self-employed parents are more willing to take risks (on average) than non-self-employed parents. Hence, children of

\footnotetext{
${ }^{5}$ The majority of the studies analysing channels of transmission of self-employment from parents to children argue that intra-family business take-overs play a minor role. However, Fairlie and Robb (2007) report that $8.2 \%$ of current business owners inherited their business or received it as a gift. Based on the exact match between occupation-sector combination of fathers and sons, Dunn and Holtz-Eakin (2000) report that $36 \%$ of second generation self-employed sons are occupational followers as compared to $8 \%$ of those who never become self-employed.
} 
self-employed parents would be more willing to take risks than children of non-selfemployed parents due to intergenerational transmission of risk attitudes. In fact, this is born out by the data. In the West German sample of the German SocioEconomic Panel Study (SOEP), individuals whose fathers were self-employed are significantly more willing to take risks than individuals whose fathers were in regular employment. ${ }^{6}$ This link is illustrated by the arrow from family to risk attitudes in Figure 4.1. In light of this evidence, the relationship between risk attitudes and self-employment might not be causal even if it is identified using a measure of risk attitudes prior to the actual transition because both these measured risk attitudes and the propensity to become self-employed were influenced by parents. ${ }^{7}$

In this chapter, we analyse a setting in which the scope for such a third factor explanation is limited or even non-existent. We provide new evidence to support a causal interpretation of the correlation between risk attitude and the probability of becoming self-employed. We exploit the fact that self-employment was banned for at least 45 years in Ukraine $^{8}$ and heavily regulated in East Germany, ${ }^{9}$ so that there

\footnotetext{
${ }^{6}$ The difference of .32 in the mean of risk attitudes between children of fathers who were selfemployed when children were 15 years of age and children of fathers who were not self-employed (when children were 15 years of age) is statistically significant (two tailed t-test, p-value $<$ $0.001)$.

${ }^{7}$ Using risk attitudes of the father as an instrument, we find a significant positive effect of own (instrumented) risk attitudes on the probability of being self-employed in the West German sample of the SOEP. This estimation suggests a causal interpretation of the role of willingness to take risk for the probability of becoming self-employed since it is unlikely that risk attitude of fathers were influenced by self-employment experience of their children. However, the instrument is likely to be invalid because of the third factor such as father's self-employment experience.

${ }^{8}$ In Soviet Ukraine, an extremely restricted institutional regulation with respect to free trade and entrepreneurial activities was in force since the late 1920's (in the East), or since the World War II (in the West), until the end of 1980's. Any private for-profit activity was illegal, until approximately 1985, when the 'Perestroika' initiatives had grown and the total control over the population had declined substantially. The first legally registered self-employed appeared in 1987, but the number of self-employed individuals started growing in the 1990's, after the official separation of Ukrainian SSR (Soviet Socialist Republic) from the Soviet Union in 1991. (See Figure 1.2b in Chapter 1 for the dynamics of self-employment in Ukraine since 1986). Before that, commercial activities conducted not by the state and not for the state were considered a criminal offence (for example, Gelfand, 1964; Trofimov, 1975; Andruhin, 2011).

${ }^{9}$ In (former) East Germany, the communist government limited self-employment severely, subjecting it to strict rules and regulations. Starting with agriculture in 1950's and production firms in 1960's, self-employment was virtually abolished. Remnants in specific sectors and occupations formally constituted self-employment in the GDR (Pickel, 1992). Local planning authorities had the power to decide on the entry, allocation of labour and other production factors, amount of output in terms of goods and services, and even on customer service (Prantl and Spitz-Oener, 2009). Under such conditions, even though these 'enterprises' were considered private, they were not comparable to private enterprises in West Germany or in other market economies. Only after reunification, the German Trade and Crafts Code valid in West Germany were extended to East Germany, in 1990. These conditions precluded transmission of information or creation of business networks in the former GDR (Lechner and Pfeiffer, 1993).
} 
were two generations who grew up without having experienced from their parents what it is like to be self-employed. This feature of the institutional regulation allows investigating the effect of risk attitude on self-employment separately from the effect of family.

In the empirical analysis, we use two panel household surveys: the Ukrainian Longitudinal Monitoring Survey (ULMS) and the East Germany sub-sample of the German Socio-Economic Panel Study (SOEP). Next to general demographic and socio-economic characteristics, the data sets contain a direct measure of risk attitude and information on parental education and occupation. The SOEP contains measures of self-employment intentions elicited just before reunification of Germany. In the additional analysis we use the Noord-Brabant cohort study to illustrate the role of risk attitudes for the decision to become self-employed for individuals who are born in entrepreneurial families.

The main features of the data sets, study samples and variable definitions are tackled in section 4.2. In section 4.3, the empirical approach and the findings from the empirical analysis are displayed and discussed. The last section concludes.

\subsection{DATA AND VARIABLES}

The ULMS panel consists of three waves, which were collected in 2003, 2004, and 2007. ${ }^{10}$ The analysis in this chapter is based on the last wave, as in 2007 information on risk attitudes was collected. This sample is restricted to individuals between 18 and 65 years old. It excludes individuals who are not participating in the labour market, military occupations, farmers, individuals receiving pension or involved in full-time education, as well as individuals who are family members helping a self-employed one.

The self-employment status variable is equal to one if the answer to the question about current status on the labour market is either self-employed, entrepreneur or employer in 2007. The reference zero category corresponds to individuals who are in paid employment. Risk attitude is measured by a subjective self-assessment of willingness to take risk in general on the scale from zero to ten, in which higher values reflect greater willingness to take risks. The exact wording of the question, translated from Ukrainian or Russian reads: "How do you see yourself: Are you generally a person who is fully willing to take risks or do you try to avoid taking risks? Please give me a number from 0 to 10 , where the value 0 means: 'Risk averse' and the value 10 means: 'Fully prepared to take risks'. You can use

\footnotetext{
${ }^{10}$ For the detailed overview of the ULMS, see Lehmann, Muravyev, and Zimmermann (2012).
} 
the values in between to make your estimate." Dohmen, Falk, Huffman, Sunde, Schupp, and Wagner (2011) have shown that this question is significantly related to paid lottery choices, and it explains behaviour in a range of important real life decision domains. Descriptive statistics with mean and standard deviation of the main variables are shown in Table 4.1 .

Table 4.1: Descriptive statistics

\begin{tabular}{lccccc}
\hline & \multicolumn{2}{c}{ ULMS } & \multicolumn{2}{c}{ SOEP $^{1}$} \\
\cline { 2 - 6 } Variable & Mean & SD $^{2}$ & Mean & SD \\
\hline 1 if (ever) Self-employed & 0.09 & 0.29 & 0.10 & 0.30 \\
1 if Intends to become self-employed & & & 0.08 & 0.27 \\
Risk attitude & 3.89 & 2.86 & 4.41 & 1.68 \\
1 if Male & 0.51 & 0.50 & 0.51 & 0.50 \\
Age & 38.79 & 10.80 & 38.77 & 11.35 \\
1 if Higher education & $0.45^{4}$ & 0.50 & 0.35 & 0.48 \\
Log household income & & 6.33 & 0.69 & 7.56 & 0.33 \\
\hline Sample & 2726 & & 1624 & \\
\hline
\end{tabular}

1 SOEP. Sample: former East Germany.

2 SD means standard deviation.

${ }^{3}$ Log household income is the mean of monthly household income over 2003 and 2004 in the ULMS (in the national currency: hryvnya). In the SOEP: in 1990 (national currency: Deutsche Mark).

4 Education was considered a priority in the Soviet Union (Åslund, 2007), access to higher education was cheap and universal. The share of adult population with tertiary education in Ukraine is high compared to countries such as Austria (18\%), Germany (25\%), the UK or the Netherlands (30\%). See Kupets, Leshchenko, Osinkina, Taran, and Komarov (2009).

Easy access to information on self-employment, access to wealth and to social networks enhance business opportunities and potentially can also reduce perceived uncertainty associated with self-employment. We use information on occupational status and educational achievement of both parents to control for access to information and networks. ${ }^{11}$ The egalitarian policy of the Soviet Union assured that there was little income inequality, and therefore, the distribution of wealth across households was quite homogenous in the beginning of transition. ${ }^{12}$ However, many apartments and houses were privatised in the early years of transition, increasing heterogeneity across households with respect to access to credit since home ownership serves as a collateral to get credit in a bank. To control for this, we use household income information collected in 2003/2004 and home ownership in 2003.

${ }^{11}$ More educated individuals would be more likely to have been former members of the official ruling Communist party and they could have retained some personal access to politically and economically important networks.

${ }^{12}$ According to the official Gini coefficient measure, income inequality did not increase dramatically during the transition years. The Gini coefficient remained at about 28-30 in 2003-2007. 
The SOEP is a large representative panel survey, which covers the population of former East Germany from 1990 onwards. ${ }^{13}$ In 1990, right before the full reunification of Germany, self-employment aspirations were elicited. The exact wording of the question measuring self-employment intention is: "What are your expectations for the future as far as your occupation is concerned? How probable do you consider it to be that you become self-employed in the next two years? Highly Probable; Probable; Not Very Probable; Highly Improbable". The answer is used to construct a binary variable, which is equal to one if the answer is 'highly probable' or 'probable'. The variable is equal to zero if it is 'not very probable' or 'highly improbable'.

The measure of risk attitude (standardised in regressions) is identical to the one in the ULMS: the answer to the general risk question, with higher values reflecting higher risk-tolerance. ${ }^{14}$ In fact, the ULMS borrowed this question from the SOEP. We use household income in 1990 and home ownership (in 1990) as proxies for access to capital markets. We construct a dummy that equals one if an individual was self-employed at any time between 1991 and 2011.

The SOEP sample is restricted to exclude individuals of non-German nationality or born outside of Germany, individuals who have never worked; individuals above the age of 65 and those who were in civil or military service in 1990. Additionally, individuals whose fathers were self-employed or self-employed farmers, as well as individuals who were self-employed themselves at the moment of the survey (less than $1 \%$ of the sample) are excluded.

\subsection{Results}

\subsubsection{EVIDENCE FROM UKRAINE}

We first analyse the determinants of self-employment in Ukraine, and estimate a probit model in which the dependent variable is the indicator variable for selfemployment status. Marginal effect estimates of this probit regression evaluated at sample means are presented in Table 4.2. In column (1) the standardised measure of risk attitude is the only explanatory variable in the model. In the following columns, sets of explanatory variables are added: demographic characteristics, size of a place of birth, household wealth proxies, education and marital status, as well

\footnotetext{
${ }^{13}$ For the details on the SOEP data see Wagner, Frick, and Schupp (2007).

${ }^{14}$ In the SOEP, general willingness to take risks was measured several times during the panel, with the first time in 2004. We take the person average of all available measures to minimise potential measurement error.
} 
as parental background characteristics (education and occupation of father and mother), and regional dummies.

Table 4.2: Self-employment in Ukraine

\begin{tabular}{|c|c|c|c|c|c|}
\hline & (1) & (2) & (3) & (4) & $(5)$ \\
\hline Risk attitude & $\begin{array}{l}0.033^{* * *} \\
(0.005)\end{array}$ & $\begin{array}{l}0.031^{* * *} \\
(0.005)\end{array}$ & $\begin{array}{l}0.028^{* * *} \\
(0.005)\end{array}$ & $\begin{array}{l}0.028^{* * * *} \\
(0.005)\end{array}$ & $\begin{array}{l}0.025^{* * *} \\
(0.005)\end{array}$ \\
\hline Age & & $\begin{array}{l}0.015^{* * *} \\
(0.004)\end{array}$ & $\begin{array}{l}0.016^{* * *} \\
(0.004)\end{array}$ & $\begin{array}{l}0.014^{* * *} \\
(0.004)\end{array}$ & $\begin{array}{l}0.013^{* * *} \\
(0.004)\end{array}$ \\
\hline Age squared/100 & & $\begin{array}{c}-0.019^{* * *} \\
(0.005)\end{array}$ & $\begin{array}{c}-0.019^{* * *} \\
(0.005)\end{array}$ & $\begin{array}{c}-0.017^{* * *} \\
(0.005)\end{array}$ & $\begin{array}{c}-0.016^{* * *} \\
(0.005)\end{array}$ \\
\hline 1 if Male & & $\begin{array}{l}0.042^{* * *} \\
(0.011)\end{array}$ & $\begin{array}{c}0.043^{* * *} \\
(0.010)\end{array}$ & $\begin{array}{l}0.045^{* * *} \\
(0.011)\end{array}$ & $\begin{array}{c}0.045^{* * *} \\
(0.010)\end{array}$ \\
\hline 1 if Born in village & & & $\begin{array}{c}-0.040^{* * *} \\
(0.013)\end{array}$ & $\begin{array}{c}-0.044^{* * *} \\
(0.014)\end{array}$ & $\begin{array}{c}-0.046^{* * *} \\
(0.014)\end{array}$ \\
\hline 1 if Born in town & & & $\begin{array}{c}-0.040^{* *} \\
(0.019)\end{array}$ & $\begin{array}{c}-0.044^{* *} \\
(0.019)\end{array}$ & $\begin{array}{c}-0.051^{* * *} \\
(0.018)\end{array}$ \\
\hline 1 if Birth place unknown & & & $\begin{array}{c}-0.009 \\
(0.018)\end{array}$ & $\begin{array}{c}-0.010 \\
(0.017)\end{array}$ & $\begin{array}{c}-0.019 \\
(0.017)\end{array}$ \\
\hline 1 if Home owner ${ }^{1}$ & & & & $\begin{array}{l}0.043^{* * *} \\
(0.015)\end{array}$ & $\begin{array}{l}0.045^{* * *} \\
(0.015)\end{array}$ \\
\hline Log income in $2003 / 2004^{2}$ & & & & $\begin{array}{c}-0.025^{* *} \\
(0.011)\end{array}$ & $\begin{array}{c}-0.020^{* *} \\
(0.010)\end{array}$ \\
\hline 1 if High income ${ }^{3}$ & & & & $\begin{array}{l}0.059^{* * *} \\
(0.019)\end{array}$ & $\begin{array}{c}0.058^{* * *} \\
(0.019)\end{array}$ \\
\hline 1 if Higher education & & & & $\begin{array}{c}-0.008 \\
(0.012)\end{array}$ & $\begin{array}{c}-0.005 \\
(0.012)\end{array}$ \\
\hline 1 if Medium education & & & & $\begin{array}{c}-0.027^{* *} \\
(0.014)\end{array}$ & $\begin{array}{r}-0.024^{*} \\
(0.013)\end{array}$ \\
\hline 1 if Married & & & & $\begin{array}{c}-0.014 \\
(0.013)\end{array}$ & $\begin{array}{c}-0.015 \\
(0.012)\end{array}$ \\
\hline 1 if Has children & & & & $\begin{array}{c}0.028^{*} \\
(0.017)\end{array}$ & $\begin{array}{c}0.028^{*} \\
(0.016)\end{array}$ \\
\hline Parental background & No & No & Yes & Yes & Yes \\
\hline Regional dummies & No & No & No & No & Yes \\
\hline Sample & 2706 & 2706 & 2706 & 2706 & 2706 \\
\hline
\end{tabular}

Source: ULMS.

Note: Dependent variable is equal to 1 if individual is self-employed (zero if paid employment). Entries in the table are marginal effects after a probit estimation, evaluated at means of variables. Constant is included in all specifications. Standard errors in parentheses are clustered on household level. Significance stars indicate $* * * \mathrm{p}<0.01, * * \mathrm{p}<0.05,{ }^{*} \mathrm{p}<0.1$. Coefficient on risk attitude is standardised. Reference categories are: Lower education; Born in City. Parental background includes controls for education and occupation of mother and father.

${ }^{1} 1$ if household resided in own property (as opposed to rented) in 2003.

${ }^{2} \log$ household income is an average of monthly household income from 2003/2004.

31 if household income in 2003/2004 was higher or equal to 90th percentile of household income distribution.

The resulting coefficient on risk attitude suggests that a one standard deviation increase in willingness to take risks is associated with a 2.5 to 3 percentage 
points higher probability of being self-employed. Compared to the sample mean of $9 \%$ (see Table 4.1), this is a sizeable effect. It is comparable to half of the gender effect or to being a home owner.

The fact that risk attitude is significantly related to self-employment even when circumstances in which direct and indirect channels through which family can affect self-employment of the children are (partially) blocked by institutional regulations suggests that the relationship between risk attitude and self-employment that has been documented in the literature (see Cramer, Hartog, Jonker, and Van Praag, 2002; Ekelund, Johansson, Järvelin, and Lichtermann, 2005; Caliendo, Fossen, and Kritikos, 2009; Brown, Dietrich, Ortiz-Nuñez, and Taylor, 2011) is unlikely to be an artifact of a third factor related to transmission of risk attitudes and self-employment within the family or the proximate social environment. ${ }^{15}$ In that sense, our findings support a causal interpretation of the effect of risk preference of self-selection into self-employment, as suggested by Caliendo, Fossen, and Kritikos (2009) and Brown, Dietrich, Ortiz-Nuñez, and Taylor (2011). ${ }^{16}$

In contrast to previous literature showing that individuals from wealthier households have a higher likelihood of becoming self-employed, ${ }^{17}$ we do not find a significant effect of household income measured three years prior to the analysis year on the probability of being self-employed. In line with the findings of Hurst and Lusardi (2004), members of households in the top percentiles of the wealth distribution are more likely to become self-employed. This result follows from specifications (4) and (5), which include a dummy variable indicating that a household is at or above the $90^{\text {th }}$ percentile of the household income distribution. Formal education is not related to the probability of being self-employed in Ukraine, whereas being born in a village, which might illustrate lack of social connections important for setting up a business, is negatively related to self-employment.

\subsubsection{Evidence From the FORMER EAST GERMAnY}

The regulations of the Soviet Union, which prohibited private entrepreneurship in Ukraine and promoted redistribution policies in order to equalise incomes and wealth, created a setting, in which it is unlikely that self-employment experience

\footnotetext{
${ }^{15}$ Dohmen, Falk, Huffman, and Sunde (2012) provide evidence for intergenerational transmission of risk attitudes, while Lindquist, Sol, and van Praag (2012) document evidence for intergenerational correlation in self-employment.

${ }^{16}$ Some regions of Ukraine, namely in the West, were annexed to the Soviet Ukraine later than the others, which might bring about some heterogeneity in the information set. Adding regional dummies (column (5)) does not affect the results.

${ }^{17}$ (E.g., Holtz-Eakin, Joulfaian, and Rosen, 1994; Lindh and Ohlsson, 1996; Blanchflower and Oswald, 1998)
} 
was transmitted from the parents. However, as the analysis of self-employment in Ukraine pertains to 2007, it might be that some information on self-employment from the neighbouring countries or previous early-transition entrepreneurial experience could have intervened with the relationship between risk attitudes and self-employment. In the following, we turn to the estimation of the effect of risk attitude on the probability of stated intentions to become self-employed in East Germany just before reunification.

Table 4.3: Self-employment intentions in 1990

\begin{tabular}{|c|c|c|c|c|}
\hline & $(1)$ & $(2)$ & (3) & (4) \\
\hline Risk attitude & $\begin{array}{l}0.020^{* * *} \\
(0.007)\end{array}$ & & $\begin{array}{l}0.019^{* * *} \\
(0.007)\end{array}$ & $\begin{array}{c}0.014^{* *} \\
(0.006)\end{array}$ \\
\hline 1 if Home owner in $1990^{1}$ & & $\begin{array}{c}0.036^{* *} \\
(0.015)\end{array}$ & $\begin{array}{l}0.036^{* *} \\
(0.015)\end{array}$ & $\begin{array}{c}0.033^{* *} \\
(0.014)\end{array}$ \\
\hline Log household income in 1990 & & $\begin{array}{c}0.031 \\
(0.026)\end{array}$ & $\begin{array}{c}0.029 \\
(0.025)\end{array}$ & $\begin{array}{c}0.009 \\
(0.024)\end{array}$ \\
\hline 1 if High household income ${ }^{2}$ & & $\begin{array}{c}-0.021 \\
(0.026)\end{array}$ & $\begin{array}{r}-0.022 \\
(0.026)\end{array}$ & $\begin{array}{r}-0.015 \\
(0.024)\end{array}$ \\
\hline 1 if Male & & & & $\begin{array}{c}0.023^{* *} \\
(0.011)\end{array}$ \\
\hline Age in 1990 & & & & $\begin{array}{c}0.013^{* *} \\
(0.005)\end{array}$ \\
\hline$(\text { Age in } 1990)^{2} / 100$ & & & & $\begin{array}{c}-0.018^{* * *} \\
(0.006)\end{array}$ \\
\hline 1 if Medium education & & & & $\begin{array}{c}-0.001 \\
(0.033)\end{array}$ \\
\hline 1 if Higher education & & & & $\begin{array}{c}0.024 \\
(0.034)\end{array}$ \\
\hline Father's occupation & No & No & No & Yes \\
\hline Regional dummies & No & No & No & Yes \\
\hline Sample & 1626 & 1626 & 1626 & 1624 \\
\hline \multicolumn{5}{|c|}{$\begin{array}{l}\text { Source: SOEP. Sample: former East Germany. } \\
\text { Notes: Estimation: probit. Marginal effects evaluated at sample means are reported. Dependent variable: } \\
\text { self-employment aspiration. The binary dependent variable is equal to } 1 \text { if individual intends to become self- } \\
\text { employed (elicited in } 1990) \text {. The mean of dependent variable is } 0.08 \text {. Risk attitude is the standardised average } \\
\text { of general willingness to take risks. Clustered standard errors are in parentheses. Significance stars indicate } \\
* * * p<0.01, * * p<0.05, * \mathrm{p}<0.1 \text {. Sample: Individuals from the East Germany, sampled in } 1990 \text {. } \\
{ }^{1} 1 \text { if household resides in own property (as opposed to rented). } \\
21 \text { if household income in } 1990 \text { was higher or equal to } 90 \text { th percentile of household income distribution. }\end{array}$} \\
\hline
\end{tabular}

Table 4.3 presents the result of the probit estimation in which the dependent variable is equal to one if an individual stated that he or she is likely to become selfemployed (entries in the table are marginal effects evaluated at sample means). In column (1), only willingness to take risks (standardised) is included as an explanatory variable. The positive and significant effect of risk attitudes on the intention 
Table 4.4: Self-employment in East Germany

\begin{tabular}{|c|c|c|c|c|c|}
\hline & (1) & (2) & (3) & (4) & (5) \\
\hline 1 if Self-employment intention & $\begin{array}{l}0.188^{* * * *} \\
(0.021)\end{array}$ & & & $\begin{array}{c}0.164^{* * *} \\
(0.019)\end{array}$ & $\begin{array}{l}0.124^{* * *} \\
(0.016)\end{array}$ \\
\hline Risk attitude & & $\begin{array}{l}0.047^{* * *} \\
(0.007)\end{array}$ & & $\begin{array}{l}0.039^{* * *} \\
(0.007)\end{array}$ & $\begin{array}{l}0.025^{* * *} \\
(0.006)\end{array}$ \\
\hline 1 if Home owner in $1990^{1}$ & & & $\begin{array}{c}0.016 \\
(0.016)\end{array}$ & $\begin{array}{c}0.005 \\
(0.015)\end{array}$ & $\begin{array}{c}0.013 \\
(0.012)\end{array}$ \\
\hline Log household income in 1990 & & & $\begin{array}{l}0.110^{* * *} \\
(0.028)\end{array}$ & $\begin{array}{l}0.091^{* * *} \\
(0.025)\end{array}$ & $\begin{array}{l}0.065^{* * *} \\
(0.021)\end{array}$ \\
\hline 1 if High household income ${ }^{2}$ & & & $\begin{array}{c}-0.032 \\
(0.028)\end{array}$ & $\begin{array}{c}-0.026 \\
(0.026)\end{array}$ & $\begin{array}{c}-0.015 \\
(0.021)\end{array}$ \\
\hline 1 if Male & & & & & $\begin{array}{c}0.022^{* *} \\
(0.011)\end{array}$ \\
\hline Age in 1990 & & & & & $\begin{array}{c}0.005 \\
(0.004)\end{array}$ \\
\hline$(\text { Age in } 1990)^{2} / 100$ & & & & & $\begin{array}{c}-0.011^{* *} \\
(0.005)\end{array}$ \\
\hline 1 if Medium education & & & & & $\begin{array}{c}0.037 \\
(0.031)\end{array}$ \\
\hline 1 if Higher education & & & & & $\begin{array}{l}0.073^{* *} \\
(0.032)\end{array}$ \\
\hline Father's occupation & No & No & No & No & Yes \\
\hline Regional dummies & No & No & No & No & Yes \\
\hline Sample & 1626 & 1626 & 1626 & 1626 & 1624 \\
\hline
\end{tabular}

Source: SOEP. Sample: former East Germany.

Notes: Estimation: probit. Marginal effects evaluated at sample means are reported. Dependent variable: self-employment between 1991 and 2011. The binary dependent variable is equal to 1 if individual was selfemployed at least in one year between 1991 and 2011. The mean of dependent variable is 0.10. Risk attitude is the standardised average of general willingness to take risks. Clustered standard errors are in parentheses. Significance stars indicate $* * * \mathrm{p}<0.01,{ }^{*} * \mathrm{p}<0.05, * \mathrm{p}<0.1$.

${ }^{1} 1$ if household resides in own property (as opposed to rented).

21 if household income in 1990 was higher or equal to 90 th percentile of household income distribution.

to become self-employed confirms that higher willingness to take risk is associated with a higher probability to become self-employed even in conditions of very limited knowledge about self-employment transmitted by the previous generation. This result indicated that the correlation between risk attitudes and self-employment is unlikely driven by parental background, as the intergenerational transmission of self-employment experience was limited in the German Democratic Republic.

In column (2), we regress the intention to become self-employed on several measures of access to capital in 1990, but exclude risk attitudes. There is no effect of household wealth, but being a home owner is positively and significantly related to the intention to become self-employed. In column (3), when risk attitude and access to capital measures are included as explanatory variables at the same time, there is no change in the coefficients: willingness to take risks and the possibility to 
gain access to credit (using real estate as a collateral) are significant predictors of the self-employment intentions just before reunification. These two effects are also independent of each other, and their effect is virtually unchanged when a set of control variables, including socio-demographic characteristics, father's occupation, and regional dummies, is added in specification (4).

Making use of the rich panel structure of the SOEP, we analyse to what extent future self-employment is predicted by the stated intentions in 1990. The dependent variable in Table 4.4 is the actual probability of being self-employed between 1991 and 2011. The upshot of the estimates presented in Table 4.4 is that entrepreneurial intentions are a significant predictor of future self-employment. Predicted probabilities of becoming self-employed from column (5), when a full set of control variables is added, including risk attitudes and access to capital measures, are significantly different for individuals who intended to become self-employed in 1990 vs. those who had no such intention: $32 \%$ and $8 \%$ respectively.

Interestingly, household income in 1990 has no effect on the self-employment intention, whereas it is significantly related to the probability of becoming selfemployed in the years following reunification. In contrast, while residence ownership predicts self-employment intentions, it is irrelevant for the actual probability of becoming self-employed. The effect of household income in 1990 (as a proxy for credit constraints) decreases once risk attitudes and self-employment intentions are included as control variables. The coefficient on willingness to take risks decreases somewhat when the self-employment intention from 1990 is included in the regression, but there is no significant interaction effect. The data suggests that willingness to take risks, access to wealth, and previously stated self-employment intention increase the probability of the transition into self-employment.

\subsubsection{Evidence From the Netherlands}

The additional analysis of this section illustrates the risk-decreasing role of information on self-employment. For this, we use the Noord-Brabant cohort study from the Netherlands (for more information on the data, see van Praag (1992); Hartog, Jonker, and Pfann (2002)). The advantage of this data set is that in addition to the information on self-employment status and the risk attitude measure, information on how someone became self-employed is also included. We split the sample into two: the sample of individuals whose father was a regular employee and the sample of individuals whose father was self-employed. ${ }^{18}$ We also define two binary

\footnotetext{
${ }^{18}$ This cohort study contains individuals who were 12 years of age in 1952. In the 1950's it was not common for Dutch women to be formally employed, therefore we treat father's self-employment as an indicator of an entrepreneurial family.
} 
Table 4.5: Self-employment in the Netherlands

\begin{tabular}{|c|c|c|c|}
\hline \multirow{2}{*}{$\begin{array}{l}\text { Panel } A \\
\text { Dependent variable }\end{array}$} & \multirow{2}{*}{$\begin{array}{r}\text { Father employee } \\
\text { Started own }\end{array}$} & \multicolumn{2}{|c|}{ Father self-employed } \\
\hline & & Started own business & \multirow{2}{*}{$\frac{\text { Took over }}{(3)}$} \\
\hline & (1) & $(2)$ & \\
\hline \multirow[t]{2}{*}{ Risk attitude } & $0.029^{* * *}$ & 0.017 & -0.005 \\
\hline & $(0.010)$ & $(0.020)$ & $(0.022)$ \\
\hline \multirow[t]{2}{*}{ Constant } & $0.075^{* * *}$ & $0.130^{* * *}$ & $0.143^{* * *}$ \\
\hline & $(0.010)$ & $(0.020)$ & $(0.020)$ \\
\hline \multicolumn{4}{|l|}{ Panel B } \\
\hline \multirow[t]{2}{*}{ Risk attitude } & $0.024^{* *}$ & 0.014 & -0.017 \\
\hline & $(0.010)$ & $(0.020)$ & $(0.022)$ \\
\hline \multirow[t]{2}{*}{ IQ measure } & -0.000 & 0.001 & $0.003^{*}$ \\
\hline & $(0.001)$ & $(0.002)$ & $(0.002)$ \\
\hline \multirow[t]{2}{*}{1 if Male } & 0.029 & $0.107^{* *}$ & $0.187^{* * *}$ \\
\hline & $(0.022)$ & $(0.041)$ & $(0.042)$ \\
\hline \multirow[t]{2}{*}{1 if Firstborn } & 0.026 & 0.026 & 0.014 \\
\hline & $(0.022)$ & $(0.047)$ & $(0.047)$ \\
\hline \multirow[t]{2}{*}{1 if Vocational education } & 0.009 & 0.027 & -0.053 \\
\hline & $(0.027)$ & $(0.056)$ & $(0.055)$ \\
\hline \multirow[t]{2}{*}{1 if Higher education } & 0.011 & -0.076 & $-0.230^{* * *}$ \\
\hline & $(0.027)$ & $(0.051)$ & $(0.050)$ \\
\hline \multirow[t]{2}{*}{1 if Missing education } & 0.061 & $0.131^{*}$ & -0.010 \\
\hline & $(0.041)$ & $(0.069)$ & $(0.070)$ \\
\hline \multirow[t]{2}{*}{ Constant } & 0.101 & 0.021 & -0.209 \\
\hline & $(0.096)$ & $(0.188)$ & $(0.186)$ \\
\hline Sample & 713 & 297 & 301 \\
\hline Mean of dependent variable & 0.074 & 0.131 & 0.143 \\
\hline
\end{tabular}

Source: Noord-Brabant.

Notes: Dependent variable: in columns (1) and (2) the dependent variable is equal to 1 if individual started his or her own business, to 0 if he/she is an employee. In column (3) the dependent variable is equal to 1 if individual took over a business from a family member, it is equal to 0 if he/she is an employee. Estimation: OLS. Estimation sample: in column (1) individuals who were born to fathers in regular employment. In columns (2) and (3) the estimation sample consists of individuals born to fathers who were self-employed. Additional control variables in panel B include dummies for parental education. Standard errors are in parentheses. Significance stars indicate ${ }^{* * *} \mathrm{p}<0.01,{ }^{* *} \mathrm{p}<0.05,{ }^{*} \mathrm{p}<0.1$.

dependent variables with zero corresponding to regular employment. The first dependent variable is equal to 1 if an individual became self-employed by starting his or her own business; the second one is equal to one if an individual became self-employed by taking over a business from a family member.

The results are shown in Table 4.5, in which Panel A presents the results without control variables. Control variables are added in Panel B. The share of individuals who become self-employed is almost double in the sample of individuals coming from entrepreneurial families as compared to non-entrepreneurial (the last row of Table 4.5), independently of the mode of becoming self-employed. The 
estimates show that while risk attitude is significantly related to the probability of being self-employed (starting an own business) when born to a family in regular employment (column (1)), there is no such relationship between willingness to take risks and the probability of being self-employed when born to an entrepreneurial family (columns (2) and (3)). Moreover, in column (3) the coefficient on risk attitude even turns negative (insignificant), suggesting that in case of taking over a family business when one's father was self-employed might even be a less risky option than choosing regular employment. The results of this additional analysis imply that having access to valuable information about self-employment from the family might influence how risky self-employment is perceived.

\subsection{CONCLUding REMARKS}

The analysis of the role of risk attitude for the propensity of becoming selfemployed in conditions in which parents cannot transmit information about own self-employment experience enhances our understanding of the nature of the relationship between willingness to take risks and entrepreneurship. Our results indicate that it is unlikely that this relationship is driven by parental background variables that affect risk attitudes and the propensity to become self-employed. Using data on individuals from Ukraine and East Germany, whose ancestors could not experience what it is like to be self-employed as entrepreneurial activities were banned or at least heavily regulated by the political regime, we provide field evidence supporting the causal interpretation of the effect of risk attitude on selfemployment.

We do not claim that we can prove causality. One caveat is that other factors that we have not identified in our study could potentially drive the correlation between risk attitudes and self-employment. But we have arguably identified the most plausible channel, namely parental transmission of experience, resources, information and preferences, that might generate a spurious correlation between risk preference and self-employment, and we have shown that this channel is an unlikely candidate. A second caveat is that, although the communist regimes in Ukraine and East Germany strived to equalise financial means across households, there still existed privileges that we cannot observe in our survey data and hence cannot fully account for. In particular, some individuals might have had preferential access to knowledge and capital from the West, or might have received such information from friends or relatives living in Western countries. These individuals might also be more likely to be risk-takers. However, we believe that such mechanisms are unlikely to drive the strong and significant correlation between risk attitudes and 
self-employment as the communist governments did their best to minimise communication across borders, so that there is little scope for such channels to drive the results we have documented.

We at least partially shut down the channel through which family can directly or indirectly affect self-employment of the children, and thereby show that it is unlikely that the documented relationship between risk attitudes and self-employment is driven by a third factor. Our additional analysis illustrates how access to information on self-employment, as indicated by coming from an entrepreneurial family and taking over the business, diminishes the role of willingness to take risks for self-employment. Combined with previous evidence that discards reverse causality, i.e. shows that is unlikely that exposure to self-employment affects risk attitudes (e.g. Caliendo, Fossen, and Kritikos, 2009), our results hence suggest a causal effect of risk preferences on the decision to become self-employed. 

5 Risk attitudes, Job mobility AND SUBSEQUENT WAGE GROWTH DURING THE EARLY CAREER 


\subsection{INTRODUCTION}

The majority of life time job changes occur during the first ten years of labour market experience (Topel and Ward, 1992; Dustmann and Pereira, 2008). ${ }^{1}$ This period is also accompanied by largest wage increases (Topel and Ward, 1992). The proposition that job mobility affects wages has been extensively studied in the literature. Positive effects of early career job mobility are explained in theoretical models (e.g. Burdett, 1978; Jovanovic, 1979a) and supported by empirical evidence (Topel and Ward, 1992; Hunt, 2001; le Grand and Taehlin, 2002; Fuller, 2008). It has also been argued that higher returns are associated with longer tenure. The productivity of a job match is not certain ex ante because job characteristics only reveal over time, suggesting that high job mobility can be counterproductive (Jovanovic, 1979b; Johnson, 1978). Empirical evidence in favour of this explanation has also been collected (Light and McGarry, 1998; Zimmermann, 1998; Neumark, 2002). The debate about whether job mobility is beneficial for wage growth has not been resolved so far.

In this paper, we argue that the willingness to take risks is a key factor that affects job changing behaviour of labour market entrants, who subsequently experience heterogeneous patterns of wage growth. Risk attitudes have been shown to influence various labour market outcomes. In particular, individuals who are more willing to take risks are more likely to invest in human capital (Shaw, 1996; Brown and Taylor, 2005; Budria, Diaz-Serrano, Ferrer-i-Carbonell, and Hartog, 2012), become private sector employees (Fuchs-Schündeln and Schündeln, 2005; Pfeifer, 2010) or self-employed (Caliendo, Fossen, and Kritikos, 2009; Fossen, 2011, Chapter 4 of this dissertation), and, in general, sort into occupations with high earnings variance (Bonin, Dohmen, Falk, Huffman, and Sunde, 2007, Chapter 3 of this dissertation) or high mortality risk (DeLeire and Levy, 2004).

We argue that risk attitudes matter for job changing behaviour because job change is a risky decision. Costs of a job change are quantitatively large (van den Berg, 1992). Benefits of a new job are uncertain because employment contracts are typically incomplete. Thus, to change jobs, workers need to incur several kinds of costs while future benefits are uncertain at the moment the decision is taken. This implies that risk averse individuals will make fewer job changes than more risk tolerant individuals, assuming that job match quality and an external flow of job offers are independent of risk attitudes. Additionally, since risk averse individuals

\footnotetext{
${ }^{1}$ This chapter is joint work with Bethlehem A. Argaw and Michael F. Maier. We would like to thank the participants of the seminars at Maastricht University and the ZEW for their helpful comments. The chapter also benefitted from the participants of the Scottish Economic Society conference (SES, 2014).
} 
demand higher compensation for the same risk compared to more risk tolerant individuals, job changes of risk averse individuals will be accompanied by larger wage increases relative to risk tolerant individuals.

We test these predictions empirically using the German Socio-Economic Panel Study (SOEP) data, a household panel survey, which contains a direct measure of individual risk attitudes. We first relate risk attitudes of labour market participants to the number of job changes they make during the early years of their career. Second, we analyse whether the relationship between the total number of job changes and the wage growth is affected by risk attitudes. Our first result is that individuals who are more willing to take risks make more job changes than individuals who are less willing to take risks in a given period of time. We then document a significant difference in the wage growth associated with job changes of risk averse individuals compared to more risk tolerant individuals, such that wage gains associated with job changes are higher, on average, for risk averse individuals.

Our results shed some light on the contradictory findings in the literature studying the effects of job mobility on wage growth. Different wage growth patterns associated with job changes made by risk averse and risk tolerant individuals that we empirically document in this paper enhance our understanding of the relationship between job mobility and wage growth. The paper proceeds as follows. In the next section we summarise previous literature. In section 5.3 we sketch our conceptual framework to explain why risk attitudes should affect job changes and how the relationship between job changes and associated wage growth depends on the willingness to take risks. In section 5.4, our empirical approach and data are described. Section 5.5 presents our main findings, which are tested for sensitivity in Section 5.6. The last section concludes.

\subsection{Previous literature}

An early strand of the literature explains the effects of changing job on wage growth in theoretical models. Mobility from job to job is given a structural explanation and the wage evolution is predicted according to different mobility patterns. Job mobility in these models is generated by individuals learning about their true productivity at the current job match or by learning about external opportunities. The jobs are treated as 'experience goods' or as 'search goods', respectively. ${ }^{2}$

The predictions of search good models and experience good models with respect to wage growth are different. In an experience good model (e.g. Johnson,

\footnotetext{
2The terms 'experience goods' and 'search goods' follow the terminology of Nelson (1970).
} 
1978; Jovanovic, 1979b), the match quality is not known ex ante. Productivityrelated information of the current job accumulates over time and is learned by the worker. In this model, an exogenous flow of job (wage) offers is assumed, so there are no search costs. Individuals change the job, when the productivity of a current job match (and therefore the wage) falls below an ex-ante expected level. Experience good models predict either a positive or a negative relation between job mobility and wage growth due to imperfect information on the ex-ante productivity of the match.

In a search good model (e.g. Burdett, 1978; Jovanovic, 1979a), individuals process new information about the productivity of alternative job matches and change the job if a more productive job match associated with a higher wage is offered. In these models the match quality of the offered job is known ex ante. Workers can shift the distribution of arrivals of job offers by searching. The search good model predicts that individuals accept only job offers with higher match productivity associated with higher wages.

The different assumptions for models on job mobility and their predictions with respect to related wage growth call for empirical testing. An early analysis for the US by Topel and Ward (1992) finds decreasing job mobility during the first ten years on labour market as experience accumulates, which is consistent with a search good model. The authors find wage growth on average to be positively associated with job mobility.

The empirical investigation of the relationship between job mobility and wage growth crucially depends on the consideration of factors which cause heterogeneity. Light and McGarry (1998) show for the US that overall job mobility during the eight years after school exit is negatively associated with the wage level when accounting for job specific effects. Job mobility is driven by time-varying heterogeneity, which is consistent with a theoretical model in which jobs are considered experience goods. Neumark (2002) stresses unobserved factors which can either cause a positive or a negative bias when neglected. Consistent with an experience good model, his results for the US indicate that job mobility negatively affects adult wages. Positive effects of job mobility on wage growth are also documented by e. g. le Grand and Taehlin (2002) for Sweden and Fuller (2008) for the US. However, evidence on negative effects or no effects of job mobility on wage growth has also been accumulated (e.g. Munasinghe and Sigman, 2004). Perez and Sanz (2005) provide cross country evidence in the European context.

The case of Germany is not directly comparable to the results from the US, as mobility patterns differ considerably. In Germany, individuals during their career change jobs less often (Dustmann and Pereira, 2008; Borghans and Golsteyn, 2012). 
Dustmann and Pereira (2008) also suggest that the characteristics of job movers in Germany are different. Movers might be a negative selection as sticky wages on the current job or information asymmetries on worker's ability play a role in job mobility patterns. Other studies for Germany find job mobility to be a crucial factor that positively affects wage growth. Zimmermann (1998) finds for West Germany that male workers who change firms have a five percent lower yearly growth in monthly wage. Hunt (2001) reports that during the 1990's, 20 percent of wage growth could be attributed to job changes. A recent study by Alm, Engel, and Weyh (2013) finds that in East Germany, wage growth of job changers is about three percent per year higher than wage growth of job stayers.

Given the risk associated with changing jobs, it is likely that risk attitudes can influence the decision to move to another job. Risk attitudes affect a variety of labour market decisions, which in turn, can significantly affect wages. In particular, risk averse individuals are more likely to follow a career in a public sector (Pfeifer, 2010), whereas risk-averse individuals are more likely to become self-employed (see Chapter 4 of this dissertation). High earnings risk occupations, which tend to pay higher wages, attract individuals who are more willing to take risks (Bonin, Dohmen, Falk, Huffman, and Sunde, 2007; Hartog and Vijverberg, 2007a). Shaw (1996) shows empirically that risk attitudes can affect wages because more risk-tolerant individuals are more likely to invest into risky human capital. Risk averse individuals, on the contrary, have lower wage growth due to lower returns to education, experience and tenure. For the UK the study of Brown and Taylor (2005) shows a negative correlation between risk aversion and wage growth. Budria, Diaz-Serrano, Ferrer-i-Carbonell, and Hartog (2012) replicate Shaw (1996) for four different countries and find mixed evidence concerning the relationship between risk attitude and wage growth.

\subsection{CONCEPTUAL FRAMEWORK}

Conceptually, our starting point is the fact that young labour market participants tend to change jobs more frequently than older workers (Topel and Ward, 1992). Recent empirical evidence suggests that younger individuals are initially unsure about their skills and abilities and experiment with jobs to learn about them (Antonovics and Golan, 2012). The explanation for this behaviour was proposed by Johnson (1978) in his theoretical model of 'job-shopping' behaviour. Following Johnson's (1978) 'experience good' approach, we assume that quality of any given job match is not known ex ante and that the external flow of job offers is indepen- 
dent of searching. ${ }^{3}$ The distribution of this flow is constant and it is the same for all people independent of their risk attitude. We also assume that match quality in a specific job is unrelated to risk attitudes. ${ }^{4}$

To change jobs, workers need to incur costs while benefits are not certain. Costs include loss of fringe benefits or pension claims acquired on the current job but also include costs of adaption to a new living environment (van den Berg, 1992). The benefits of a new job are uncertain because of incomplete contracts, as it is impossible to fully specify employment conditions (Grossman and Hart, 1981; Bull, 1987). Changing jobs is a risky decision because workers have to incur costs with out being fully certain about the the benefits of the new job. In the expected utility framework this implies that risk averse individuals demand higher compensation for the risk associated with a job change, than more risk tolerant individuals do.

If we disregard non-monetary aspects of employment compensation, ${ }^{5}$ workers will voluntarily change their job only if they receive a job offer which exceeds a specific monetary threshold. We argue that this threshold is higher for risk averse individuals compared to risk tolerant individuals, because job change is a risky decision. Risk averse individuals will switch jobs only if offered a wage which is higher than their current wage but also higher than the wage which would induce more risk tolerant but otherwise similar individuals to change their jobs.

Given that all other conditions are equal, including the distribution of external wage offers, the proposition that risk averse individuals demand higher monetary compensation for the same risk associated with a job change generates two empirical predictions. First, risk tolerant individuals change jobs more frequently relative to more risk averse individuals. Second, job changes of risk averse individuals are associated with larger wage increases than for more risk tolerant individuals. These predictions are schematically illustrated in Figure 5.1. The solid line shows the wage growth pattern associated with job changes of a risk tolerant individual. ${ }^{6}$ Each 'step' is a wage increase due to a job change. The different pattern of wage

\footnotetext{
${ }^{3}$ In fact, this framework can be extended by the fact that job search is costly. Since costs of job search cannot perfectly predict the next job match, risk averse individuals would be less likely to start searching while on the job.

${ }^{4}$ In the empirical analysis, we control for a range of observable factors, conditional on which the assumption of exogeneity of a particular job match quality to risk attitudes is likely to hold.

${ }^{5}$ For simplicity, we assume that the value of a new job is solely reflected in wage compensation. However, other factors, such as an opportunity to gain better information about one's skills, as well as other forms of non-monetary compensation, can also affect a worker's decision to change a job.

${ }^{6}$ For simplicity, we do not show wage growth during current employment in this figure. We also disregard the possibility that, because job changes can occur for other reasons than monetary gains, not each job change will empirically be associated with a wage increase.
} 
growth associated with job changes of a risk averse individual is shown by the dashed line.

Figure 5.1: Expected relationship between risk attitude and wage growth depending on job changing behaviour

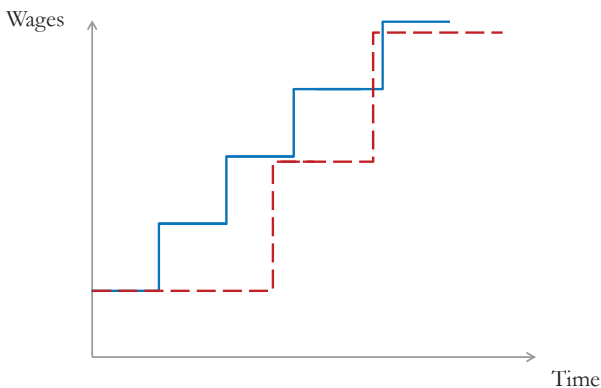

Note: Job changes are associated with wage increases for risk averse as well as for risk tolerant individuals. Risk tolerant individuals (solid line) make more job changes and experience lower wage increases relative to risk averse individuals (dashed line), who make less job changes with higher associated wage increases.

\subsection{EMPIRICAL APPROACH}

\subsubsection{EMPIRICAL STRATEGY}

We use the following specification to estimate the effect of risk attitude on the total number of job changes of labour market entrants.

$$
\text { Jobchange }_{i}=\alpha_{0}+\alpha_{1} \text { Riskattitude }_{i}+\delta \mathbf{X}_{i}+\mu_{i}
$$

where $J_{\text {obchange }}$ is the total number of job changes that an individual $i$ makes in the first few years of employment, Riskattitude $e_{i}$ measures individual $i$ 's risk attitude in occupational matters, with higher values reflecting more risk toler- 
ance. $\mathbf{X}_{i}$ includes control variables capturing demographic characteristics, socioeconomic characteristics and business cycle effects.

We focus on voluntary job changes, i.e., job changes that are initiated by the worker. Following the literature, such as Perez and Sanz (2005); Pavlopoulos, Fouarge, Muffels, and Vermunt (forthcoming), we distinguish voluntary changes from changes for other reasons using the unemployment duration workers experience between jobs. We consider a job change as voluntary if individuals did not have a break longer than six months between employments. It could be argued that the ex-ante risk of unemployment is part of the risk that workers face when they make a job change. ${ }^{7}$ By focusing on the workers with only short breaks in employment, we might be underestimating the effect of risk attitude on total number of job changes. Furthermore, since we control for initial sorting factors, we can regard job changes resulting from, for example, fixed contracts if not necessarily voluntary in the strict sense but as foreseeable from the standpoint of workers.

Individuals who experience a better matched entry job in terms of productivity and preferences are less likely to switch jobs than individuals with a worse match. To hold the initial job match quality constant, we use various measures that capture match quality of the first job. These include measures for workers' job satisfaction, indicators for whether the task that workers perform matches their qualification and whether the worker is on apprenticeship or on-the-job training. To control for external factors which can affect job opportunities and hence the probability of finding a good initial job match, we include year fixed effects, indicators for residing in West Germany (in 1989) and for German nationality.

We estimate equation (5.1) using ordinary least squares regression (OLS). Factors other than those listed in equation (5.1) may affect the number of job changes that labour market entrants make. However, as long as these factors are not correlated with risk attitude, OLS regression gives a consistent estimate for the effect of risk attitude on job mobility. The number of job changes that workers in general and labour market entrants in particular make in Germany is low compared to the US and the UK. Dustmann and Pereira (2008) attribute this to the higher costs of firing and the substantial job entry screening by employers. As a robustness check in section 5.6, we estimate a an ordered logit to reflect the discrete nature of job changes in Germany. ${ }^{8}$ We also performed a negative binomial model estimation,

\footnotetext{
${ }^{7}$ Unemployment risk ex-post, i.e. in case the following match turns out to be of a lower productivity than expected, is a relevant dimension of the risk a worker faces when s/he decides to change jobs. In the current set-up this part of the risk is neglected.

${ }^{8}$ See section 5.4 .2 for details on variable measurement.
} 
because the count data model is better fit for the dependent variable. The results are very similar to our preferred OLS estimates. ${ }^{9}$

We use the following specification to estimate the effect of job mobility on wage growth. In order to capture heterogeneous effect with respect to risk attitude, we interact job mobility and risk attitude in the equation:

$$
\begin{gathered}
\text { Wagegrowth }_{i}=\beta_{0}+\beta_{1} \text { Jobchange }_{i}+\beta_{2} \text { Riskattitude }_{i} \\
+\beta_{3} \text { Jobchange }_{i} * \text { Riskattitude }_{i}+\gamma \mathbf{X}_{i}+\epsilon_{i}
\end{gathered}
$$

where Wagegrowth $h_{i}$ is defined as the difference between the log real wage after several years in the labour market and the log real wage at labour market entry. Jobchange $_{i}$, Riskattitude $_{i}$ and $\mathbf{X}_{i}$ are defined as in equation (5.1). While equation (5.1) shows the relationship between risk attitude and job changes, we examine how this relationship translates into wage growth using equation (5.2).

We draw two predictions on the sign of the coefficients on the variables of interest from equation (5.1) and (5.2) based on the ideas discussed in section 5.3. The risks associated with a job change imply that risk averse individuals change jobs less often compared to risk-tolerant workers, given the same productivity match and an independent flow of wage offers. That is, the least squares estimate of $\alpha_{1}$ in equation (5.1) is predicted to be positive. Similarly, when risk averse workers change jobs, they require higher wage compensation compared to risk tolerant workers. Holding the number of job changes constant, the difference between final and initial log real wages is expected to be larger for risk averse than for more risk-tolerant workers. Hence, the least squares estimate of $\beta_{3}$ in equation (5.2) is expected to be negative.

Previous studies find that individuals with high risk tolerance invest more in human capital (Brown and Taylor, 2005; Budria, Diaz-Serrano, Ferrer-i-Carbonell, and Hartog, 2012), sort into occupation with high earning variance (Bonin et al. 2007; Chapter 3 of this dissertation) and become self-employed (see Chapter 4 of this dissertation), whereas risk averse individuals sort into public sector employment (Bellante and Link, 1981; Pfeifer, 2010). The least squares estimates of the risk attitude effect in equation (5.1) and (5.2) can be biased if initial sorting is ignored. We capture differences in educational choice using an indicator for upper secondary school leaving certificate, known as Abitur in Germany, and an indicator for university degree. We also use occupation fixed effects and occupation-specific earnings variance to control for occupational sorting. In addition, we check the

\footnotetext{
${ }^{9}$ The negative binomial regression does not converge when the extensive set of control variables is included.
} 
robustness of the estimation results by restricting the sample to labour market entrants who started their career as dependent workers in the private sector.

\subsubsection{DATA}

The German Socio-Economic Panel Study (SOEP) is a representative household panel survey. Individuals and households in the SOEP are followed since $1986 .{ }^{10}$ Our research question pertains to early career job mobility. Hence, we restrict the sample to individuals who enter the labour market when they are already in the SOEP since 1998. To focus on a homogeneous group of young labour market entrants, we confine our sample to individuals who are between 17 and 35 years of age in their entrance year, and who do not have gaps in employment of more than six months during the first seven consecutive years of labour market experience. ${ }^{11}$ There is no widely accepted definition of how many years the labour market experience of entrants is considered to be the 'early career'. For example, Light and McGarry (1998) study early career job mobility in the US during the first two, four, and eight years of labour market experience. Since job mobility is lower in Germany than in the US, we use the seven years definition in order to accumulate a sufficient number of job changes and to maintain an adequate number of observations for the analysis. ${ }^{12}$ In Table 5.B (Appendix) job change frequencies for the selected years of experience are displayed.

The dependent variable in our first equation is the total number of job changes during the first seven years of employment. This variable is constructed using the job change variable, which is equal to one if the respondent has started a new job since the last interview or in the previous year. ${ }^{13}$ The dependent variable in our second equation is the percentage wage growth during the first seven years of labour market experience. It is measured as the log real wage difference between the first job on and the job after seven years of consecutive employment. The sample distributions of the main variables is shown in Table 5.1. ${ }^{14}$

The main explanatory variable is willingness to take risks in occupational matters. This variable is measured on a scale from zero to ten, in which higher values reflect greater willingness to take risks. The exact wording of the question,

\footnotetext{
${ }^{10}$ For the details on the SOEP data see Wagner, Frick, and Schupp (2007).

${ }^{11}$ Table 5.A in the Appendix describes step by step the procedure of sample selection and reasons for deletion of observations.

${ }^{12}$ In section 5.6, we test sensitivity of our findings using alternative definitions of early career.

${ }^{13}$ The variable is constructed to provide longitudinal consistency (DIW, 2010).

${ }^{14}$ We have conducted additional estimations using the mean wage growth over the first years of employment. Results are qualitatively similar and are available on request.
} 
Table 5.1: Descriptive statistics

\begin{tabular}{|c|c|c|c|c|}
\hline Variable & Mean & $\mathrm{SD}^{1}$ & Min & Max \\
\hline Share of individuals changing jobs & 0.57 & 0.50 & 0 & 1 \\
\hline Number of job changes (at least 1 ) & 1.40 & 0.65 & 1 & 4 \\
\hline Wage growth (percentage) & 0.78 & 0.64 & -1.37 & 2.88 \\
\hline Wage growth (absolute) & 1110.85 & 908.56 & -1658.18 & 4040.49 \\
\hline Risk attitude & 4.60 & 2.33 & 0 & 10 \\
\hline 1 if Male & 0.49 & 0.50 & 0 & 1 \\
\hline Age at first employment & 22.61 & 5.08 & 17 & 35 \\
\hline 1 if has Abitur & 0.45 & 0.50 & 0 & 1 \\
\hline Education degree $^{2}$ & 1.17 & 0.62 & 0 & 2 \\
\hline Log of initial wage & 6.81 & 0.85 & 4.06 & 8.76 \\
\hline 1 if has German nationality & 0.86 & 0.35 & 0 & 1 \\
\hline 1 if Originates from West Germany & 0.73 & 0.44 & 0 & 1 \\
\hline Initial job satisfaction & 7.73 & 1.74 & 3 & 10 \\
\hline Initial wage variance in occupation & 0.35 & 0.06 & 0.22 & 0.60 \\
\hline 1 if not Trained for the occupation & 0.08 & 0.27 & 0 & 1 \\
\hline 1 if in Apprenticeship or training & 0.53 & 0.50 & 0 & 1 \\
\hline
\end{tabular}

Source: SOEP. Sample: labour market entrants.

Notes: The descriptive statistics are presented for the main estimation sample.

$1 \mathrm{SD}$ is standard deviation.

2 Education degree is equal to 0 if individual's education is at a basic level, it is equal to 1 in case of intermediate education, and it is equal to 2 in case higher education was completed.

translated from German reads: "People can behave differently in different situations. How would you rate your willingness to take risks in the following areas. How is it in your occupation? Please give me a number from 0 to 10 , where the value 0 means: 'Risk averse' and the value 10 means: 'Fully prepared to take risks'. You can use the values in between to make your estimate." Dohmen, Falk, Huffman, Sunde, Schupp, and Wagner (2011) have shown that this question is significantly related to paid lottery choices, and it explains behaviour in a range of important real life decision domains.

\subsection{Results}

\subsubsection{Risk ATTITUDES AND JOB CHANGES}

First, we analyse whether individuals who are more willing to take risks are more likely to change jobs during the first years on the labour market. The results of an OLS estimation, in which the dependent variable is the total number of job changes during the first seven years on the labour market, are presented in 
Table 5.2. ${ }^{15}$ In column (1), simple correlation between individual willingness to take risks and the number of job changes is displayed. In the following columns, sets of variables are added to control for basic demographic and socio-economic characteristics, business cycle effects, initial occupational sorting and initial job match quality. The coefficient on risk attitude remains positive and significant irrespective of the specification. This result is in line with the empirical prediction from section 5.3, supporting the proposition that risk averse individuals are less likely to switch jobs.

Interpreting the effect of risk attitude from column (4), one standard deviation increase in willingness to take risks in occupational matters increases the probability of the next job change by approximately $20 \%$. This effect is about one third of the Abitur effect. Higher education has a positive effect on job mobility of graduates because it provides them with a broader set of skills, which increases the range of job opportunities compared to intermediate education. Higher initial wage has a significant negative effect on the total number of job changes in the first years of the labour market. This is consistent with the prediction of the 'experience good' model (Johnson, 1978; Jovanovic, 1979b) according to which workers change jobs when the value of an outside offer is higher than the value of the current productivity match. It is less likely to receive a higher wage offer relative to the current wage if the initial draw is from the higher end of the wage distribution. Initial job satisfaction, as an indicator of job match quality, has an expected negative effect on the number of job changes, however the coefficient is not significant.

An intriguing question to study in more detail would be to analyse to which extent risk attitude matters for job changes across occupations (i.e. to a different occupation than the initial one) as compared to job changes within occupation. Given the sample size, it is not possible to analyse different kinds of job changes separately. However, adding fixed effects of the first occupation (on one-digit ISCO-88 $\operatorname{code}^{16}$ ) does not affect the estimated coefficients, which means that risk attitude matters for changes within as well as across occupations.

Earnings variance in the initial occupation, which has been shown to attract individuals with higher tolerance for taking risks, ${ }^{17}$ has a positive but insignificant effect on the total number of job changes. This is consistent with the idea that because more risk-tolerant individuals sort into more risky jobs, they also would

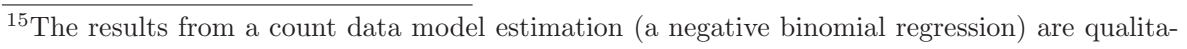
tively similar.

${ }^{16}$ ISCO stands for International Standard Classification of Occupations (edition of 1988).

${ }^{17}$ See, for example, Fouarge, Kriechel, and Dohmen (2012); Chapter 3 of this dissertation.
} 
Table 5.2: Risk attitudes and the total number of job changes

\begin{tabular}{|c|c|c|c|c|}
\hline & (1) & $(2)$ & (3) & $(4)$ \\
\hline Willingness to take risks & $\begin{array}{l}0.063^{* *} \\
(0.025)\end{array}$ & $\begin{array}{l}0.085^{* * *} \\
(0.027)\end{array}$ & $\begin{array}{l}0.080^{* * *} \\
(0.027)\end{array}$ & $\begin{array}{l}0.084^{* * *} \\
(0.027)\end{array}$ \\
\hline 1 if Male & & $\begin{array}{c}-0.158 \\
(0.120)\end{array}$ & $\begin{array}{c}-0.147 \\
(0.121)\end{array}$ & $\begin{array}{c}-0.171 \\
(0.155)\end{array}$ \\
\hline Age at first employment & & $\begin{array}{r}-0.011 \\
(0.020)\end{array}$ & $\begin{array}{r}-0.025 \\
(0.022)\end{array}$ & $\begin{array}{r}-0.023 \\
(0.024)\end{array}$ \\
\hline 1 if has Abitur & & $\begin{array}{l}0.689^{* * *} \\
(0.161)\end{array}$ & $\begin{array}{c}0.633^{* * *} \\
(0.160)\end{array}$ & $\begin{array}{l}0.605^{* * *} \\
(0.164)\end{array}$ \\
\hline 1 if Education is low or missing & & $\begin{array}{c}-0.124 \\
(0.246)\end{array}$ & $\begin{array}{r}-0.041 \\
(0.245)\end{array}$ & $\begin{array}{c}-0.026 \\
(0.250)\end{array}$ \\
\hline 1 if Intermediate education & & $\begin{array}{c}0.125 \\
(0.172)\end{array}$ & $\begin{array}{c}0.214 \\
(0.172)\end{array}$ & $\begin{array}{c}0.248 \\
(0.161)\end{array}$ \\
\hline Log of initial wage & & $\begin{array}{r}-0.231^{*} \\
(0.119)\end{array}$ & $\begin{array}{c}-0.276^{* *} \\
(0.137)\end{array}$ & $\begin{array}{c}-0.356^{* *} \\
(0.141)\end{array}$ \\
\hline 1 if German nationality & & $\begin{array}{r}-0.043 \\
(0.166)\end{array}$ & $\begin{array}{c}-0.041 \\
(0.173)\end{array}$ & $\begin{array}{c}-0.123 \\
(0.174)\end{array}$ \\
\hline 1 if Originates from West Germany & & $\begin{array}{c}0.084 \\
(0.125)\end{array}$ & $\begin{array}{c}0.121 \\
(0.127)\end{array}$ & $\begin{array}{c}0.166 \\
(0.135)\end{array}$ \\
\hline Initial job satisfaction & & & $\begin{array}{r}-0.030 \\
(0.039)\end{array}$ & $\begin{array}{r}-0.039 \\
(0.041)\end{array}$ \\
\hline 1 if not Trained for the occupation & & & $\begin{array}{r}-0.190 \\
(0.218)\end{array}$ & $\begin{array}{r}-0.112 \\
(0.234)\end{array}$ \\
\hline Initial wage variance in occupation & & & $\begin{array}{c}1.729 \\
(1.075)\end{array}$ & $\begin{array}{c}0.821 \\
(1.242)\end{array}$ \\
\hline 1 if in Apprenticeship or training & & & $\begin{array}{r}-0.275 \\
(0.169)\end{array}$ & $\begin{array}{c}-0.290^{*} \\
(0.168)\end{array}$ \\
\hline Constant & $\begin{array}{l}0.477^{* * *} \\
(0.117)\end{array}$ & $\begin{array}{l}2.258^{* * *} \\
(0.740)\end{array}$ & $\begin{array}{c}2.600^{* *} \\
(1.008)\end{array}$ & $\begin{array}{l}3.482^{* * *} \\
(1.074)\end{array}$ \\
\hline Year fixed effects & No & Yes & Yes & Yes \\
\hline Occupation fixed effects & No & No & No & Yes \\
\hline $\mathrm{R}^{2}$ & 0.033 & 0.283 & 0.309 & 0.379 \\
\hline Sample & 173 & 173 & 173 & 173 \\
\hline
\end{tabular}

Source: SOEP. Sample: labour market entrants. Dependent variable: total number of job changes during the first seven years of experience on the labour market.

Notes: Estimation: OLS. Robust standard errors are in parentheses. ${ }^{* *},{ }^{* *},{ }^{*}$ denote significance at the 0.01 , 0.05 , and 0.10 levels.

foresee more frequent job changes as a result of choosing a particular occupation. In that sense, even if not all job changes captured by our measure are voluntary in the strict sense, they were foreseen by labour market entrants at the moment of making their occupational choice.

In this analysis, we assume that risk attitudes are stable over time. Several recent studies support this assumption, providing empirical evidence which suggests that although some variation is possible, there are no systematic shifts related to any other demographic characteristic than age (e.g. Harrison, Johnson, McInnes, 
and Rutström, 2005; Sahm, 2012; Andersen, Harrison, Lau, and Rutström, 2008; Baucells and Villasís, 2009; Reynaud and Couture, 2012). Additionally, using the full SOEP sample, we correlated risk attitudes (in occupational matters) measured in 2004 with risk attitudes measured in 2009 (the last years in which this measure is available): the correlation coefficient was .47. We also correlated willingness to take risks (in general) as measured in 2004 with the same measure taken in 2011: the correlation coefficient was again .47. The median of the change of each of the measures was zero, suggesting that even if there might be some random noise around the risk attitude measure, on average it remains stable over time. Using a structured approached to testing stability of economic preferences, Salamanca (2014), using the SOEP data, found that after accounting for individual characteristics, the correlation coefficient between measures taken in different years was above .9. This evidence supports the assumption of the stability of risk attitudes, at least within the relatively short time horizon relevant for this study.

\subsubsection{Risk ATtitude, Job MOBility AND WAGE GROWTH}

Given the robust positive association between risk attitudes and the number of job changes among labour market entrants, we examine the subsequent effect on wage growth in the second step. In this section, we specifically analyse the heterogeneity of the relationship between job mobility and wage growth with respect to individuals' attitude towards risk. Table 5.3 presents estimation results from OLS regressions in which wage growth is the dependent variable.

Column (1) shows the correlation between the number of job changes and the mean wage growth that workers experience during the first seven years in the labour market. In columns (2) and (3), risk attitude and control variables capturing demographic characteristics, socio-economic characteristics and business cycle effects are added. The total number of job changes workers experience during the first seven years in the labour market is associated with higher mean wage growth. However, the positive correlation between job mobility and wage growth declines both in magnitude and significance once we take into account risk attitudes. This result is an indication of a modifying effect of risk attitudes on the relationship between job changes and wage growth. In columns (4) to (6) we, therefore, interact the number of job changes with risk attitudes. These specifications allow to estimate the heterogeneous effect of job mobility on wage growth depending on risk attitude. The monetary and non-monetary risks associated with a job change are evaluated differently depending on workers' willingness to take risk. To make 
Table 5.3: Risk attitudes, total number of job changes and total wage growth

\begin{tabular}{|c|c|c|c|c|c|c|}
\hline & (1) & (2) & (3) & (4) & (5) & (6) \\
\hline Total job changes & $\begin{array}{c}0.159^{* *} \\
(0.068)\end{array}$ & $\begin{array}{c}0.103^{* *} \\
(0.046)\end{array}$ & $\begin{array}{l}0.076^{*} \\
(0.045)\end{array}$ & $\begin{array}{l}0.335^{* * *} \\
(0.112)\end{array}$ & $\begin{array}{l}0.306^{* * *} \\
(0.102)\end{array}$ & $\begin{array}{l}0.281^{* * *} \\
(0.100)\end{array}$ \\
\hline Risk attitude & & & $\begin{array}{l}0.040^{* *} \\
(0.015)\end{array}$ & $\begin{array}{l}0.074^{* * *} \\
(0.023)\end{array}$ & $\begin{array}{l}0.063^{* * *} \\
(0.020)\end{array}$ & $\begin{array}{l}0.062^{* * *} \\
(0.020)\end{array}$ \\
\hline Job changes*Risk attitude & & & & $\begin{array}{c}-0.050^{* * *} \\
(0.018)\end{array}$ & $\begin{array}{c}-0.039^{* *} \\
(0.017)\end{array}$ & $\begin{array}{c}-0.037^{* *} \\
(0.016)\end{array}$ \\
\hline 1 if Male & & $\begin{array}{l}0.200^{* * *} \\
(0.067)\end{array}$ & $\begin{array}{l}0.170^{* *} \\
(0.068)\end{array}$ & $\begin{array}{l}0.167^{* * *} \\
(0.063)\end{array}$ & $\begin{array}{c}0.156^{* *} \\
(0.061)\end{array}$ & $\begin{array}{c}0.127^{*} \\
(0.073)\end{array}$ \\
\hline Age at first employment & & $\begin{array}{c}-0.034^{* *} \\
(0.014)\end{array}$ & $\begin{array}{c}-0.030^{* *} \\
(0.014)\end{array}$ & $\begin{array}{c}-0.029^{* *} \\
(0.014)\end{array}$ & $\begin{array}{c}-0.004 \\
(0.014)\end{array}$ & $\begin{array}{c}0.003 \\
(0.014)\end{array}$ \\
\hline Log of initial wage & & $\begin{array}{c}-0.518^{* * *} \\
(0.093)\end{array}$ & $\begin{array}{c}-0.564^{* * *} \\
(0.087)\end{array}$ & $\begin{array}{c}-0.557^{* * *} \\
(0.081)\end{array}$ & $\begin{array}{c}-0.557^{* * *} \\
(0.072)\end{array}$ & $\begin{array}{c}-0.539^{* * *} \\
(0.065)\end{array}$ \\
\hline 1 if West Germany origin & & $\begin{array}{c}0.102 \\
(0.072)\end{array}$ & $\begin{array}{c}0.111 \\
(0.071)\end{array}$ & $\begin{array}{c}0.078 \\
(0.072)\end{array}$ & $\begin{array}{c}0.021 \\
(0.070)\end{array}$ & $\begin{array}{c}0.016 \\
(0.074)\end{array}$ \\
\hline 1 if German nationality & & $\begin{array}{r}-0.121 \\
(0.096)\end{array}$ & $\begin{array}{r}-0.140 \\
(0.095)\end{array}$ & $\begin{array}{r}-0.143 \\
(0.092)\end{array}$ & $\begin{array}{c}-0.155^{*} \\
(0.087)\end{array}$ & $\begin{array}{c}-0.188^{* *} \\
(0.088)\end{array}$ \\
\hline 1 if has Abitur & & $\begin{array}{c}0.150 \\
(0.107)\end{array}$ & $\begin{array}{c}0.163 \\
(0.107)\end{array}$ & $\begin{array}{c}0.163 \\
(0.109)\end{array}$ & $\begin{array}{c}0.196^{*} \\
(0.107)\end{array}$ & $\begin{array}{c}0.218^{* *} \\
(0.110)\end{array}$ \\
\hline 1 if Low education & & $\begin{array}{c}-0.273^{* *} \\
(0.138)\end{array}$ & $\begin{array}{c}-0.315^{* *} \\
(0.135)\end{array}$ & $\begin{array}{r}-0.278^{*} \\
(0.142)\end{array}$ & $\begin{array}{c}-0.244^{* *} \\
(0.108)\end{array}$ & $\begin{array}{c}-0.267^{* *} \\
(0.103)\end{array}$ \\
\hline 1 if Intermediate education & & $\begin{array}{c}0.117 \\
(0.118)\end{array}$ & $\begin{array}{c}0.125 \\
(0.117)\end{array}$ & $\begin{array}{c}0.124 \\
(0.111)\end{array}$ & $\begin{array}{c}0.125 \\
(0.106)\end{array}$ & $\begin{array}{c}0.045 \\
(0.110)\end{array}$ \\
\hline Initial job satisfaction & & & & & $\begin{array}{l}0.045^{* *} \\
(0.018)\end{array}$ & $\begin{array}{c}0.039^{*} \\
(0.018)\end{array}$ \\
\hline Initial wage variance in occ. & & & & & $\begin{array}{c}0.162 \\
(0.470)\end{array}$ & $\begin{array}{r}-0.211 \\
(0.582)\end{array}$ \\
\hline 1 if not Trained for the occ. & & & & & $\begin{array}{r}-0.018 \\
(0.140)\end{array}$ & $\begin{array}{c}-0.003 \\
(0.131)\end{array}$ \\
\hline 1 if in Training & & & & & $\begin{array}{l}0.428^{* * *} \\
(0.111)\end{array}$ & $\begin{array}{l}0.472^{* * *} \\
(0.110)\end{array}$ \\
\hline Constant & $\begin{array}{l}0.656^{* * *} \\
(0.062)\end{array}$ & $\begin{array}{l}4.886^{* * *} \\
(0.520)\end{array}$ & $\begin{array}{l}4.977^{* * *} \\
(0.500)\end{array}$ & $\begin{array}{l}4.924^{* * *} \\
(0.503)\end{array}$ & $\begin{array}{l}3.446^{* * *} \\
(0.554)\end{array}$ & $\begin{array}{l}4.094^{* * *} \\
(0.546)\end{array}$ \\
\hline Year Fixed Effects & No & Yes & Yes & Yes & Yes & Yes \\
\hline Occup. Fixed Effects & No & No & No & No & No & Yes \\
\hline R-squared & 0.041 & 0.588 & 0.606 & 0.647 & 0.716 & 0.739 \\
\hline Observations & 173 & 173 & 173 & 173 & 173 & 173 \\
\hline
\end{tabular}

Source: SOEP. Sample: labour market entrants. The dependent variable is wage growth during the first seven years of labour market experience and it is defined as the difference between final and entry log real wage.

Notes: Estimation: OLS. Robust standard errors are in parentheses. $* * *, * *, *$ denote significance at the 0.01 , 0.05 , and 0.10 levels.

a job change, risk averse workers demand higher wage compensation than more risk tolerant workers. Such a heterogeneous pattern is supported by the data. The interaction term between job changes and risk attitude is negative and significant, indicating that the wage increase associated with each job change is, on 
average, lower for risk tolerant individuals compared to risk averse individuals. ${ }^{18}$ The number of job changes that risk averse workers make is strongly associated with a positive mean wage growth. In terms of magnitude, each job change made by risk-averse workers during the first seven years into the labour market increases wage by about 28 percent relative to the labour market entry wage. On the other hand, for individuals with risk attitude at the median, each job change results in a 9.8 percent higher wage growth whereas it reduced mean wage growth by 1.2 percent for risk tolerant individuals. This pattern is illustrated in Figure 5.2.

Figure 5.2: Wage growth and job mobility profiles by risk attitude: out of sample prediction

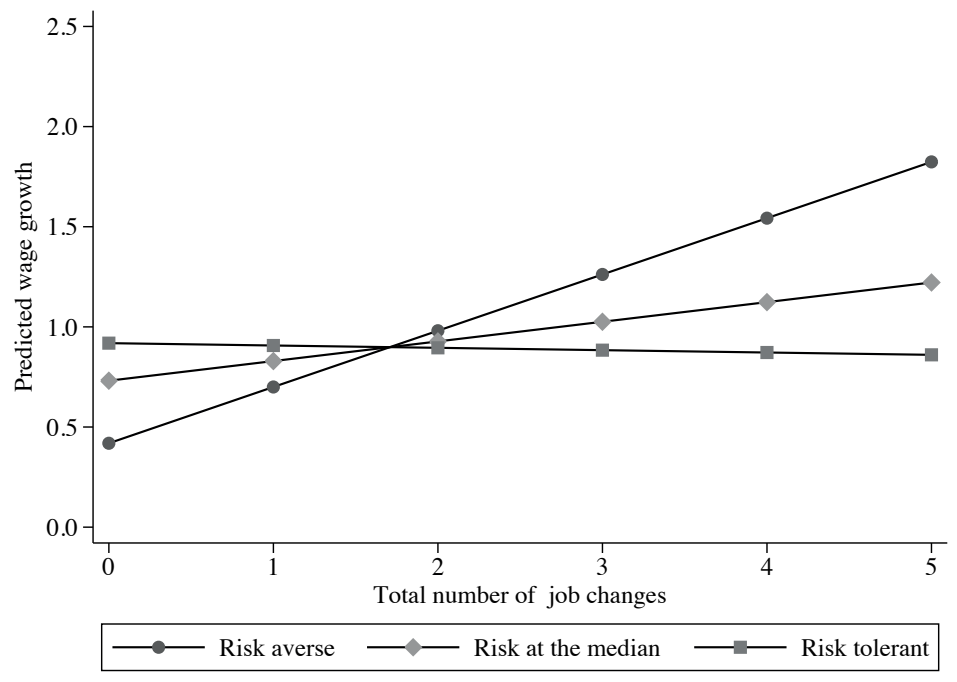

The relationship between the number of job changes and the predicted wage growth are shown separately for risk averse, risk attitude at the median and risk tolerant individuals. At zero job changes, risk averse individuals have lower predicted mean wage growth compared to individuals with risk attitude at the median and risk tolerant individuals. As individuals make more job changes, the relationship is reversed. The average wage growth increases with the total number of job changes for both risk averse and individuals with risk attitude at the median, al-

\footnotetext{
${ }^{18}$ For ease of interpretation, we use the 5 th, 50th and 90th percentiles of the risk attitude distribution to define risk averse workers, workers with risk attitude at the median and risk tolerant workers respectively. These corresponds to risk attitude values of zero, five and eight respectively on a scale from zero to ten.
} 
beit at a lower rate for the latter group. On the contrary, risk tolerant individuals experience a lower mean wage growth as they make more job changes.

\subsection{Robustness CHECKS}

Empirical findings suggest that risk-tolerant individuals are more likely to make risky choices. The risk associated with a job change and the subsequent wage growth are likely to differ between public sector and private sector employment on the one hand and self-employment and dependent employment on the other. In order to net out the initial sorting into different employment-types, in this section we further restrict the sample to labour market entrants who started their career as dependent workers in the private sector. In Table 5.4 the estimation results using this restricted sample are displayed. In Panel $\mathrm{A}$, the dependent variable is the number of job changes. In Panel B, the dependent variable is wage growth. The upshot of the estimates in Table 5.4 is that excluding initial sorting with respect to different employment-types does not significantly alter the results.

Our second robustness check concerns with the definition of early labour market experience. There is no widely accepted definition of how many years the labour market experience of entrants is considered to be 'early career'. Moreover, the number of job changes that workers experience in Germany is considerably lower compared to the US and the UK, where the majority of the studies investigating the effect of job mobility on wage come from. In our sample, labour market entrants change three jobs in the first six years of experience and it reaches five jobs after nine years in the labour market (see Table 5.B in the Appendix).

Table 5.5 presents the results of estimations across different definitions of early career job mobility ( 5 to 10 years of the early career working experience). The structure of the table is similar to Table 5.4, however each column corresponds to the sample constructed using a different number of years of labour market experience. The estimates reported in this table are qualitatively similar to the findings reported in the main results section. In Panel A, the association between risk attitude and the total number of job changes is positive. The positive effect of risk attitudes on the number of job changes is estimated imprecisely in the first five and six years of labour market experience, as columns (1) and (2) indicate. The effect of risk attitude increases in terms of magnitude and significance with the number of years workers stay employed. Panel B of Table 5.5 shows the subsequent 
Table 5.4: Robustness check accounting for initial sorting factors

\begin{tabular}{|c|c|c|c|}
\hline \multirow[b]{2}{*}{ Risk attitude } & (1) & $(2)$ & $(3)$ \\
\hline & $\begin{array}{l}0.082^{* * *} \\
(0.026)\end{array}$ & $\begin{array}{l}0.080^{* * *} \\
(0.026)\end{array}$ & $\begin{array}{l}0.086^{* * *} \\
(0.027)\end{array}$ \\
\hline Background characteristics & Yes & Yes & Yes \\
\hline Year fixed effects & Yes & Yes & Yes \\
\hline Job match indicators & No & Yes & Yes \\
\hline Occupation fixed effects & No & No & Yes \\
\hline $\mathrm{R}^{2}$ & 0.305 & 0.327 & 0.393 \\
\hline Observations & 163 & 163 & 163 \\
\hline \multicolumn{4}{|c|}{ Panel B. Dependent variable: wage growth } \\
\hline \multirow[b]{2}{*}{ Total number of job changes } & $(1)$ & $(2)$ & $(3)$ \\
\hline & $\begin{array}{c}0.295^{* *} \\
(0.117)\end{array}$ & $\begin{array}{l}0.254^{* *} \\
(0.112)\end{array}$ & $\begin{array}{c}0.231^{* *} \\
(0.103)\end{array}$ \\
\hline Risk attitude & $\begin{array}{l}0.073^{* * *} \\
(0.023)\end{array}$ & $\begin{array}{l}0.071^{* * *} \\
(0.022)\end{array}$ & $\begin{array}{l}0.054^{* * *} \\
(0.020)\end{array}$ \\
\hline Total job changes $*$ Risk attitude & $\begin{array}{c}-0.050^{* * *} \\
(0.019)\end{array}$ & $\begin{array}{c}-0.045^{* *} \\
(0.018)\end{array}$ & $\begin{array}{c}-0.031^{*} \\
(0.016)\end{array}$ \\
\hline Background characteristics & Yes & Yes & Yes \\
\hline Year fixed effects & Yes & Yes & Yes \\
\hline Job match indicators & No & Yes & Yes \\
\hline Occupation fixed effects & No & No & Yes \\
\hline $\mathrm{R}^{2}$ & 0.669 & 0.691 & 0.764 \\
\hline Observations & 163 & 163 & 163 \\
\hline
\end{tabular}

Source: SOEP. Sample: labour market entrants.

Notes: Estimation: OLS. Dependent variable: the number of job changes during the first seven years of labour market experience in Panel A; wage growth during the first seven years of labour market experience in Panel Bs. Robust standard errors are in parentheses. ${ }^{* *},{ }^{* *},{ }^{*}$ denote significance at the $0.01,0.05$, and 0.10 levels.

effect on wage growth for the samples constructed using a different number of years of labour market experience. The interaction effect of risk attitude and job changes on wage growth remains negative and significant in most cases.

As the next robustness check, we construct a categorical job change variable to reflect the discontinuous nature of job change behaviour in Germany. The variable is equal to zero if a worker made zero job changes during the first seven years of employment. The variable is equal to one if a worker made one job change. It is equal to two if a worker made two of more job changes. Column (1) of Table 5.6 shows the estimation result from an ordered logit model using the categorical job change as a dependent variable. The effect of risk attitude on job mobility remains significant at an one percent significance level. The estimated odds ratio on risk attitude is greater than one indicating that as risk attitude increases, the odds 
Table 5.5: Robustness check using different years of experience

\begin{tabular}{|c|c|c|c|c|c|c|}
\hline & $(1)$ & $(2)$ & $(3)$ & $(4)$ & $(5)$ & (6) \\
\hline & 5 Years & 6 Years & 7 Years & 8 Years & 9 Years & 10 Years \\
\hline \multirow[t]{2}{*}{ Risk attitude } & 0.018 & 0.039 & $0.084^{* * *}$ & $0.085^{* * *}$ & $0.087^{* *}$ & $0.142^{* *}$ \\
\hline & $(0.020)$ & $(0.025)$ & $(0.027)$ & $(0.032)$ & $(0.042)$ & $(0.054)$ \\
\hline $\mathrm{R}^{2}$ & 0.211 & 0.237 & 0.379 & 0.429 & 0.497 & 0.518 \\
\hline Observations & 248 & 207 & 173 & 137 & 102 & 74 \\
\hline \multicolumn{7}{|c|}{ Panel B. Dependent variable: wage growth } \\
\hline & $(1)$ & $(2)$ & $(3)$ & $(4)$ & $(5)$ & (6) \\
\hline & 5 Years & 6 Years & 7 Years & 8 Years & 9 Years & 10 Years \\
\hline \multirow[t]{2}{*}{ Job changes $^{1}$} & $0.272^{* * *}$ & $0.268^{* * *}$ & $0.281^{* * *}$ & $0.161^{*}$ & $0.219^{*}$ & $0.349^{* *}$ \\
\hline & $(0.077)$ & $(0.079)$ & $(0.100)$ & $(0.086)$ & $(0.113)$ & $(0.141)$ \\
\hline \multirow[t]{2}{*}{ Risk attitude } & $0.053^{* * *}$ & $0.059^{* * *}$ & $0.062^{* * *}$ & $0.060^{* * *}$ & $0.098^{* * *}$ & $0.085^{* *}$ \\
\hline & $(0.015)$ & $(0.017)$ & $(0.020)$ & $(0.020)$ & $(0.029)$ & $(0.038)$ \\
\hline \multirow[t]{2}{*}{ Job ch. ${ }^{*}$ Risk $^{2}$} & $-0.036^{* *}$ & $-0.041^{* * *}$ & $-0.037^{* *}$ & -0.016 & -0.032 & $-0.046^{*}$ \\
\hline & $(0.014)$ & $(0.012)$ & $(0.016)$ & $(0.015)$ & $(0.023)$ & $(0.027)$ \\
\hline $\mathrm{R}^{2}$ & 0.633 & 0.644 & 0.606 & 0.772 & 0.762 & 0.780 \\
\hline Observations & 248 & 207 & 173 & 137 & 102 & 74 \\
\hline
\end{tabular}

Source: SOEP. Sample: labour market entrants.

Notes: Estimation: OLS. Dependent variable: the number of job changes during the first years of labour market experience indicated in the header of each column in the top panel; wage growth during the first years of labour market experience indicated in the header of each column in the bottom panel. All specifications include controls for background characteristics, job match indicators, business cycle effects and occupational fixed effects. Robust standard errors are in parentheses. ${ }^{* * *}, * *, *$ denote significance at the $0.01,0.05$, and 0.10 levels.

${ }^{1}$ Total number of job changes made during the number of years as shown in the column.

${ }^{2}$ Interaction term between risk attitude and the total number of job changes.

to make a job change increases. Specifically, a one unit change in risk attitudes increases the odds of two or more job changes as compared to one or no job change by 0.25 . In column (2) of Table 5.6, the least squares estimation of the wage growth model are shown. The effect of job changes on wage remains positive for risk averse workers and it increases as they make more job changes. The interaction between risk attitudes and job changes remains negative when job change is measured as a discrete variable, although the effect is estimated imprecisely for two or more job changes.

\subsection{Conclusion}

In this paper, we argue that risk attitudes is an important factor that influences job mobility decisions and generates heterogeneous wage growth patterns. Job change is a risky decision which entails significant costs while benefits (in terms of 
Table 5.6: Robustness check using a categorical job change variable

\begin{tabular}{lcc}
\hline Dependent variable & Job mobility & Wage growth \\
\hline & $(1)$ & $(2)$ \\
Risk attitude & $1.251^{* * *}$ & $0.076^{* * *}$ \\
& $(0.103)$ & $(0.023)$ \\
One job change & & $0.395^{* *}$ \\
& & $(0.152)$ \\
Two or more job changes & & $0.480^{* *}$ \\
& & $(0.239)$ \\
One job change $*$ Risk attitude & & $-0.069^{* *}$ \\
Two or more job changes $*$ Risk attitude & & $(0.029)$ \\
Constant 1 & & -0.066 \\
Constant 2 & -5.820 & $(0.041)$ \\
Year fixed effects & $(3.234)$ & 173 \\
Occupation fixed effects & -3.362 & Yrdered logit \\
\hline Model & 173 & Yes \\
\hline
\end{tabular}

Source: SOEP. Sample: labour market entrants.

Notes: Estimation: column (1) Ordered logit; column (2) OLS. Dependent variable: in column (1): a categorical variable equal to 0 if there were no job changes, equal to 1 if there was one change, and equal to 2 if the total number of job changes during the first seven years of experience on the labour market is more than one; in column (2): the wage growth during the first seven years of labour market experience. Robust standard errors are in parentheses. $* * *, * *, *$ denote significance at the $0.01,0.05$, and 0.10 levels.

the conditions of another employment) cannot be entirely foreseen. Based on our conceptual framework we test two hypotheses: First, more risk averse individuals are less likely to change jobs than more risk tolerant individuals, all other conditions equal. And second, the wage increase associated with each job change for the risk averse individuals is larger than for risk tolerant individuals since a risk averse individual demands more compensation associated with a risky job change. These two hypotheses are supported by our empirical findings: Risk tolerant individuals are more likely to switch jobs and their subsequent wage growth is lower in magnitude than wage growth of risk averse individuals, given the same number of job changes.

We test the sensitivity of our findings in a number of robustness checks. Namely, we address sample heterogeneity and sample composition in more detail and analyse whether a more robust specification of the job mobility variable 
can affect our findings. There are, however, some reasons why the results should be interpreted with caution. One concern is the low number of observations. This follows from the sample restrictions that we impose to have a sufficiently long observation period (of consecutive employment) for each individual and a reasonably homogeneous sample. For the future, we consider using an alternative data set to check the external validity of our results. With a larger data set we also intend to investigate the effect of risk attitudes on job mobility and wage growth with respect to different levels of education. Second, although we control for all factors which we suspect to drive initial sorting we do not have exogenous variation in job changes. The causal link between risk attitudes, job mobility and subsequent wage growth could be estimated by exploiting a policy change.

Our measure of job changes may not comprise all the risks inherent to job changes. In particular, some job changes in our sample might have been job changes within the same enterprise, which entails significantly less uncertainty than job change to another employer. We also cannot account for the aspects of non-monetary compensation at the new job. Non-monetary compensation of another employment increases uncertainty even further because it is even more difficult to fully specify in a contract. Since there are aspects of uncertainty that our job mobility measure does not capture, our estimates of the effect of risk attitudes on job mobility and the subsequent wage growth can be considered as lower bound.

The analysis performed in this paper is motivated by the 'experience good' model of job mobility, according to which an external flow of job offers is assumed independently of workers' characteristics. However, search on-the-job is costly, which would reduce willingness of risk-averse individuals to search for alternative employment. From this perspective, the 'search good' model would generate a similar prediction on the effect of risk attitudes on job mobility decisions and the subsequent wage growth. Our conceptual framework could be extended by including the fact that individuals can search on-the-job. Our analysis contributes to two previously distinct fields in the literature. On the one hand, our results shed some light on the contradictory findings in the literature concerned with the effects of job mobility on wage growth during the early career. On the other hand, we extend the empirical evidence on the effect of risk attitudes on labour market outcomes. To our knowledge, we are the first to document a robust correlation between willingness to take risks and the number of job changes. 
5 Job mobility during the early career

\section{Appendix}

Table 5.A: Sample selection procedure

\begin{aligned} & \hline Respondents Sample selection steps \\ &-42538 SOEP sample starting from 1998 \\ & 2813 selecting the sample of labour market entrants \\ &-32 keeping labour market entrants between 17 and 35 years of age \\ & 2781 \\ &-650 measure of willingness to take risk unavailable \\ & 2131 \\ &-13 missing wage information \\ & 2118 \\ &-304 no gaps in employment (yearly) \\ & 1814 \\ &-831 no gaps in employment (no longer than six months unemployed) \\ & 983 \\ &-790 at least seven years of employment \\ & 193 \\ &-20 missing data on control variables \\ & 173 Final estimation sample \\ & \hline\end{aligned}

Source: SOEP.

Notes: Step by step deletion of respondents which do not fit the sample definition or for which essential information is missing. 
Table 5.B: Distribution of job changes during the early career

\begin{tabular}{|c|c|c|c|c|c|c|c|c|c|c|}
\hline \multirow[b]{2}{*}{ Number of job changes } & \multicolumn{2}{|c|}{5 Years $^{2}$} & \multicolumn{2}{|c|}{6 Years } & \multicolumn{2}{|c|}{7 Years } & \multicolumn{2}{|c|}{8 Years } & \multicolumn{2}{|c|}{9 Years } \\
\hline & $\mathrm{N}^{1}$ & $\%$ & $\mathrm{~N}$ & $\%$ & $\mathrm{~N}$ & $\%$ & $\mathrm{~N}$ & $\%$ & $\mathrm{~N}$ & $\%$ \\
\hline 0 & 127 & 51.21 & 95 & 45.89 & 76 & 43.93 & 56 & 40.88 & 35 & 34.31 \\
\hline 1 & 100 & 40.32 & 83 & 40.1 & 68 & 39.31 & 51 & 37.23 & 36 & 35.29 \\
\hline 2 & 18 & 7.26 & 25 & 12.08 & 24 & 13.87 & 22 & 16.06 & 23 & 22.55 \\
\hline 3 & 3 & 1.21 & 4 & 1.93 & 4 & 2.31 & 6 & 4.38 & 5 & 4.9 \\
\hline 4 & & & & & 1 & 0.58 & 2 & 1.46 & 2 & 1.96 \\
\hline 5 & & & & & & & & & 1 & 0.98 \\
\hline Sample size & 248 & & 207 & & 173 & & 137 & & 102 & \\
\hline Mean (number of changes) & 0.58 & & 0.70 & & 0.76 & & 0.88 & & 1.08 & \\
\hline $\mathrm{SD}^{3}$ (number of changes) & 0.68 & & 0.76 & & 0.82 & & 0.93 & & 1.05 & \\
\hline
\end{tabular}
Source: SOEP.

Notes: Sample: Labour market entrants.

${ }^{1}$ Number of respondents in a given category.

${ }^{2}$ Years of (uninterrupted) working experience indicating different samples of labour market entrants which are observed.

${ }^{3} \mathrm{SD}$ stands for standard deviation. 

6 Conclusions 


\section{Conclusions}

This dissertation contributes to the rapidly expanding literature that documents the importance of heterogeneous preferences, norms and values for behaviour. The investigation of the role of preferences for economic decision-making is conducted in four separate studies, using large representative panel surveys. Chapter 2 has analysed how trust affects co-evolvement of economic and political systems and Chapters 3 to 5 have investigated how willingness to take risks is related to occupational choice and mobility. By using structural changes in institutions realised during the economic and political transition of Ukraine and taking advantage of a recently available data set with direct measures of preferences (the ULMS), Chapters 2 to 4 shed some light on causality of the observed relationships.

In Chapter 2, investigation of the origins of civic capital, a set of pro-cooperative values and norms of behaviour facilitated by social trust, in two historically different parts of Ukraine highlighted the critical role of (historical) institutions for accumulation of civic capital. Using the fact that Soviet occupation blocked the opportunities for establishing institutions that would be aligned with the level of cooperative norms and values on the whole territory of Ukraine, Chapter 2 presented field evidence supporting the causal interpretation of the role of civic capital for the formation of preferences for economic and political systems.

The findings of Chapter 2 suggest that there is no direct causal link between economic and democratic development. Political preferences for certain types of political and economic systems co-evolve in the dimension of regulation, such that trusting individuals in a trusting environment prefer systems with little regulation. This finding is important for the discussion of whether economic liberalisation has a causal effect on democratic development, or whether democratic institutions facilitate economic growth (Barro, 1999; Tavares and Wacziarg, 2001; Giavazzi and Tabellini, 2005; Acemoglu, Johnson, Robinson, and Yared, 2008; Grosjean and Senik, 2011). In fact, it implies that it is unlikely that efforts to create functioning democratic institutions and to promote economic growth by liberalising markets will be successful in distrustful populations. Because of historical roots of civic capital, it is difficult to restore trust once it was damaged by unfavourable historical conditions.

Chapter 3 illustrated the causal effect of risk attitudes on occupational sorting using the fact that the economic transition of Ukraine exogenously shifted the distribution of earnings risks across occupations. Lack of correlation between risk attitudes and earnings risk in occupations before transition, when earnings risk was similar in all occupations, and the positive correlation between the earnings risk and individual willingness to take risks that emerged after transition, when 
heterogeneity of earnings risk across occupations increased dramatically, point to the causal effect of risk attitude on occupational choice and mobility.

The fact that earnings risk is a relevant dimension of occupational choice implies that risk attitudes affect the allocation of workers across occupations, such that workers who are more willing to take risks self-select into occupations with higher earnings risk. More risk-averse workers sort into occupations with lower earnings variance trading off wages for security. Another implication is that if the overall earnings risk is high, some individuals are discouraged from participating in the labour market, since their expected earnings are not sufficient to compensate them for the risk.

Since occupational choice is directly influenced by educational choice, the findings of Chapter 3 are relevant for human capital investment decisions. Timely information provision to facilitate good matching between occupational characteristics and individual preferences is warranted. A wrong occupational choice is likely to lead to several adverse consequences, including stress, anxiety, feeling of underutilised potential, and loss of human capital in case of changing occupations later in life.

The empirical approach of Chapter 4 exploited the fact that Ukraine and East Germany had no or very limited experience with self-employment because of the centrally-planned economic structure imposed by the communist regime. By (partially) shutting down the channel of intra-family transmission of self-employment and information about what it is like to be self-employed, the study provided field evidence supporting the causal interpretation of the effect of risk attitudes on the probability of being self-employed. Additional evidence from the Netherlands points out that access to information about what it is like to be self-employed can decrease the risk associated with self-employment.

The contribution of Chapter 4 is to document the effect of risk attitudes on self-employment in the conditions when other factors or unobserved fixed effects are unlikely to matter. In this sample, risk attitude is a stable predictor of selfemployment, unlike household income. This implies that financial stimulation of self-employment might not achieve desired increases in self-employment rates among the unemployed if the majority of the unemployed are risk-averse. The findings of this chapter indicate that the provision of information may mitigate the risk associated with self-employment. Heterogenous risk attitudes can explain the differences in self-employment in various populations (e.g. Hout and Rosen, 2000).

Chapter 5 showed that risk-averse individuals change jobs less frequently than more risk-tolerant individuals because they demand a higher compensation to make a job change than more risk-tolerant individuals do. The expected benefits of the 


\section{Conclusions}

new job are uncertain, which makes job change a risky decision. Consequently, more risk-tolerant individuals make job changes more often, but these job changes are associated with lower wage increases than less frequent job changes of risk averse individuals. This explanation is supported by empirical findings based on a sample of labour market entrants observed during their early career in the SOEP.

Chapter 5 contributes to the literature by suggesting a mechanism, which can explain mixed evidence on the effect of job mobility of young labour market participants on the subsequent wage growth (Topel and Ward, 1992; Light and McGarry, 1998; Hunt, 2001; Neumark, 2002). Chapter 5 is also the first study to empirically document the relationship between willingness to take risks and the total number of job changes during the early career. The fact that risk attitude affects job mobility decisions is important to take into consideration when efforts to stimulate mobility among workers are undertaken. Especially in the case of older workers, who are on average more risk-averse than younger workers, incentives to change jobs need to be high enough to compensate for the loss of security associated with the old job.

Chapters 2, 3, and 4 demonstrated that the method of historical investigation of a single country with a turbulent history and exogenous variation in institutions provides useful insights in the origin of preferences and their role for economic decision-making. The added value of this approach is that structural changes in historical institutions can be used as a source of exogenous variation to highlight causal effects of preferences on economic outcomes in the field setting, using survey data. Caution is warranted, however, for the conclusions of Chapter 2 and 3 are based on a single country study. Such conclusions may not be general in case the effect of civic capital on the co-evolution of political preferences in the Ukrainian population was facilitated by some country-specific geographic or ethnic factor. Similarly, the link between risk attitudes and occupational sorting might be corrupted if risk attitudes and the evolvement of the occupational wage structure in Ukraine were simultaneously affected by some other factor.

In Chapter 4, the Ukrainian evidence is supplemented by the evidence from East Germany, which experienced similar restrictions of private entrepreneurship because of the communist regime. A test of the hypothesis of whether information about self-employment decreases the risk of self-employment, comes from the Netherlands, a country with a rich history of entrepreneurship. The data set from the Netherlands contains information on whether a business was a start-up or whether it was transferred from a family member. A combined use of three data sets from three different populations provides an interesting set-up, in which data from each population serve to address different sub-questions. A limitation of this 
approach is that the conditions under which the results are valid in one population, might not hold in another population.

In Chapter 5, evidence supporting the theoretical explanation of the relevance of risk attitudes for occupation mobility patterns and the subsequent wage growth is presented. The fact that risk attitudes matter for job mobility decisions on the German labour market, which is characterised by high regulation and infrequent change of employers, suggests that the role of risk attitudes might be even larger in more flexible labour markets. A causal interpretation of these findings is limited because of the descriptive nature of the study and a low number of observations.

The chapters of this dissertation largely rely on self-reported data with respect to measures of preferences as well as of economic outcomes. The analysis in Chapter 3, in particular, relies on self-reported information about the past as part of the identification. While all the efforts to verify the validity of this information are taken, in an ideal setting an administrative data set with the occupation and wage data before transition would have been used. The argument of Chapters 2 to 5 is based on the assumption about the stability of economic preferences, such as trust and risk attitudes, over time. Recent empirical studies generally agree that economic preferences can be treated as stable parameters. However, in an ideal world, preferences were measured before the outcomes.

This dissertation has shown that economic preferences affect economic activity. Individuals make different decisions in very similar situations because they have heterogeneous preferences. While the analyses in this dissertation naturally have limitations, the importance of these findings demonstrates the need for further research.

Some relevant questions are beyond the scope of the current dissertation. For example, the investigation of how historical events ruin trust and exploration of the ways to restore broken trust are not addressed here. Can fair and transparent institutions created exogenously repair civic capital faster than under natural evolution? Risk attitudes affect occupational choice with respect to cross-sectional earnings risk. It is likely that cross-sectional earnings risk incorporates the risk of unemployment and longitudinal earnings risk to some extent, but how do different facets of risk in the future occupation impact educational choices? What kind of information can reduce the risk of self-employment for the risk-averse? Which personality traits can compensate for the lack of willingness to take risks? The causality of the link between risk attitudes and the total number of voluntary job changes documented here can be investigated by exploiting a policy change. A larger data set from a more flexible labour market can provide a possibility to study 


\section{Conclusions}

whether the relationship between risk attitudes, job changes and wage increases is the same for different schooling levels. 


\section{BIBLIOGRAPHY}

ÅberG, M. (2000): "Putnam's Social Capital Theory Goes East: A Case Study of Western Ukraine and L'viv," Europe-Asia Studies, 52(2), 295-317.

Acemoglu, D., And S. Johnson (2005): "Unbundling Institutions," Journal of Political Economy, 113(5), 949-995.

Acemoglu, D., S. Johnson, J. A. Robinson, and P. Yared (2008): "Income and Democracy," The American Economic Review, 98(3), 808-842.

Aghion, P., C. P. Algan, Yann, And A. Shleifer (2010): "Regulation and Distrust," Quarterly Journal of Economics, (August), 1015-1049.

Algan, Y., and P. Cahuc (2010): "Inherited Trust and Growth," The American Economic Review, 100(5), 2060-2092.

Alm, B., D. Engel, And A. Weyh (2013): "Einkommenseffekte von Betriebswechslern: Neue Befunde für Ostdeutschland," IAB-Discussion Paper 08/2013.

Almond, G. A., And S. Verba (1963): The Civic Culture. Boston: Little, Brown.

Andersen, S., G. W. Harrison, M. I. Lau, and E. E. Rutström (2008): "Lost in State Space: are Preferences Stable?," International Economic Review, 49(3), 1091-1112.

Andersson, L., And M. Hammarstedt (2010): "Intergenerational Transmissions in Immigrant Self-Employment: Evidence from Three Generations," Small Business Economics, 34(3), 261-276.

Andruhin, E. (2011): "Entrepreneurship in the Soviet Union during 1950-1980's. [Predprinimatelskaya Deyatelnost Naseleniya SSSR v 50-80-ye Gody XX veka.]," Ph.D. thesis, Kursk State University.

Antonovics, K., And L. Golan (2012): "Experimentation and Job Choice," Journal of Labor Economics, 30(2), 333-366.

Arcidiacono, P. (2004): "Ability Sorting and Returns to College Major," Journal of Econometrics, 121(1-2), 343-375.

Arrow, K. (1972): "Gifts and Exchanges," Philosophy and public affairs, 1(4), 343-362. 


\section{Bibliography}

Åslund, A. (2007): How Capitalism Was Built: The Transformation of Central and Eastern Europe. Cambridge University Press.

Badescu, G., and E. M. Uslaner (2003): Social Capital and the Transition to Democracy. Routledge.

Banerjee, A. V., and A. F. Newman (1993): "Occupational Choice and the Process of Development," Journal of Political Economy, 101(2), pp. 274-298.

Barro, R. J. (1999): "Determinants of Democracy," Journal of Political Economy, 107(6), S158-S183.

Baucells, M., And A. Villasís (2009): "Stability of risk Preferences and the Reflection Effect of Prospect Theory," Theory and Decision, 68(1-2), 193-211.

Becker, S., K. Boeckh, C. Hainz, and L. Woessmann (2011): "The Empire Is Dead, Long Live the Empire! Long-Run Persistence of Trust and Corruption in the Bureaucracy," ZA DP No. 5584.

Bellante, D., And A. N. Link (1981): "Are Public Sector Workers more Risk Averse than Private Sector Workers?," Industrial and Labor Relations Review, 34(3), 408-412.

Benewitz, M. C., and A. Zucker (1968): "Human Capital and Occupational Choice: A Theoretical Model," Southern Economic Journal, 34(3), pp. 406-409.

Bentolila, S., C. Michelacci, and J. Suarez (2010): "Social Contacts and Occupational Choice," Economica, 77(305), 20-45.

Berkhout, P., J. Hartog, and D. Webbink (2010): "Compensation for Earnings Risk under Worker Heterogeneity," Southern Economic Journal, 76(3), 762790 .

Bisin, A., And T. Verdier (2001): "The Economics of Cultural Transmission and the Dynamics of Preferences," Journal of Economic Theory, 97(2), 298 319 .

Blanchflower, D. G., and A. J. Oswald (1998): "What Makes an Entrepreneur?," Journal of Labor Economics, 16(1), 26-60.

Blau, D. M. (1987): "A Time-Series Analysis of Self-Employment in the United States," Journal of Political Economy, 95(3), 445-467.

Blau, P. M., J. W. Gustad, R. Jessor, H. S. Parnes, and R. C. Wilcock (1955): "Occupational Choice: a Conceptual Framework," Industrial and Labor Relations Review, 9, 531-543.

Boeri, T., and K. Terrell (2002): "Institutional Determinants of Labor Reallocation in Transition," The Journal of Economic Perspectives, 16(1), 51-76. 
Boix, C., And S. Stokes (2003): "Endogenous Democratization," World Politics, 55(4), 517-549.

Bonin, H., T. Dohmen, A. Falk, D. Huffman, and U. Sunde (2007): "Cross-Sectional Earnings Risk and Occupational Sorting: The Role of Risk Attitudes," Labour Economics, 14(6), 926-937.

Borghans, L., and B. Golsteyn (2012): "Job Mobility in Europe, Japan and the United States," British Journal of Industrial Relations, 50(3), 436-456.

Borghans, L., B. Ter Weel, and B. A. Weinberg (2008): "Interpersonal Styles and Labor Market Outcomes," Journal of Human Resources, 43(4), 815858.

Boskin, M. J. (1974): "A Conditional Logit Model of Occupational Choice," Journal of Political Economy, 82(2), pp. 389-398.

Brown, S., M. Dietrich, A. Ortiz-Nuñez, and K. Taylor (2011): "SelfEmployment and Attitudes towards Risk: Timing and Unobserved Heterogeneity," Journal of Economic Psychology, 32(3), 425-433.

Brown, S., L. Farrell, M. N. Harris, and J. G. Sessions (2006): "Risk Preference and Employment Contract Type," Journal of the Royal Statistical Society: Series A (Statistics in Society), 169(4), 849-863.

Brown, S., and K. Taylor (2005): "Wage Growth, Human Capital and Financial Investment," The Manchester School, 73(6), 686-708.

Budria, S., L. Diaz-Serrano, A. Ferrer-I-Carbonell, and J. Hartog (2012): "Risk Attitude and Wage Growth: Replicating Shaw (1996)," Empirical Economics, 44 (2), 981-1004.

Bull, C. (1987): "The Existence of Self-Enforcing Implicit Contracts," The Quarterly Journal of Economics, 102(1), 147-159.

Burdett, K. (1978): "A Theory of Employee Job Search and Quit Rates," The American Economic Review, 68(1), 212-220.

Burke, A. E., F. R. FitzRoy, and M. A. Nolan (2002): "Self-Employment Wealth and Job Creation: The Roles of Gender, Non-Pecuniary Motivation and Entrepreneurial Ability," Small Business Economics, 19, 255-270.

Caliendo, M., F. M. Fossen, and A. S. Kritikos (2009): "Risk Attitudes of Nascent Entrepreneurs: New Evidence from an Experimentally Validated Survey," Small Business Economics, 32(2), 153-167.

Cantillon, R. (1755): Essai sur la Nature du Commerce.

Cesarini, D., C. Dawes, M. Johannesson, P. Lichtenstein, and B. WalLACE (2009): "Genetic Variation in Preferences for Giving and Risk Taking," Quarterly Journal of Economics, 124(2), 809-842. 


\section{Bibliography}

Cramer, J., J. Hartog, N. Jonker, and C. Van PraAg (2002): "Low risk aversion encourages the choice for entrepreneurship: an empirical test of a truism," Journal of Economic Behavior \& Organization, 48(1), 29-36.

Cullen, J. B., and R. H. Gordon (2007): "Taxes and Entrepreneurial RiskTaking: Theory and Evidence for the U.S.," Journal of Public Economics, 91(78), 1479-1505.

DeLeire, T., And H. Levy (2004): "Worker Sorting and the Risk of Death on the Job," Journal of Labor Economics, 22(4), 925-953.

DIW (2010): "Documentation of Cross-Sectional Files 'Person-Related Status and Generated Variables'. SOEP," Discussion paper, Berlin.

Djankov, S., E. Glaeser, R. La Porta, F. Lopez-de Silanes, and A. Shleifer (2003): "The New Comparative Economics," Journal of comparative economics, 31(4), 595-619.

Doepke, M., And F. Zilibotti (2008): "Occupational Choice and the Spirit of Capitalism," The Quarterly Journal of Economics, 123(2), 747-793.

Dohmen, T., And A. FAlK (2011): "Performance Pay and Multidimensional Sorting: Productivity, Preferences, and Gender," The American Economic Review, 101(2), 556-590.

Dohmen, T., A. Falk, D. Huffman, and U. Sunde (2012): "The Intergenerational Transmission of Risk and Trust Attitudes," The Review of Economic Studies, 79(2), 645-677.

Dohmen, T., A. Falk, D. Huffman, U. Sunde, J. Schupp, and G. G. WAGner (2011): "Individual Risk Attitudes: Measurement, Determinants, and Behavioral Consequences," Journal of the European Economic Association, 9(3), $522-550$.

(2012): "The Measurement and Stability of Risk Preferences," Maastricht University, mimeo.

Dunn, T., and D. Holtz-Eakin (2000): "Financial Capital, Human Capital, and the Transition to Self-Employment: Evidence from Intergenerational Links," Journal of Labor Economics, 18(2), 282-305.

Dustmann, C., And S. C. Pereira (2008): "Wage Growth and Job Mobility in the United Kingdom and Germany," Industrial and Labor Relations Review, 61(3), 374-393.

Eisenhower, D., N. A. Mathiowetz, and D. Morganstein (2004): "Recall Error: Sources and Bias Reduction Techniques," in Measurement Errors in Surveys, ed. by P. P. Biemer, R. M. Groves, L. E. Lyberg, N. A. Mathiowetz, and S. Sudman. John Wiley \& Sons, Inc., Hoboken, NJ, USA. 
Ekelund, J., E. Johansson, M. Järvelin, and D. Lichtermann (2005): "Self-Employment and Risk Aversion: Evidence from Psychological Test Data," Labour Economics, 12(5), 649-659.

Evans, D. S., And B. Jovanovic (1989): "An Estimated Model of Entrepreneurial Choice under Liquidity Constraints," Journal of Political Economy, 97(4), 808-827.

Evans, D. S., and L. S. Leighton (1989): "Some Empirical Aspects of Entrepreneurship," The American Economic Review, 79(3), 519-535.

Fairlie, R. W., And A. RobB (2007): "Families, Human Capital, and Small Business: Evidence from the Characteristics of Business Owners Survey," Industrial and Labor Relations Review, 60(2), 225-245.

FALTER, J.-M. (2007a): "Entrepreneurship and Intergenerational Links in Switzerland," Labour, 21(1), 121-134.

(2007b): "Self-Employment and Earning Inequality," Journal of Income Distribution, 16(2), 106-127.

Fossen, F. M. (2011): "The Private Equity Premium Puzzle Revisited-New Evidence on the Role of Heterogeneous Risk Attitudes," Economica, 78(312), 656675 .

Founarge, D., B. Kriechel, and T. Dohmen (2012): "Occupational Sorting of School Leavers: The Role of Economic Preferences," Research Centre for Education and the Labour Market (ROA).

Fuchs-Schündeln, N., And M. Schündeln (2005): "Precautionary Savings and Self-Selection: Evidence from the German Reunification "Experiment"," Quarterly Journal of Economics, 120(3), 1085-1120.

Fukuyama, F. (1995): Trust: The Social Virtues and The Creation of Prosperity. Stata Press.

Fuller, S. (2008): "Job Mobility and Wage Trajectories for Men and Women in the United States," American Sociological Review, 73, 158-183.

Gächter, S., and B. Herrmann (2009): "Reciprocity, Culture and Human Cooperation: Previous Insights and a New Cross-Cultural Experiment," Philosophical Transactions of the Royal Society, 364, 791-806.

Gelfand, I. (1964): Criminal Responsibility for (Trade) Speculation. [Ugolovnaya Otvetstvennost za Spekulyatsyiu]. Kiev.

Giavazzi, F., and G. Tabellini (2005): "Economic and Political Liberalizations," Journal of Monetary Economics, 52(7), 1297 - 1330, Political economy and macroeconomics. 


\section{Bibliography}

Glaeser, E., R. La Porta, F. Lopez-de Silanes, and A. Shleifer (2004): "Do institutions Cause Growth?," Journal of Economic Growth, 9(3), 271-303.

Glaeser, E. L., D. Laibson, and B. Sacerdote (2002): "An Economic Approach to Social Capital," The Economic Journal, 112(483), F437-F458.

Glaeser, E. L., And A. Shleifer (2003): "The Rise of the Regulatory State," The Journal of Economic Literature, 41(2), 401-425.

Gomez, R., And E. Santor (2001): "Membership has Its Privileges: The Effect of Social Capital and Neighbourhood Characteristics on the Earnings of Microfinance Borrowers," The Canadian Journal of Economics, 34(4), 943-966.

Grazier, S., and P. Sloane (2008): "Accident Risk, Gender, Family Status and Occupational Choice in the UK," Labour Economics, 15(5), 938 - 957.

Grosfeld, I., A. Rodnyansky, and E. Zhuravskaya (2010): "Persistent Anti-Market Culture: A Legacy of the Pale of Settlement and of the Holocaust," HAL-PSE Working Papers.

Grosjean, P., And C. Senik (2011): "Democracy, Market Liberalization and Political Preferences," The Review of Economics and Statistics, 93(1), 365-381.

Grossman, S. J., and O. D. Hart (1981): "Implicit Contracts, Moral Hazard, and Unemployment," The American Economic Review, 71(2), pp. 301-307.

Grytsak, Y. (2000): Outlines of Ukrainian History: Formation of Ukrainian Nation in the 19th-20th centruy. [Narysy Istoriyi Ukrainy: Formuvannya Modernoyi Ukrayinskoyi Natsyi XIX-XX st.]. Kyiv: Geneza, second edn.

Guiso, L., T. Jappelli, and L. Pistaferri (2002): "An Empirical Analysis of Earnings and Employment Risk," Journal of Business and Economic Statistics, 20(2), 241-253.

Guiso, L., P. Sapienza, and L. Zingales (2004): "The Role of Social Capital in Financial Development," The American Economic Review, 94(3), 526-556.

(2006): "Does Culture Affect Economic Outcomes?," The Journal of Economic Perspectives, 20(2), 23-48.

Guiso, L., P. Sapienza, and L. Zingales (2008a): "Alfred Marshall Lecture Social Capital as Good Culture," Journal of the European Economic Association, 6(2-3), 295-320.

Guiso, L., P. Sapienza, And L. Zingales (2008b): "Long Term Persistence," SSRN eLibrary.

(2011): "Civic Capital as the Missing Link," in Handook of Social Economics, ed. by J. Benhabib, A. Bisin, and M. Jackson, vol. 1A. Elsevier. 
Ham, R., P. Junankar, and R. Wells (2009): "Occupational Choice: Personality Matters," IZA discussion papers 4105.

Hamermesh, D. S. (1999): "Changing Inequality In Markets For Workplace Amenities," The Quarterly Journal of Economics, 114(4), 1085-1123.

Harrison, G. W., E. Johnson, M. M. McInnes, and E. E. Rutström (2005): "Temporal Stability of Estimates of Risk Aversion," Applied Financial Economics Letters, 1(1), 31-35.

Hartog, J. (2011): "A Risk Augmented Mincer Earnings Equation? Taking Stock," in Research in Labor Economics, no. October 2006, pp. 129-173.

Hartog, J., N. Jonker, and G. Pfann (2002): "Tweede Vervolgonderzoek Mathijssen-Sonnemans Cohort, 1952-1993," Discussion paper, Netherlands Institute for Scientific Information Services.

Hartog, J., and C. M. van PraAg (2010): "If you are so Smart, Why Aren't You an Entrepreneur? Returns to Cognitive and social Ability: Entrepreneurs versus Employees," Journal of Economics and Management Strategy, 19(4), 947989 .

Hartog, J., And W. Vijverberg (2007a): "On Compensation for Risk Aversion and Skewness Affection in Wages," Labour Economics, 14(6), 938-956.

(2007b): "On Compensation for Risk Aversion and Skewness Affection in Wages," Labour Economics, 14(6), 938-956.

Heckman, J., J. Stixrud, and S. Urzua (2006): "The Effects of Cognitive and Noncognitive Abilities on Labor Market Outcomes and Social Behavior," Journal of Labor Economics, 24(3), 411-482.

Heckman, J. J., and B. E. Honore (1990): "The Empirical Content of the Roy Model," Econometrica, 58(5), 1121-1149.

Heckman, J. J., and Y. Rubinstein (2001): "The Importance of Noncognitive Skills: Lessons from the GED Testing Program," The American Economic Review, 91(2), pp. 145-149.

Heineck, G., And B. Süssmuth (2013): "A Different Look at Lenin's Legacy: Social Capital and Risk Taking in the in the Tswo Germanies," Journal of Comparative Economics, 41(3), 789 - 803.

Helliwell, J. F. (1994): "Empirical Linkages between Democracy and Economic Growth," British Journal of Political Science, 24, 225-248.

Henrich, J., R. Boyd, S. Bowles, C. Camerer, E. Fehr, H. Gintis, and R. McElreath (2001): "In Search of Homo Economicus: Behavioral Experiments in 15 Small-Scale Societies," The American Economic Review, 91(2), pp. 73-78. 


\section{Bibliography}

Herrmann, B., C. Thöni, and S. Gächter (2008): "Antisocial Punishment Across Societies," Science, 319, 1362-1367.

Holtz-Eakin, D., D. Joulfaian, and H. S. Rosen (1994): "Sticking It Out: Entrepreneurial Survival and Liquidity Constraints," The Journal of Political Economy, 102(1), 53-75.

Hout, M., And H. Rosen (2000): "Self-Employment, Family Background, and Race," Journal of Human Resources, 35(4), 670-692.

Hundley, G. (2006): "Family Background and the Propensity for SelfEmployment," Industrial Relations, 45(3), 377-392.

Hunt, J. (2001): "Post-unification Wage Growth in East Germany," The Review of Economics and Statistics, pp. 190-195.

Hurst, E., And A. Lusardi (2004): "Liquidity Constraints, Household Wealth, and Entrepreneurship," Journal of Political Economy, 112(2), 319-347.

Inglehart, R. (1988): "The Renaissance of Political Culture," American Political Science Review, 82(4), 64-78.

Iyigun, M. F., AND A. L. Owen (1998): "Risk, Entrepreneurship, and HumanCapital Accumulation," The American Economic Review, 88(2), pp. 454-457.

Jacob, M., And M. Tyrell (2010): "The Legacy of Surveillance: An Explanation for Social Capital Erosion and the Persistent Economic Disparity between East and West Germany," SSRN.

Johnson, W. R. (1978): "A Theory of Job Shopping," Quarterly Journal of Economics, 92(2), 261-277.

Jovanovic, B. (1979a): "Firm-specific Capital and Turnover," Journal of Political Economy, 87(6), 1246-1260.

(1979b): "Job Matching and the Theory of Turnover," Journal of Political Economy, 87(5), 972-990.

Kanbur, S. M. (1979): "Of Risk Taking and the Personal Distribution of Income," Journal of Political Economy, 87(4), pp. 769-797.

Killingsworth, M. R. (1984): Labor Supply. Cambridge university press.

KInG, A. G. (1974): "Occupational Choice, Risk Aversion, and Wealth," Industrial and Labor Relations Review, 27(4), 586-596.

Knack, S., and P. Keefer (1995): "Institutions and Economic Performance: Cross-Country Tests Using Alternative Institutional Measures," Economics 83 Politics, 7(3), 207-227. 
Knack, S., And P. Keefer (1997): "Does Social Capital Have an Economic Payoff? A Cross-Country Investigation," The Quarterly Journal of Economics, 112(4), 1251-1288.

Knight, F. H. (1921): Risk, Uncertainty and Profit. Houghton-Mifflin, New York.

Krueger, A. B., And D. Schade (2008): "Sorting in the Labor Market: Do Gregarious Workers Flock to Interactive Jobs ?," Journal of Human Resources, 43(4), 859-883.

Kupets, O., N. Leshchenko, E. Osinkina, S. Taran, and V. Komarov (2009): "Ukraine Country Report," Discussion paper, European Training Foundation, ENPI 08-14 Black Sea Market Reviews.

LaPorta, R., F. Lopez-de Silanes, A. Shleifer, and R. W. Vishny (1997): "Trust in Large Orhanizations," American Economic Review, 87(2), 333-338.

LAZEAR, E. P. (2004): "Balanced Skills and Entrepreneurship," The American Economic Review, 94(2), 208-211.

680.

Le Grand, C., and M. Taehlin (2002): "Job Mobility and Earning Growth," European Sociological Review, 18 (4), 381-400.

Lechner, M., And F. Pfeiffer (1993): "Planning for Self-Employment at the Beginning of a Market Economy: Evidence from Individual Data of East German Workers," Small Business Economics, 5(2), 111-128.

Lehmann, H., And A. Muravyev (2012): "Labour Market Institutions and Labour Parket Performance," Economics of Transition, 20(2), 235-269.

Lehmann, H., A. Muravyev, and K. Zimmermann (2012): "The Ukrainian Longitudinal Monitoring Survey: Towards a Better Understanding of Labor Markets in Transition," IZA Journal of Labor $\&$ Development, 1(1), 9.

Leigh, J. P. (1981): "Occupational Sorting under Earnings Uncertainty," Nebraska Journal of Economics and Business, 20, 59-71.

Light, A., And K. McGarry (1998): "Job Change Patterns and the Wages of Young Men," The Review of Economics and Statistics, 80 (2), 276-286.

Lindh, T., And H. Ohlsson (1996): "Self-Employment and Windfall Gains: Evidence from the Swedish Lottery," The Economic Journal, 106(439), pp. 15151526.

Lindquist, M. J., J. Sol, And C. M. van PraAg (2012): "Why Do Entrepreneurial Parents Have Entrepreneurial Children?," IZA Discussion Paper No. 6740 . 


\section{Bibliography}

Lipset, S. M. (1959): "Some Social Requisites of Democracy: Economic Development and Political Legitimacy," The American Political Science Review, 53(1), 69-105.

Magocsi, P. R. (2010): History of Ukraine: The Land and Its Peoples. University of Toronto Press, Scholarly Publishing Division.

McCrae, R. R., P. T. Costa, F. Ostendorf, A. Angleitner, M. Hrebícková, M. D. Avia, J. Sanz, M. L. Sánchez-Bernardos, M. E. Kusdil, R. Woodfield, P. R. Saunders, and P. B. Smith (2000): "Nature over Nurture: Temperament, Personality, and Life Span Development," Journal of personality and social psychology, 78(1), 173-86.

McGoldrICK, K. (1995): "Do Women Receive Compensating Wages for Earnings Uncertainty?," Southern Economic Journal, 62(1), pp. 210-222.

Miller, R. A. (1984): "Job Matching and Occupational Choice," Journal of Political Economy, 92(6), 1086.

Munasinghe, L., And K. Sigman (2004): "A Hobo Syndrome? Mobility, Wages, and Job Turnover," Labour Economics, 11, 191-218.

Nelson, P. (1970): "Information and Consumer Behavior," Journal of Political Economy, 78(2), 311-329.

Neumark, D. (2002): "Youth Labor Markets in the United States: Shopping Around vs. Staying Put," The Review of Economics and Statistics, 84(3), 462482.

Nunn, N., And L. Wantchekon (2011): "The Slave Trade and the Origins of Mistrust in Africa," The American Economic Review, 101(5), 3221-3252.

OECD (2008): "Self-Employment," Discussion paper, OECD Publishing.

of the Ukrainian Soviet Socialist Republic., C. S. B. (1992): National Economy: Annual Statistics ReportKiev: Tehnika.

Paldam, M., And G. Swedsen (2001): "Missing Social Capital and the Transition in Eastern Europe," Journal for Institutional Inoovation, Development and Transition, 5, 21-34.

Papaionnnou, E., and G. Siourounis (2008a): "Democratisation and Growth," Economic Journal, 118(532), 1520-1551.

(2008b): "Economic and Social Factors Driving the Third Wave of Democratization," Journal of Comparative Economics, 36(3), 365-387.

PARKER, S. (2004): The Economics of Self-Employment and Entrepreneurship. Cambridge University Press. 
PARKer, S. C. (1999): "The Inequality of Employment and Self-Employment Incomes: a Decomposition Analysis for the U.K.", Review of Income and Wealth, $45(2), 263-274$.

Pavlopoulos, D., D. Fouarge, R. Muffels, and J. Vermunt (forthcoming): "Who Benefits from a Job Change: The Dwarfs or the Giants?," European Societies.

Perez, J. I. G., And Y. R. SAnz (2005): "Wage Changes Through Job Mobility in Europe: A Multinomial Endogenous Switching Approach," Labour Economics, 12, 531-555.

Pettersson, J. (2004): "Democracy, Consolidation and Growth," Research Papers in Economics. Stockholm University, Department of Economics.

Pfeifer, C. (2010): "Risk Aversion and Sorting into Public Sector Employment," German Economic Review, 12(1), 85-99.

PICKel, A. (1992): Radical Transitions: the Survival and Revival of Entrepreneurship in the GDR. Westview press, HarperCollins Canada.

Pinotti, P. (2008): "Trust, Honesty, and Regulations," MPRA paper, 7740.

Prantl, S., And A. Spitz-Oener (2009): "How does Entry Regulation Influence Entry into Self-Employment and Occupational Mobility?," Economics of Transition, 17(4), 769-802.

Przeworski, A., And F. Limongi (1993): "Political Regimes and Economic Growth," Journal of Economic Perspectives, 7(3), 51-69.

Putnam, R. D. (1993): Making Democracy Work. Civic Traditions in Modern Italy. Princeton University Press.

Rainer, H., And T. Siedler (2009): "Does Democracy Foster Trust?," Journal of Comparative Economics, 37(2), 251-269.

Rees, H., And A. Shah (1986): "An Empirical Analysis of Self-Employment in the U.K.," Journal of Applied Econometrics, 1(1), 95-108.

Reynaud, A., And S. Couture (2012): "Stability of Risk Preference Measures: Results from a Field Experiment on French farmers," Theory and decision, 73(2), 203-221.

Riabchuk, M. (2008): "Ukraine: Lessons Learned from Other Postcommunist Transitions," Orbis, 52(1), 41-64.

Rodrik, D., And R. WAcziarg (2005): "Do Democratic Transitions Produce Bad Economic Outcomes?," The American Economic Review, 95(2), 50-55.

Rosen, H., and P. Willen (2002): "Risk, Return and Self-employment," University of Chicago/Princeton University Discussion Paper. 


\section{Bibliography}

Roy, A. (1951): "Some Thoughts on the Distribution of Earnings," Oxfrod Economic Papers, 3(2), 135-146.

SAhm, C. R. (2012): "How Much Does Risk Tolerance Change?," Quarterly Journal of Finance, 02(04), 1250020.

SalamancA, N. (2014): "A Structured Approach to Testing the Stability of Individual Preferences," Paper presented at Maastricht University (2014).

Schiller, B. R., And P. E. Crewson (1997): "Entrepreneurial Origins: a Longitudinal Inquiry," Economic Inquiry, 35(3), 523-531.

Schumpeter, J. A. (1934): The Theory of Economic Development. Harvard University Press, Cambridge, MA.

(1939): Business Cycles. McGraw-Hill, New York.

Schweri, J., J. Hartog, and S. C. Wolter (2011): "Do Students Expect Compensation for Wage Risk?," Economics of Education Review, 30(2), 215227.

Shaw, K. L. (1987): "Occupational Change, Employer Change, and the Transferability of Skills," Southern Economic Journal, 53(3), pp. 702-719.

(1996): "An Empirical Analysis of Risk Aversion and Income Growth," Journal of Labor Economics, 14(4), 626-653.

Skriabikova, O. J., T. Dohmen, and B. Kriechel (2014): "New evidence on the relationship between risk attitudes and self-employment," Labour Economics, in press.

Stiglitz, J. E., And A. Weiss (1981): "Credit Rationing in Markets with Imperfect Information," The American Economic Review, 71(3), pp. 393-410.

Subtelny, O. (ed.) (2005): Ukraine: A History. University of Toronto Press, fifth edn.

Sunde, U. (2006): "Wirtschaftlische Entwicklung und Demokratie - Ist Demokratie ein Wolhstandsmotor oder ein Wohlstandsprodukt?," Perspektiven der Wirtscahtspolitik, 7(4), 471-499.

Svejnar, J. (1999): "Labor markets in the Transitional Central and East European Economies," in Handbook of Labor Economics, ed. by O. Ashenfelter, and D. Card, vol. 3 of Handbook of Labor Economics, chap. 42, pp. 2809-2857. Elsevier.

TABellini, G. (2008a): "Presidential Address Institutions and Culture," Journal of the European Economic Association, 6(2-3), 255-294.

(2008b): "The Scope of Cooperation: Values and Incentives," Quarterly Journal of Economics, 123(3), 905-950. 
(2010): "Culture and Institutions: Economic Development in the Regions of Europe," Journal of the European Economic Association, 8(4), 677-716.

Tavares, J., And R. Wacziarg (2001): "How Democracy Affects Growth," European Economic Review, 45(8), 1341-1378.

Topel, R. H., And M. P. Ward (1992): "Job Mobility and the Careers of Young Men," The Quarterly Journal of Economics, 107(2), 439-479.

Trofimov, S. (1975): Struggle against the Forbidden Trade in Ukrainian SSR. [Borba s Zapreschennym Promyslom v Ukrainskoy SSR.]. RIO by MOOP USSR, Kiev.

Uslaner, E. M. (1999): "Democracy and Social Capital," in Democracy and Trust, ed. by M. E. Warren, pp. 121-151. Cambridge University Press.

(2008): "Where You Stand Depends Upon Where Your Grandparents Sat: The Inheritability of Generalized Trust," Public Opinion Quarterly, 72(4), $725-740$.

van den Berg, G. (1992): "A Structural Dynamic Analysis of Job Turnover and the Costs Associated with Moving to another Job," The Economic Journal, 102, 1116-1133.

VAn PraAG, C., And J. CRAmer (2001): "The roots of entrepreneurship and labour demand: Individual ability and low risk aversion," Economica, 68(269), $45-62$.

VAn PraAG, M. (1992): "Zomaar een Dataset: De Noordbraabantse Zesde klassers," Vakgroep: Micro-economie. Universiteit van Amsterdam.

Viscusi, W. K., And J. Hersch (2001): "Cigarette Smokers as Job Risk Takers," Review of Economics and Statistics, 83(2), 269-280.

Wagner, G. G., J. R. Frick, And J. Schupp (2007): "The German Socio-Economic Panel Study (SOEP) - Scope, Evolution and Enhancements," Schmollers Jahrbuch, 127 (1), 139-169.

WEIss, R. (1970): "The effect of Education on the Earnings of Blacks and Whites," Review of Economics and Statistics, 52(2), 150-159.

ZAK, P. J., And S. KnaCK (2001): "Trust and growth," The economic journal, 111(470), 295-321.

Zimmermann, K. F. (1998): "German Mobility and Wages," in Internal Labour Markets, Incentives and Employment, ed. by I. Obashi, and T. Tachibanaki. Macmillan Press, London.

Zumbuehl, M., T. Dohmen, and G. Pfann (2013): "Parental Investment and the Intergenerational Transmission of Economic Preferences and Attitudes," ROA-RM-2013/11. 



\section{SumMarY in DUTCH}

\section{VOORKEUREN, HISTORISCHE INSTITUTIES, EN ECONOMISCHE UITKOMSTEN: EEN EMPIRISCHE STUDIE}

Een van de klassieke economische vraagstukken betreft het vaststellen van de belangrijke factoren van individuele keuzes op de arbeidsmarkt, zoals de beslissing om te gaan werken of studeren, de keuze van een beroep, het veranderen van baan en de loonontwikkeling. De effecten van de verschillende 'harde' factoren, zoals de prijs van arbeid, marktrentes, rijkdom, onderwijsniveau, gezinssamenstelling, beroep van de ouders enz. zijn in de literatuur uitgebreid beschreven. Er is echter veel minder bekend over de effecten van 'zachte' factoren, zoals persoonskenmerken en individuele voorkeuren. Het is belangrijk om te weten hoe deze factoren menselijk gedrag kunnen beïnvloeden, omdat recente bevindingen laten zien dat mensen in vergelijkbare situaties wel verschillende keuzes maken (Kahneman en Tversky, 1979). Belangrijke economische keuzes, zowel op arbeidsmarkt als ook in bredere zin, zoals de keuze voor een bepaalde type van economische en politieke systemen, kunnen beter worden verklaard als er rekening wordt gehouden met de persoonlijke individuele voorkeuren.

Het belang van voorkeuren en persoonskenmerken wordt algemeen erkend. Theoretische overwegingen van de klassieke auteurs zien vertrouwen en risicovoorkeuren als belangrijke drijfveren van economische groei. Vertrouwen werkt als maatschappelijk smeermiddel en maakt economische transacties mogelijk (Arrow, 1972). Ondernemers moeten bereid zijn risico's te nemen om succesvol te kunnen handelen bij een fluctuerende vraag. In recente empirische studies wordt gesuggereerd dat in maatschappijen waar men elkaar wantrouwt, er minder wordt geïnvesteerd, de economische groei lager is en dat er meer overheidstoezicht nodig is (Ahgion et al., 2010; Algan en Cahuc 2010). Daarnaast zijn er structurele correlaties tussen de risicovoorkeur van mensen en de arbeidsmarktkeuzes die als riskant kunnen worden gekarakteriseerd. Bijvoorbeeld: risicomijdende mensen werken vaker in de publieke sector en kiezen minder vaak voor het zelfstandig 


\section{Summary in Dutch}

ondernemerschap. De causaliteit van deze relaties is echter moeilijk vast te stellen, omdat er vaak andere factoren zijn die zowel de metingen van de voorkeuren als de economische keuzes van individuen kunnen beïnvloeden.

\section{DOEL EN METHODE}

Het doel van dit proefschrift is het vaststellen van de causale effecten van de belangrijke individuele economische voorkeuren, zoals de risicovoorkeuren en het collectieve vertrouwen in onbekende mensen ten opzichte van de bekende, op een aantal economische uitkomsten. De uitkomsten, die in verschillende hoofstukken worden behandeld, zijn als volgt: hoofdstuk 2 laat zien hoe het collectieve vertrouwen de keuze voor verschillende politieke en economische systemen beïnvloedt. In hoofdstuk 3 wordt aangetoond dat de individuele risicovoorkeur een effect heeft op de beroepskeuze, gemeten aan de verschillen in de loonspreiding tussen verschillende beroepen. De focus van hoofdstuk 4 ligt op het identificeren van de effecten van risicovoorkeuren op de keuze van het type dienstverband, met name de keuze om werknemer of zelfstandig ondernemer te willen worden. In hoofdstuk 5 staat de relatie tussen risicovoorkeuren, baanmobiliteit en de loonontwikkeling van jonge werknemers centraal.

Deze relaties worden onderzocht door het uitvoeren van econometrische analyses van grote panel databestanden die afkomstig zijn van jaarlijkse enquêtes onder de Oekraïense bevolking (ULMS) en in Duitsland (SOEP). Een aanvullende analyse in hoofdstuk 4 is gebaseerd op een Nederlandse databestand (Noord-Brabant). De keuze van de casuslanden wordt deels gedicteerd door beschikbaarheid van de data (hoofdstuk 5). Echter de belangrijkste reden om te focussen op Oekraïne (hoofdstuk 2, hoofdstuk 3 en een deelanalyse in hoofdstuk 4) is het feit dat verschillende instituties in Oekraïne een aantal belangrijke verschillen op het geografisch territorium kennen en een drastische verandering ondergingen in de loop der geschiedenis. Hetzelfde geldt voor Oost-Duitsland (deelanalyse in hoofdstuk 4). Het begrip instituties wordt in dit proefschrift breed geïnterpreteerd. Het omvat zowel instituties die de politieke regimes karakteriseren, als economische instituties, zoals de inrichting van een bepaalde type van economisch systeem, alsook sociale en maatschappelijke instituties, die medebepalen hoe een maatschappij in elkaar zit en hoe mensen met elkaar omgaan.

Dankzij de unieke methode die in dit proefschrift gehanteerd wordt, is het mogelijk om in sommige gevallen conclusies te trekken met betrekking tot causaliteit van de geïdentificeerde relaties. Met name het gebruik van de onverwachte veranderingen in de instituties, die door de economische en politieke transitie in 
Oekraïne en in Oost-Duitsland werden veroorzaakt, maakt het mogelijk om een aantal factoren als exogeen te beschouwen. Exogeniteit van de factoren is van belang, omdat als mensen door hun keuzes en (omgevings-)factoren elkaar wederzijds kunnen beïnvloeden (d.w.z. dat de factoren endogeen zijn), het onmogelijk is om zekerheid te krijgen over de causale relatie tussen oorzaak en gevolg. Het vaststellen van causale relaties kan helpen om betere beleidsmaatregelen te nemen die individuele keuzes kunnen beïnvloeden.

\section{VERTROUWEN EN DE KEUZE VAN ECONOMISCHE EN POLITIEKE SYSTEMEN}

Hoe kan het collectieve vertrouwen in onbekende mensen (ten opzichte van het vertrouwen in bekende relaties, zoals hechte familie- en vriendenkringen) de keuze van een economisch en politiek systeem beïnvloeden? In hoofdstuk 2 wordt deze vraag beatwoord middels een analyse die gebruik maat van verschillen in de historische instituties die bestonden in verschillende delen van de Oekraïne.

De geschiedenis van Oekraïne door de eeuwen heen wordt gekenmerkt door langdurige periodes van overheersing door naburige heersers. Met name het oosten van het land werd eeuwenlang bestuurd door het Russische Rijk, terwijl het westen onder de invloed van Polen, Litouwen, en later het Habsburgse Rijk was. De bevindingen uit verschillende disciplines laten zien dat het Habsburgse Rijk, door het respect hebben voor de verschillende, multinationale bevolking van het Rijk tezamen met een bureaucratische benadering van de relaties met de lokale bevolking, het collectieve vertrouwen in het westen minder negatief beïnvloedde dan het regime van het Russische Rijk in het oosten van het land. Het beoogde doel van het Russische Rijk was om de lokale bevolking onderdeel van het Russische Rijk te maken, middels repressies en vervolgingen (Magocsi, 2010). Gebaseerd op de geschiedenis van de Oekraïne, is aan te tonen dat de instituties verschillend waren in het oosten en het westen totdat de bolsjewieken aan de macht zijn gekomen. Oekraïne is een sovjet-socialistisch republiek geworden na 1922 in het oosten en na 1945 in het westen. In 1991 met de val van de Sovjetunie is Oekraïne een onafhankelijke staat met gelijke economische en politieke instituties op het gehele territorium geworden.

In recente wetenschappelijke studies wordt aangetoond dat het collectieve vertrouwen (i.e. tot hoever mensen het vertrouwen hebben in de mensen die ze nog nooit gekend hebben ten opzichte van de mensen met welke ze een hechte relatie hebben, zoals familie en vrienden) negatief beïnvloed wordt door externe gebeurtenissen, zoals oorlogen, slavenhandel, repressieve autoritaire politieke regimes enz. (Nunn en Wantchekon, 2011). Het vertrouwen wordt 'doorgegeven' aan de 


\section{Summary in Dutch}

volgende generaties, omdat de ouders hun kinderen opvoeden zodat de kinderen de voorkeuren en persoonskenmerken die gelijk aan hun ouders zijn. Op deze manier blijft het niveau van vertrouwen relatief stabiel, zolang geen andere externe gebeurtenissen het beïnvloeden. Het vertrouwen dat eeuwen geleden negatief is beïnvloed, blijft daarom ook op een laag niveau.

Door de ontwikkeling van de (historische) instituties in Oekraïne verschillen de niveaus van vertrouwen in het oosten en het westen. Het Russische Rijk heeft het vertrouwen in het oosten zodanig negatief beïnvloed, dat de gevolgen ervan nog vandaag de dag zichtbaar zijn. Het ontbreken van het collectief vermogen tot een relatie van vertrouwen in te gaan met onbekende mensen zorgt ervoor dat de mensen liever geen vrije markt economie en geen democratisch politiek systeem willen hebben. Een vrije markt economie houdt in dat mensen, onbeperkt door de regering, vrij kunnen handelen. Als een partner in handel zich niet aan de afspraken houdt, terwijl de andere partner dat wel doet, wordt die laatstgenoemde partner daar een dupe van. Om deze situatie te voorkomen, kiest de bevolking voor een sterke staatstoezicht in de vorm van een door de staat gecontroleerde economie. Anderzijds, kan een democratisch politiek systeem niet zonder onderliggend vertrouwen functioneren. Om de onverwachte uitkomsten van een democratisch proces tegen te gaan, kiest de bevolking liever een autocratisch politiek regime.

In het westen van Oekraïne daarentegen, hebben mensen meer vertrouwen door de eeuwen heen kunnen opbouwen. Omdat de mensen in het westen meer vertrouwen hebben in onbekende mensen met welke ze economische relaties ingaan of die hun politieke keuzes moeten representeren, willen ze liever voor minder staatsingreep in de regulering van de maatschappij. Ze geven de voorkeur aan meer liberale systemen, zoals een vrije markteconomie en een democratisch politiek systeem. Deze onderliggende verschillen in het collectieve vertrouwen schijnen vandaag de dag (anno 2014) te echon in keuzes dat bevolking in het westen maakt richting de ontwikkeling van het democratische staat tegenover de keuzes in oosten, die de sterk reguleerde systemen ondersteunen.

\section{RisicovoORKEUREN: BEROEPSKEUZE}

De transitie, die in 1991 begon met een referendum waarin de meerderheid van de bevolking ervoor koos om een onafhankelijk land te worden, heeft een aantal belangrijke economische instituties veranderd. Met name is de loonstructuur in verschillende beroepen veranderd van een gecentraliseerde stelsel, dat gebruikt werd toen het land onderdeel van de Sovjetunie uit maakte, naar een markt-gedreven structuur. Deze verandering in de structuur van beloning leent zich ervoor om het effect 
van risicovoorkeur op de beroepskeuze te analyseren. In hoofdstuk 3 wordt hier nader op ingegaan. Het gecentraliseerde stelsel van de Sovjetunie zorgde ervoor dat de onverklaarde loonvariabiliteit binnen beroepen heel klein was. De onverklaarde loonvariabiliteit is datgene wat van de totale loonvariabiliteit overblijft nadat deze gecorrigeerd is voor de 'harde factoren' die de loonvariabiliteit verklaren (menselijk kapitaal variabelen). Lage onverklaarde variabiliteit betekent dat individuen met hoge zekerheid kunnen verwachten wat hun verdiensten zullen zijn. Hoge onverklaarde variabiliteit is daarentegen risicovol, omdat mensen niet weten of ze veel of weinig gaan verdienen in dat beroep. Omdat het Sovjetstelsel de lonen centraal vaststelde, was de zekerheid in alle beroepen zeer hoog.

Met de politiek-economische transitie werd het instituut van loonbepaling veranderd, zodat de loonvariabiliteit in veel beroepen gegroeid is, terwijl in anderen niet. Bijvoorbeeld, binnen de functie 'bedrijfsmanager' nam de variabiliteit drastisch toe, terwijl in het beroep 'hulpdocenten' de variabiliteit bijna hetzelfde bleef als voor de transitie. Hoewel de andere baankarakteristieken ongeveer gelijk zijn gebleven, is de loonvariabiliteit heel anders geworden ten opzichte van het moment dat mensen hun oorspronkelijke beroepskeuze op de arbeidsmarkt maakten. Zoals verwacht had de risicovoorkeur voor de transitie (in 1986) geen invloed op de beroepskeuze, afgemeten aan de loonvariabiliteit. Na de transitie (in 2007) heeft risicovoorkeur echter een significant effect op de keuze van beroep. Met name de mensen die van beroep wisselen tussen 1986 en 2007 laten zien hoe de correlatie tussen risicovoorkeur en beroepskeuze ontstaat na de transitie. In hoofdstuk 3 wordt het bewijs gepresenteerd dat het effect van risicovoorkeur op de beroepskeuze een causaal karakter heeft.

\section{RisicovoORKEUREN：DIENSTVERBAND}

Een andere belangrijke institutionele beperking die door de transitie werd opgeheven, was het verbod op ondernemerschap. In hoofdstuk 4 wordt dit thema nader uitgewerkt. Het centraal gecontroleerd economisch systeem in Oekraïne als onderdeel van de Sovjetunie stond geen particulier ondernemerschap toe. Door de strenge regelgeving in Oost-Duitsland tot 1989 leek zelfstandig ondernemerschap nauwelijks op wat wij nu onder ondernemerschap verstaan. Deze institutionele voorwaarden zorgden ervoor dat er begin jaren 1990 weinig of geen zelfstandige ondernemers waren. Deze bevinding is belangrijk omdat het laat zien dat mensen in de Oekraïne en het Oost-Duitsland geen specifieke vaardigheden en ondernemerschapskennis via hun familie konden krijgen.

Recente bevindingen laten zien dat ouders hun voorkeuren, zoals het ver- 


\section{Summary in Dutch}

trouwen en de risicovoorkeur aan kinderen doorgeven (Tabellin 2008b; Dohmen et al., 2012). Dat betekent dat ouders die risiconemend zijn ook vaker kinderen hebben, die hoger dan gemiddeld risicovoorkeur hebben. Gezien dat ondernemerschap vaak via de familie wordt doorgegeven, is het mogelijk dat de vaak geobserveerde relatie tussen risicovoorkeur en de keuze voor zelfstandig ondernemerschap een schijncorrelatie kan zijn. De kinderen erven dan niet alleen de risicovoorkeur maar ook de vakspecifieke kennis die de keuze voor zelfstandig ondernemerschap veel minder risicovol maakt. Uit de in dit proefschrift gepresenteerde analyse van Oekraïne en Oost-Duitsland blijkt dat de nieuwe generatie geen vakkennis van hun ouders had kunnen erven omdat hun ouders nooit zelfstandig zijn geweest. De positieve relatie tussen de risicohouding en de keuze voor zelfstandig ondernemerschap onder deze condities bewijst daarom dat de risicovoorkeur een causaal effect heeft op zelfstandig ondernemerschap. Aanvullend bewijs wordt geleverd met data uit Nederland, waar zelfstandig ondernemerschap een lange traditie kent. Hieruit blijkt dat er geen effect van de risicovoorkeur op de keuze voor zelfstandig ondernemerschap is als een persoon vanuit een ondernemend gezin komt en het bedrijf van de ouders overneemt.

\section{RISICOVOORKEUREN：MOBILITEIT}

In hoofdstuk 5 staat de relatie tussen risicovoorkeur en baanmobiliteit centraal. De relatie tussen het aantal verschillende banen van jonge werknemers en de loonontwikkeling tijdens de werkcarrire is in de vakliteratuur vaak bestudeerd. De conclusies lopen echter uiteen: de baanmobiliteit kan een positief, negatief of geen effect hebben op de loonontwikkeling (Topel en Ward, 1992; Light en McGarry, 1998). In hoofdstuk 5 wordt een mechanisme gepresenteerd dat deze tegenovergestelde resultaten kan verklaren. Wanneer men de factor risicovoorkeur in de analyse meeneemt blijkt dat dit een belangrijke factor is die de baanmobiliteit kan beïnvloeden, omdat van baan veranderen een risicovolle stap is. Mensen willen voor risico's gecompenseerd worden en mensen die meer risicomijdend zijn, vragen een hogere compensatie voor hetzelfde risico dan meer risiconemende mensen. Dit leidt ertoe dat mensen die minder van risico's houden, een hogere compensatie zullen vragen bij het veranderen van baan.

Aannemend dat alle andere factoren gelijk blijven, zullen risicomijdende werknemers minder vaak van baan veranderen dan risiconemende werknemers. Tegelijkertijd is de loongroei gerelateerd aan baanverandering van risicomijdende mensen hoog, omdat risicomijdende mensen alleen van baan veranderen als de compensatie hoog genoeg is (en dus hoger is dan voor mensen die minder risicomijdend 
zijn). Dit verschil in gedrag van risicomijdende en risiconemende mensen brengt verschillende patronen van loonontwikkeling met zich mee. De bevindingen uit de Duitse data komen overeen met de theoretische hypothese. Het aantal banen dat risicomijdende mensen houden in de eerste jaren op arbeidsmarkt is lager dan het aantal banen dat risiconemende mensen houden. De loongroei gerelateerd aan baanwisselingen daarentegen hoger is voor risicomijdende werknemers ten opzichte van risiconemende werknemers.

\section{Conclusie}

Dit proefschrift toont aan dat individuele voorkeuren, zoals de risicovoorkeur en het vertrouwen, economische keuzes beïnvloeden. Het collectieve vertrouwen in onbekende mensen, dat door de generaties heen wordt doorgegeven, schijnt een causale effect te hebben op de keuze van economische en politieke systemen. Als er weinig vertrouwen is in de maatschappij, kunnen de vrije markt en het democratische politieke systeem niet naar behoren functioneren. Deze conclusie wordt mede ondersteund door de eerdere ontwikkelingen in de postcommunistische landen na de val van de Sovjetunie. Terwijl de kennis en de ondersteuning van de WestEuropese landen en de V.S. prominent aanwezig was, onder andere in Oekraïne in de jaren 1990, bleek het invoeren van een democratische staat en een marktgeorinteerd economisch systeem is weinig succesvol. Een van de redenen hiervoor is het ontbrekend sociaal vertrouwen. In 2007, tijdens de zogenaamde Oranjerevolutie in Oekraïne, waren de politieke keuzes van de bevolking duidelijk verdeeld, zodat het westen grotendeels het Europese model van democratie en marktrelaties ondersteunde. De bevolking in het oosten daarentegen voorkeur had voor het herstellen het autocratisch, sterk gereguleerd systeem dat meer gelijk zou zijn aan dat van de Sovjetunie. Daarnaast laten de recente gebeurtenissen in 2014 zien dat de onderliggende verschillen in de voorkeuren nog altijd een prominente rol kunnen spelen.

De risicovoorkeur is een belangrijke drijfveer van de arbeidsmarketkeuzes, zoals beroepskeuze, de keuze van dienstverband en baanmobiliteit. Risicomijdende mensen willen liever een baan hebben die zekerheid biedt. Ze zijn dan ook bereid om gemiddeld een lager salaris te accepteren zolang ze meer zekerheid hebben over hun verdiensten. Deze bevinding laat zien hoe belangrijk de oorspronkelijke beroepskeuze op de arbeidsmarkt is, omdat de mensen die een beroep kiezen dat niet bij hun risicovoorkeuren past, eerder geneigd zijn om van beroep te wisselen. Het menselijke kapitaal dat opgebouwd word tijdens de studie en de jaren van arbeidsmarktervaring wordt minder waardevol in dat geval. Dit heeft 
negatieve economische (en emotionele) consequenties zowel voor de werknemers als voor de maatschappij, die voor deze keuzes moet betalen. Daarnaast zullen verschillende maatregelen ter bevordering van ondernemerschap het beoogde doel bereiken zolang ze gericht zijn op de mensen die met risico's kunnen omgaan. Risicomijdende mensen zijn veel minder geneigd zelfstandig ondernemers te worden tenzij ze de kennis een vaardigheden kunnen krijgen die de risico van ondernemerschap aanzienlijk kunnen verminderen.

Risicovoorkeur schijnt ook invloed te hebben op de manier waarop mensen beslissingen nemen om nieuwe, onbekende ervaringen in een andere baan op te doen. Risicomijdende mensen willen alleen van baan veranderen als de risico, die de baanverandering met zich mee brengt, aanzienlijk gecompenseerd wordt. Deze bevinding heeft implicatie voor het beleid dat mensen moet stimuleren om mobiel en vitaal te blijven. Omdat mensen naarmate ze ouder worden, meer risicomijdend worden, moeten de maatregelen die baanmobiliteit stimuleren, rekening houden met het feit dat oudere werknemers die van baan moeten veranderen, een grotere compensatie ervoor zouden willen hebben dan jongere, in het algemeen meer risiconemende werknemers. Het is belangrijk om zich te realiseren dat de veranderingen, die altijd het risico van het onbekende met zich mee brengen, meer (emotionele) kosten betekenen voor risicomijdende mensen. 


\section{NON-TECHNICAL SUMMARY}

\section{Preferences, institutions, And ECOnomic outcomes: An EMPIRICAL INVESTIGATION}

One of the classical economic problems involves determining factors that affect individual choices on the labour market, such as the decision to take paid employment or to go study, occupational choice and mobility. The effects of various 'hard' factors, such as price of labour, market rents, wealth, education level, family composition, parental occupation etc. have been extensively studied in the literature. Nevertheless, much less is known about the effects of 'soft' factors, such as personality characteristics and preferences. It is important to know how these factors can affect human behaviour, since recent findings indicate that people make different choices in similar situations (Kahneman and Tversky, 1979). Important labour market phenomena can be explained better if underlying differences in preferences are taken into account.

The role of preferences and personality traits has been recognised long ago. Theoretical arguments of classical authors involve trust and risk preference as important causes of economic growth. Trust works as a lubricant in a society and makes economic transactions possible (Arrow 1972). Entrepreneurs should be willing to accept risk in order to be able to successfully manage production in the conditions of fluctuating demand. Recent empirical findings suggest that in distrustful societies there are less financial investments, economic growth is slower and more control from the state is demanded by the citizens (Ahgion et al., 2010, Algan and Cahuc, 2010). Robust correlations are also found between risk attitudes and labour market choices characterised by a certain amount of risk. For example, risk-averse individuals are more often employed in a public sector and are less often self-employed. Causality of these relationships is however difficult to establish 
because many factors can have an impact on the measurements of preferences, as well as on economic choices.

\section{GoAl AND METhods}

The goal of this dissertation is to shed light on causality of the important economic preferences, such as trust and risk attitudes, on several economic outcomes. The outcomes that are treated in separate chapters are as follows: Chapter 2 shows how trust affects choice of different political and economic systems. In Chapter 3, the focus is on the role of risk attitudes for occupational choice, as measured by unexplained variance of earnings across occupations. The goal of Chapter 4 is to identify the effect of risk attitudes on the choice of status in employment, i.e. whether to take a paid employment or to become self-employed. In Chapter 5 , the relationship between risk attitudes, job mobility and wage growth of young employees is investigated.

These relationships are studied by means of econometric analyses of large panel datasets coming from the yearly surveys in Ukraine (ULMS) and in Germany (SOEP). An additional analysis in Chapter 4 is based on the Dutch data (NoordBrabant). The choice of the countries is partially given by availability of the data. A more important reason to focus on Ukraine is however the fact that there were very different institutions in different parts of Ukrainian territory, which underwent some drastic changes caused by the transition (Chapter 2, Chapter 3, and part of Chapter 4). The same reason is relevant for East Germany (part of the analysis in Chapter 4). The notion of institutions is interpreted broadly in this dissertation. It includes political institutions typical for a certain type of political regime, as well as institutions that shape economic systems, and cultural institutions that shape social structures.

The unique research method used in this dissertation allows to draw some conclusions with respect to causality of the identified relationships. Using the unexpected changes in institutions triggered by economic and political transition in Ukraine and in East Germany makes it possible to treat several factors as exogenous. Exogeneity of the factors is important, because people can influence factors by their behaviour and the other way around (i.e. factors are endogenous to choices). Under such conditions it is impossible to be sure whether a certain factor really has an effect. Establishing causality helps to implement policies that can really affect behaviour. 


\section{SOCIAL TRUST AND CHOICE OF ECONOMIC AND POLITICAL}

SYSTEMS

How can social trust (trust in unknown people as opposed to trusting in closed networks of family and friends) affect the choice of economic and political systems? In Chapter 2, this question is answered by means of analysis that uses the differences in historical institutions that existed on the territory of Ukraine.

The history of Ukraine is distinguished by long periods of repression by neighbouring empires. In fact, the east of the country was ruled by the Russian Empire during the centuries, whereas the west was under the influence of Polish-Lithuanian Commonwealth and later, of Habsburg Empire. Habsburg Empire, because of the well-established bureaucracy and respect to its various, multinational population, was less damaging for trust than the regime of the Russian Empire. Russian Empire tried to assimilate the local populations and to make it one whole with the empire, using repressions and persecutions (Masocsi, 2010). Based on the history of Ukraine, it is possible to argue that the institutions were different between the east and the west until the Bolsheviks took the power. Ukraine became a soviet socialist republic after 1922 in the East and after 1945 in the West. In 1991, with the collapse of the Soviet Union Ukraine has become an independent state with uniform political and economic institutions on the whole territory.

Recent research findings indicate that social trust (i.e. the collective ability to trust in people who are strangers relative to the people with whom there is a strong relationship, such as family and friends) can be damaged by external events, such as wars, slavery, a repressive authoritarian political regime etc. (Nunn and Wantchekon, 2011). Social trust is transmitted to the next generations, because parents bring up their children such that children become more like parents. In this way, the level of trust remains stable, as long as no other external events can affect it. Social trust that was damaged centuries ago, remains low for generations.

Because of the differential paths of (historical) institutional development in Ukraine, trust has been accumulated differently across west and east. The rule of Russian Empire in the East has damaged social trust to such an extent that the consequences can be seen nowadays. Lack of social trust, the inability to invest in a relationship with unknown people leads to rejection of a market economy and of a democratic political system. A free market economy implies that people, unrestricted by the government, can freely engage in trade with each other. However if the partner in trade does not keep up with their promises, while the other party does, this lastly named party ends up in a bad position. To prevent such situations, people prefer a stronger government regulation of the economy 
and chose a planned economy (Soviet style) economic system. On the other hand, a democratic political system cannot function properly without underlying social trust. To prevent unexpected outcomes of a democratic process, people choose an autocratic political regime.

In contrast, in the West of Ukraine, people managed to keep more social trust through the centuries. Because people in the West have more trust in unknown people with whom they hold economic relationships or who they choose to represent their political choices, they prefer less control from the state in regulation of economic and political matters. They chose more liberal systems, such as a market-based economy and a democratic political system. Inherited differences in social trust seem to echo in the choices Ukrainian population makes today (in 2014), when western Ukraine chooses the direction of a democratic state, whereas eastern Ukraine supports strongly regulated systems.

\section{Risk ATtitude: ocCUPATIONAL CHOICE}

The transition that started in 1991 with a referendum that proclaimed Ukraine as an independent state, has changed several important economic institutions. In particular, the wage structure in various occupations changed to a market setting wage system instead of a centralised system that was in use during the Soviet Union times. This change in the reward structure lends itself to study the effect of risk attitudes on occupational choice in Chapter 3. In the heavily centralised system in Soviet Union wage setting took place centrally, so that the unexplained wage variance in occupations was very low. The unexplained wage variance is what remains of the overall variance after it has been corrected for observable characteristics, such as education level, age, labour market experience etc. Low unexplained variance means that individuals can more exactly predict what their wages will be once they find employment. High unexplained variance is, on the contrary, risky, since workers can end up either on the high as low end of wage distribution. Because of the centralized wage setting in the Soviet Union, the earnings risk reflected in wage variance was very low in all occupations.

The institute of wage setting has changed with the economic transition, so that the earnings risk increased in various occupations. For example, in the occupation 'Corporate managers' the earnings risk has increased dramatically, whereas in the occupation 'Teaching associate professionals' the earnings risk remained as low as it was before transition. While most of the occupational characteristics remained the same, earnings risk has became very different with respect to the risk people where facing when they made their occupational choices before transition. As 
expected, risk attitudes had no effect on the choice of occupation, as measured by the unexplained wage variance, before transition (in 1986). After transition (in 2007) risk attitudes have a significant effect on occupational choice. In particular, the workers who change occupations between 1986 and 2007 explain the correlation between risk attitudes and occupational choice that develops during transition. This chapter presents field evidence that supports causal interpretation of the effect of risk attitudes on occupational choice.

\section{RisK ATTITUDE: SELF-EMPLOYMENT}

Another important institutional constraint that is removed by the transition is the restriction on self-employment, which is the focus of Chapter 4. Centrally controlled economic system in the Soviet Ukraine did not allow any private entrepreneurship. Because of strict regulation in East Germany until 1989, selfemployment there was hardly like what we understand under self-employment nowadays. These institutional constraints brought about the situation in which there were virtually no self-employed people on the whole territory of Ukraine and in East Germany in the beginning of 1990's. This finding is important because is illustrates that one of the most important transmission channels of self-employment was closed, namely the channel by which parents transmit self-employment to their children. The parents in the Soviet Ukraine and in East Germany could not transmit any specific self-employment knowledge or skills to their children because they had never been self-employed themselves.

Recent findings show that parents transmit their preferences to the children (Tabellini 2008b; Dohmen et al., 2012). This means that parents who are more willing to take risks are more likely to have children who are also more risk-tolerant. Because entrepreneurship is often transferred through the family, it is possible that the relationship between risk preferences and the choice for self-employment might be a spurious correlation. The children not only inherit the risk attitudes from their parents, but also specific knowledge about what it is like to be selfemployed. This knowledge can make the choice for self-employment much less risky. In our data from Ukraine and East Germany, people could not have inherited any knowledge about self-employment because their parents have never been selfemployed. The positive relationship between risk attitudes and the choice for selfemployment under these conditions shows that risk attitudes have a causal effect on self-employment. The additional evidence from the Netherlands, a country with a long tradition in self-employment, demonstrates that there is no effect of risk 
attitudes on the choice for self-employment if individuals come from entrepreneurial families and take over a business from their parents.

\section{Risk ATTITUDE: JOB MOBILITY}

Chapter 5 analyses the relationship between willingness to take risks and job-tojob mobility. The relationship between how many jobs young people hold and the development of their wages later in the career is extensively studied in the literature (Topel and Ward, 1992; Light and McGarry, 1998). The findings are however inconclusive: job mobility can have a positive, a negative, or zero effect on wage growth. In Chapter 5 a mechanism is proposed which can explain the inconsistent findings. Risk attitudes is an important factor which can affect job mobility, because changing jobs is a risky decision. People want to be compensated for uncertainty they need to deal with. Individuals who are more risk-averse demand a higher compensation for the same risk than more risk-tolerant individuals do. This implies that less risk-tolerant people would demand a higher compensation for changing jobs.

Assuming all other factors are held constant, risk-averse workers will change jobs less often than workers who are more willing to take risks. At the same time, the wage increases related to each job change of risk-averse individuals are high, since risk-averse people only change jobs if compensation is high enough (it is higher than compensation demanded by less risk-averse people). This difference in behaviour of risk-averse and risk-tolerant people causes different wage growth patterns. The findings based on German data confirm the theoretical predictions. The total number of jobs during the first years on the labour market is lower for more risk-averse individuals, whereas the wage increases associated with the job changes are higher.

\section{Conclusion}

This dissertation shows that individual preferences, such as risk attitude and social trust, affect economic choices. Social trust transmitted through generations is likely to have a causal effect on the choice of economic and political systems. If there is little trust in the society, a market economy and a democratic political system cannot function properly. This conclusion is supported by the early developments in the post-Soviet countries after the collapse of the Soviet Union. Despite support from the Western European countries and the US, among others in Ukraine in 1990's, implementation of a democratic political system and of a market-oriented economic system did not go as well as expected. In 2007, during the so-called 
Orange Revolution in Ukraine, the political choices were clearly divided, such that the western part of Ukraine supported a Western model of democracy and a market economy. The population in the East, in contrast, preferred to restore the autocratic, strongly regulated system similar to the organisation of the Soviet Union. Additionally, the recent events of 2014 demonstrate that underlying differences in preferences still can play a prominent role.

Risk preference is an important factor that affects labour market choices, such as occupational choice, the choice of employment status and job mobility. Riskaverse individuals prefer to have a job with high security. They are also prepared to accept lower wages as long as the stability of their earnings is guaranteed. This finding illustrates how important is the first choice of occupation, since people who are sorted in occupation that is not well-aligned with their risk attitudes, are more likely to switch occupations. Human capital accumulated during the years of studying and working in the original occupation loses its value in this case. This brings negative economic (and emotional) consequences for employees but also for the society, which has to pay for these choices. Apart from that, various measures for promoting self-employment will only be successful in risk-tolerant populations. Risk-averse individuals are much less likely to become self-employed, unless they have access to information and skills that can diminish the uncertainty associated with entrepreneurship.

Risk attitudes are likely to affect job mobility decisions. Changing jobs is a way of receiving new experience and developing new competencies. However, riskaverse people will change jobs only in case the risk, associated with changing jobs, is generously compensated. This finding has an implication for the policy that intends to stimulate people to remain vital and mobile on the labour market. Since people, as they grow older, tend to become more risk-averse, the measures stimulating job mobility in particular among older workers, should take into account that older, more risk-averse people will need a larger compensation for changing jobs than younger, in general more risk tolerant population. It is important to realise that changes that always bring the uncertainty of unknown, imply higher (emotional) costs for more risk-averse people. 



\section{BIOGRAPHY}

Olga J. (Jewgenjewna) Skriabikova was born on November 29, 1984 in Novosibirsk, former Soviet Union. She completed her Bachelor studies in Sociology, with specialisation in Social Work, cum laude in 2006 at the National University of "Kyiv-Mohyla Academy" in Kyiv, Ukraine ${ }^{1}$. She started a master program in Public Health at the same university. During her Master study in Kyiv, Olga contributed to a research project at the Coalition of HIV-services organisations. She also worked at the tuberculosis control programme at the Kiev country office of the WHO (World Health Organisation). In 2007, Olga received a MTEC (Matra Training for European Cooperation) grant, which allowed her to follow a fulltime Master program at Maastricht University, the Netherlands. She graduated as Master of Science Public Health (MPH) from Maastricht University in 2008.

In January 2009, Olga started her PhD project at the School of Business and Economics of Maastricht University. Olga worked as a researcher and a PhDcandidate at the Research Centre for Education and the Labour Market (ROA). She completed two years of Research Master courses and deepened her expertise in particular in econometrics. She was teaching Bachelor and Master courses and participated in several contract research projects. Olga attended two summer schools: Summer School in Experimental Design at Nuffield Centre for Experimental Social Sciences, Oxford University and the Summer School 'Evolution of Social Preferences', at the University of Trento. She presented her papers at international conferences, such as SOLE, ESPE, SES and EALE.

In 2013, Olga contributed to a research project 'Safer and healthier work at any age' contracted by European Agency for Safety and Health at Work (EUOSHA). Since March 2014, Olga works as a knowledge strategist at the Limburg Government.

\footnotetext{
${ }^{1 ' K y i v ' ~ a n d ~ ' K i e v ' ~ a r e ~ d i f f e r e n t ~ s p e l l i n g s ~ o f ~ t h e ~ n a m e ~ o f ~ t h e ~ s a m e ~ c i t y . ~ K y i v ~ i s ~ t h e ~ U k r a i n i a n ~}$ version, whereas Kiev is the Russian version. Both versions are accepted.
} 



\section{VALORISATION ADDENDUM}

Probably, the most important general conclusion of this dissertation is that people are different. While this is not going to be a ground-breaking eye-opener from the point of view of psychology, from the economic perspective of thinking, this means an important shift of paradigm. Most of our economic policy decisions are implicitly or explicitly based on the assumption that some underlying personal preferences, the drivers of human behaviour, are the same across individuals. A standard economic model thus assumes that everybody can deal with risks in a similar way and that humans are to the same extent impatient about receiving something today instead of waiting for tomorrow. As a result, the additional financial stimulus necessary to induce someone to take an action associated with risk or a delayed outcome is expected to be the same for every person. In other words, rationally, people are expected to make the same choices under identical circumstances.

The results presented in this dissertation show, in contrast, that depending on their economic preferences, such as social trust and willingness to take risks, people make different decisions. By making use of population wide representative surveys, by combining different data sets and by using information of historical development of institutions in three different countries, this dissertation shows that usually unobservable personal characteristics have a causal, measurable effect on economically relevant choices. The outcomes considered here vary from general support for a particular type of political or economic system to important labour market choices, such as choice of occupation, status in employment and the decision to change jobs. When trying to explain, predict or influence behaviour and choices people make, the influence of an essential factor is missing, if one does not take individual preferences into account. 


\section{THE IMPORTANCE OF SOCIAL TRUST}

In particular, the first empirical study of this dissertation considers the origins and effects of social trust. Social trust is the ability of individuals to trust unknown people, as opposed to relying on closed networks of family and friends. This very basic economic preference underlies the existence of cooperative norms, values and beliefs shared by the members of a particular society, and it has a tremendous potential to influence the direction of the economic and political development. Social trust is essential for the capacity to effectively solve a public good problem, such as allocation of collective resources. The amount of social trust varies among populations, because the accumulation of social trust is affected by external events. The argument in this dissertation shows that negative historical events, such as wars, slavery or severe repressions, destroy the ability to trust unknown individuals. Instead, people prefer to deal with their closed circle of family and friends. This inability persists through the generations because it is much more difficult to restore social trust than to destroy it.

There are at least two negative consequences of lack of social trust. First, since no market activity among unknown to each other traders can exist without some amount of trust, lack of social trust undermines the functioning of a market economic system. Even if a well-functioning law system exists and laws are legitimately enforced, it is virtually impossible to specify every single nuance of a specific situation in a contract. Contracts normally have an enforcing power, because people who write the contracts expect and thus trust that the other party will respect the conditions. If social trust is lacking, however, taking the other party to the court every time the contract is breached brings about a very inefficient outcome. It is then individually rational to only trust the partners who are well-connected through blood or other close relationship, because they will have some very strong incentives to keep their promises. The emergence of well-connected, economically powerful families, who control key industry, is a logical outcome of this type of economic development.

Another consequence of lack of social trust is the inability of a society to deal with changing political forces and democratically elected leaders. A properly functioning democracy rests on strong bureaucratic institutions with a well-defined system of checks and balances that limit executive power. This system, in its turn, relies on the contribution of citizens in elections, as the expression of societal problems that need to be solved by governmental action. When citizens do not trust that the election of leaders who are unrelated to them will serve to represent their will, they have no incentives to contribute to a democratic process. On the other 
hand, governments need to rely on support of the electorate in order to achieve meaningful changes and be able to implement unfavourable reforms. When social trust is lacking, reliance on favours to close networks becomes necessary, leading to corruption in the political process.

The developments in former Soviet Union countries, in particular in Ukraine, readily illustrate the importance of the underlying level of social trust. Already in the beginning of the 1990's, reforms of the political and economic system did not achieve the desired results. The hope of Western reformers was to initiate market reforms, so that the 'invisible hand' will correct imbalances of the outdated centrally-planned economic system. Setting up the conditions for a democratic political system by disbanding the rule of the communist elite and adopting some democratic political institutions seemed to be sufficient to set the country on the development path to a proper democratic state. One of the essential reasons for the failure of these well-meant efforts is likely to be a lack of social trust. For the reasons described above, the strongly regulated Soviet regime actually kept mafia and corruption under control to some reasonable level. The moment the strong control of the state ceased to exist, negative consequences of lack of social trust became much more prominent.

As the history of Ukraine shows, the country was separated for centuries. The East of Ukraine was under the influence of the Russian Empire and later, in the 20th century, it became a part of the Soviet Union much earlier than the West of Ukraine did. The treatment of the local population by the rulers from Russia, and later, by the Soviet Union authorities, was not favourable for the accumulation and preservation of social trust. Political repressions, a ban to use the own language, cultural persecutions and the famine in the beginning of the 1930 's contributed to the damaging of social trust. In contrast, the conditions in the West of Ukraine, even if they were not particularly favourable for building up social trust, did not have such a devastating impact on the population. The rule of Polish-Lithuanian Commonwealth and later, of the Habsburg Empire, allowed some important freedoms that were inaccessible for Ukrainians in the East. The ability to form some local governance structures, to use the own language, to practice religion in some accordance to the local rule helped to preserve social trust in the West.

Tracing the development of political preferences of the Ukrainian population in the East and in West since the beginning of the new, independent period in the Ukrainian history shows that in the aftermath of the economic and political reforms in the 1990's that allowed more freedom to the citizens, the population in the East developed preferences favouring stronger control by the government. On the 


\section{Valorisation addendum}

contrary, the population in the West in the recent years developed support for more liberal systems, such as a market economy and a democratic political state. The conflicting views, in particular with respect to the way of organising the collective decision-making, escalated when the majority of the Ukrainian population decided to follow the direction of development characteristic for Western democratic states. The population in the East, untrusting to systems with little government control, demands a stronger rule impersonated in the Russian political leader.

These differences in choices could be explained by the underlying differences in social trust. A market-based economy and the rules of the game necessary for a properly functioning democracy cannot "land" in the population that lacks social trust. Inasmuch trust in fellow though personally unknown citizens is necessary to have political leaders to pursue reforms with the view of a more efficient organisation of social, political and economic spheres of life, the conditions that ensure preservation and accumulation of social trust are invaluable to achieve these goals. The contribution of the research to the understanding of the mechanisms of accumulation of social trust illustrates the importance of counteracting oppressive political regimes for they sow the seeds that grow deep and are cumbersome to weed centuries after planting.

\section{The ROLE OF RISK ATTITUdes IN LABOUR MARKET CHOICES: OCCUPATIONAL SORTING}

The second study of this dissertation focuses on the effects of risk attitudes on choice of occupation. Occupational choice is one of the very important choices individuals make in their life. Individuals who work in occupations that fir their preferences, are likely to be more successful in developing competencies to be productive on the labour market and thus to contribute to economic development. Workers who are sorted well in occupations, are less likely to switch to another. Since the costs of investing in education are high, both from personal as from the societal perspective, it is important to facilitate the right educational and occupational choice.

One of the important aspects of occupational choice is the earnings risk. Earnings risk reflects the risk individuals are facing when they enter a particular occupation and do not know whether they will end up at the higher or the lower part of the earnings distribution. For example, public sector jobs, in particular in teaching, are currently regulated by the government so that the starting, the intermediate and the senior level earnings are known in advance. On the contrary, many private sector occupations have more variable earnings, such that it makes 
it difficult to predict at which level one may end up when he or she starts working in this occupation.

This dissertation shows that this uncertainty about earnings has an important effect. While some people are content with a high variance of earnings, which is generally compensated by their level, other people feel very uncomfortable not knowing what to expect from the next day. Consciously neglecting other important content-related aspects of an occupation, the evidence presented here demonstrates that when the earnings risk changes suddenly, workers change their occupation. Workers prefer that the earnings risk is better aligned with their risk preferences, such that risk-loving people prefer to work in occupations with high variance of earnings, whereas risk-averse people prefer low earnings risk occupations. Wages tend to compensate workers for the risk they need to deal with, be it a mortality risk or an unemployment risk or the risk of earnings uncertainty. This is one of the reasons that occupations with generally bad working conditions, also in terms of stress, may result in better earnings. In safer occupations, on the other hand, a worker "pays" for the certainty he or she enjoys.

This knowledge can help young people who start their career to realise that it is not only the level of earnings that matters in their occupational choice. Having to deal with excessive risks can be harmful for risk-averse people, because of the stress they experience. Undesirable consequences of a wrong occupational choice can bring about feelings of dissatisfaction, anxiety and even health problems. On the other hand, changing occupations later in working career devaluates the investments in studying by reducing the value of human capital human capital build up in another occupation. This is why good quality consulting and advice to individuals at the dawn of their career can facilitate a more efficient allocation of the labour force.

\section{The ROLE OF RISK ATTITUdes IN LABOUR MARKET CHOICES: SELF-EMPLOYMENT}

The third study focuses on the importance of risk preferences for the choice of selfemployment. Self-employment, as opposed to dependent employment, is a widely recognised driver of entrepreneurship. Self-employed individuals contribute to the forging of economic value, implementing innovations and creating new employment. In contrast to workers in dependent employment, however, self-employed individuals face much more uncertainty related to fluctuations of demand and supply. In addition, social security schemes in many countries are designed for workers in dependent employment, making it more complicated for self-employed workers 


\section{Valorisation addendum}

to maintain the same level of social security. Since the majority of the population is risk-averse rather than risk-taking, stimulating self-employment is a challenging task, given the uncertainties self-employed are facing.

The field evidence showing the causal effect of risk attitudes on the decision to become self-employed provided in this dissertation, explains why the attempts to stimulate self-employment by providing some initial capital are in many cases insufficient. Although financial constraints to start a business are important, lack of these constraints will not guarantee the effectiveness of the measures. Namely, access to capital needed for a start-up does not reduce the riskiness of self-employment, which makes it an unattractive option for risk-averse individuals.

The evidence presented in this dissertation indicates that having more information on what it is like to be self-employed can make self-employment less risky. In particular, there seems to be no effect of risk attitudes on the decision to become self-employed for individuals who grew up in entrepreneurial families. Having access to important information on how to run a business, have a better understanding of who your clients can be, how to organise administration and other kinds of practical issues can reduce the objective risk of running a business. Being familiar with the life-style as a self-employed can also reduce the perceived risk of entrepreneurship and the feeling of uncertainty related to it. Since most of the people are not born in entrepreneurial families, riskiness of self-employment can be reduced by facilitating access to information, for example, by means of publishing guides, bringing people together in meetings and round tables with entrepreneurs and organising courses for practical information.

\section{THE ROLE OF RISK ATTITUDES IN LABOUR MARKET CHOICES: JOB MOBILITY}

The fourth study investigates the role of risk attitudes in job mobility. This is the first empirical evidence showing the relationship between risk attitudes and job mobility decisions. In many countries, labour market entrants change jobs frequently in the beginning of their career. The question of whether this switching behaviour is beneficial for subsequent wages has not been answered yet. It is also not clear what drives this behaviour, since according to the human capital theory, it is more profitable to stay in the same job because of the returns to the accumulated firm-specific human capital. One reason can be that young people try out and "experiment" with different jobs.

However, this experimentation has costs: not only in terms of lost returns to firm-specific human capital, premiums and fringe benefits that reward individuals 
who stay on the job longer, but also in terms of having to change the known for the unknown. Individuals who change jobs, have to get used to the new environment, new colleagues, find out what their specific tasks and wages will be. It is virtually impossible to design a contract in which all the details and nuances of the employment situation can be specified. These considerations make the decision to change jobs risky and thus, unattractive to risk-averse workers.

Most of the current policies that tackle the problems of ageing workforce and demographic transition, attempt to stimulate flexibility and mobility, in particular for ageing workers, to keep the workforce vital and motivated. In the view of the finding discussed above this might not be such a universally promising approach. People tend to become more risk-averse as they grow older, which means that they experience more disutility from unexpected changes, job changes in particular. While younger and more risk-tolerant workers might get excited about challenges associated with a new job, compared to staying where they are, more risk-averse people value the status quo higher.

\section{CONCLUding REMARKS}

The development of the labour market into becoming more flexible, i.e. the more commonly used temporary contracts that often are intended to stimulate workers to function at the top of their productivity, might be undermining the workers' overall life-time productivity. Accumulation of stress caused by the necessity to deal with unwanted risks can eventually lead to health problems. Another consequence of excessive risk and uncertainty at the labour market is that people, who perceive the situation as too risky, prefer to stay inactive. In other words, the most risk-averse people may be pushed out of the labour force. These unintended consequences of making contracts and payment schemes more flexible form a serious challenge to success of these policies.

Various policy choices can be better informed if more is known about preferences and their distribution in the target population. Public policy instruments can be designed more effectively, if the choices that people are expected to make are better aligned with their preferences. The needs of particular groups can be addressed more directly, if we know more about their basic preferences, such as social trust and risk attitudes. This information is also important for firms, to take into account in team composition and selecting managers. People with similar preferences are likely to work better together, but for implementing organisational changes willingness to accept certain risks is necessary. The fact that the majority of individuals is risk-averse complicates implementing changes. For promoting co- 


\section{Valorisation addendum}

operative behaviour and working together first the conditions for social trust need to be created, because untrusting each other people do not cooperate. 


\section{ROA Dissertation Series}

1. Lex Borghans (1993), Educational Choice and Labour Market Information, Maastricht, Research Centre for Education and the Labour Market

2. Frank Cörvers (1999), The Impact of Human Capital on International Competitiveness and Trade Performance of Manufacturing Sectors, Maastricht, Research Centre for Education and the Labour Market

3. Ben Kriechel (2003), Heterogeneity Among Displaced Workers, Maastricht, Research Centre for Education and the Labour Market

4. Arnaud Dupuy (2004), Assignment and Substitution in the Labour Market, Maastricht, Research Centre for Education and the Labour Market

5. Wendy Smits (2005), The Quality of Apprenticeship Training, Conflicting Interests of Firms and Apprentices, Maastricht, Research Centre for Education and the Labour Market

6. Judith Semeijn (2005), Academic Competences and Labour Market Entry: Studies Among Dutch Graduates, Maastricht, Research Centre for Education and the Labour Market

7. Jasper van Loo (2005), Training, Labor Market Outcomes and Self-Management, Maastricht, Research Centre for Education and the Labour Market

8. Christoph Meng (2005), Discipline-Specific or Academic? Acquisition, Role and Value of Higher Education Competencies, Maastricht, Research Centre for Education and the Labour Market

9. Andreas Ammermüller (2007), Institutional Effects in the Production of Education: Evidence from European Schooling Systems, Maastricht, Research Centre for Education and the Labour Market 
10. Bart Golsteyn (2007), The Ability to Invest in Human Capital, Maastricht, Research Centre for Education and the Labour Market

11. Raymond Montizaan (2010), Pension Rights, Human Capital Development and Well-being, Maastricht, Research Centre for Education and the Labour Market

12. Annemarie Nelen (2012), Part-Time Employment and Human Capital Development, Maastricht, Research Centre for Education and the Labour Market

13. Jan Sauermann (2013), Human Capital, Incentives, and Performance Outcomes, Maastricht, Research Centre for Education and the Labour Market

14. Harald Pfeifer (2013), Empirical Investigations of Costs and Benefits of Vocational Education and Training, Maastricht, Research Centre for Education and the Labour Market

15. Charlotte Büchner (2013), Social Background, Educational Attainment and Labor Market Integration, Maastricht, Research Centre for Education and the Labour Market

16. Martin Humburg (2014), Skills and the Employability of University Graduates, Maastricht, Research Centre for Education and the Labour Market.

17. Jan Feld (2014), Making the Invisible Visible, Essays on Overconfidence, Discrimination and Peer Effects, Maastricht, Research Centre for Education and the Labour Market.

18. Olga J. Skriabikova (2014), Preferences, Institutions, and Economic Outcomes: an Empirical Investigation, Research Centre for Education and the Labour Market 